ERDA Mathematics and Computing Laboratory Courant Institute of Mathematical Seiences

New York University

\title{
NUMERICAL DESIGN OF TRANSONIC CASCADES
}

David G. Korn

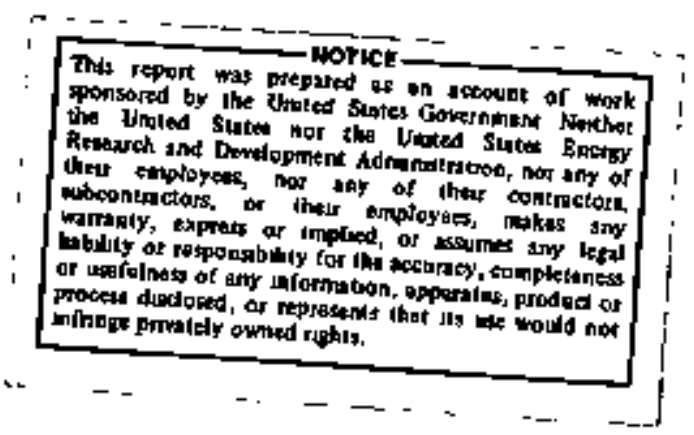

Contract No. AT(11-1)-3077

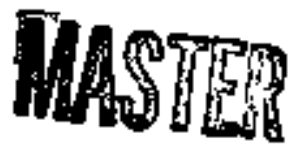




\section{DISCLAIMER}

This report was prepared as an account of work sponsored by an agency of the United States Government. Neither the United States Government nor any agency Thereot, nor any of their employees, makes any warranty, express or implied, or assumes any legal liability or responsibility for the accuracy, completeness, or usefulness of any information, apparatus, product, or process disclosed, or represents that its use would not infringe privately owned rights. Reference herein to any specific commercial product, process, or service by trade name, trademark, manufacturer, or otherwise does not necessarily constitute or imply its endorsement, recommendation, or favoring by the United States Government or any agency thereof. The views and opinions of authors expressed herein do not necessarlly state or reflect those of the United States Government or any agency thereof. 


\section{DISCLAIMER}

Portions of this document may be illegible in electronic image products. Images are produced from the best available original document. 


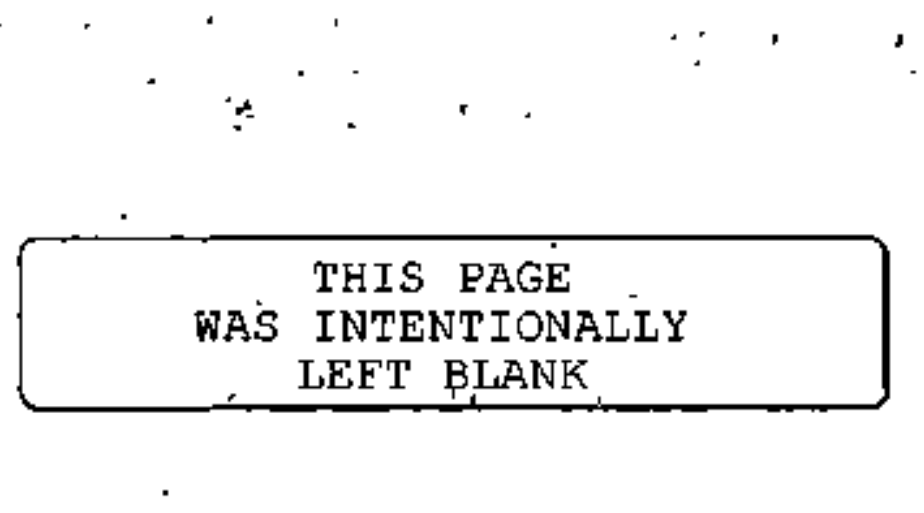




\section{Table of Contents}

Page

Abstract . . . . . + . + . + . + . . . + . . . v

1. Introduction . . . . . . . . . . . . . . . . I

2. Equations of Motion . . . . . . . . . . . . . 4

3. Singular Solution for the Cascade Problem . . . . . . . 9

4. The Selection of Initial Data . . . . . . . . . . . 15

5. Numerical Method of Solution . . . . . . . . . .. 18

6. Refínements to the Design Procedure and Results . . . . . 22

Btbliography . . . . . . . . . . . . . . . . . 26

Figures . . . . . . . . . . . . . . . . . 28

Input Description . . . . . . . . . . . . . . . . 32

output Listing . . . . . . . . . . . . . . . . 37

Fortran Program . . . . . . . . . . . . . . . . . 42 
$\therefore \quad \therefore \quad \ldots$

THIS PAGE

WAS INTENTIONALLY

, LEFT' BLANK 


\section{ABSTRACT:}

The method developed by Bauer, Garabediar, and Korn [2] for the destgr of wing sections which exhlbit shock-free flow at high stbzonic speeds has been applied to the problem of cascade design. A cascade is a perifodic distribution of two dimensional blade cross sections which serves as a basis for the design of axial flow conpressors and turbines.

Those aspects of the design procechure which are used for both atrfoll and cascade destan are reviewed brlefly in this paper. Brphasis has been made on the differences, namely in the form of the singliar solution in the hodograph plane. The sirigular solution for flow around an alrfoll consists of a pole and a nearty branch point in the hodogreph plane. The singular solution for the cascade is formed by two logaritrutic singularities resentoling a source and sink.

A listing of the computer progrem used to design transontc cascades with this method has beer included. Detalls onfitted from the text of this paper can be found by careful examination of the camputer program. In order to make it possible to run this program a description of the input needed to execute this program has also been included. The output listing for the blade shown in Figures 2 and 3 which has been included contains the 11st of 1rout parameters necessary to regenerate this case. 


\section{Introduction}

In recent years there has been a growing concern about the avallabllity and utilization of our energy resources. Considerable effort has gone into the development of new resourses and into methods of more efficient use of existing energy supplies. We will describe bere a procedure which can be used to design more efficient high sped turbomachinery which colld result in significant fiel conservation. In particular, this technology could be the basis for the design of improved axtal flow compressors used for the production of enriched uranium at gaseous diffusion plants. Also, it can be used to design lighter wefght and more effictent alrplane engines.

In this paper we used a technique developed by Baver, Garabedian and Korn [ 2 ] which has been used to oesign atrplane wing sections and apply it to the problem of designing transonic turbine and compressor blades used in axial flow compressors. The method is applicable to two-dinensionst problems and therefore our model for destgr will be a periodic distribution of two dimensionsl blade cross-sections called a cascade. As the distance between blades Increases our solution must approach that of the isolated afrifoil and therefore we can view this paper as an extension of the alrfoll design method.

As with the alrfoll problem, our concern is to find smoth, transonic steady state solutions to the equations of irrotational motion of an inviscid compressible fluid about some object. In this case the object will be a periodic distribution of blades. The equations of motion are the same as those used for the atrfoll design problem, therefore, the same technique of using conjugate characteristic coordinates extended into the complex domain can be employed. A more detalled description of this method can be found in reference \{ 2 \}. 
The min differences between desloning a compressor blade and an airfoil are the locations and types of singliarities of the solution in the hodograph plane. In the afrfotl case, the basic singularity was a pole in ? the hodograph plane at some prescribed free stream velocity. For the cascade problem the velocity far upstream of the cascade, called the inlet velocity, is different from the velocity far downstream of the cascade, called the exit velocity. In fact the purpose of the cascade is to change the inlet velocity in scome prescribed way. Thus, in the hodograph plane there are two velocities whtch correspond to infinity in the physical plane. The appropriate singularities in this case are logarithms at the inlet and exit velocities. As the distance between these logs decreases the spacing between blades Increases approachting the isolated atrfoil case. The logarithic singularities behave like a dipole and, therefore, approach the correct singularity for flow around an afrfoll in the linit.

For the cascade design problem, as with the afrfoil design problem, we solve the inverse problem; that $1 s$, we generate solutions to the equations of motion with the prescribed singlarity and examine the streamiline passing through the stagnation point. This streamine describes the shape of the body. To generate solutions to the flow equations we choose a set of parameters which define physical quentities and describe the inftial analytic function. We also prescribe where in the hodograph plane we would like the blade to lie. The program finds a solution to the equations of motion whose stagnation streamIfie matches the prescribed one in a least square sense. If this curve which represents the body is not closed or if it is not physically realizable in the physlcal plane,for exgmple negative thickness, the input paraneters mist be changed and the program rerur. 
In Section 2 the equations of motion are presented and rewritten in characteristic coordinates which are extended into the complex domein. A formulation of a method to generate solutions with the appropriate singularIty for a cascade appearg in Section 3 . In Section 4 we discuss the problem of choosing the inttial function. In Section 5 a description is given of the numerical technique which has been programed on a CDC 6600 computer. We have enumerated many of the modifications of the destgr procedime of reference [ 2 ] and presented some results in Section 6. Flnally, a listing of the FORIRAN program used to generate the results of Section 6 has been Included, which should help explatn nany of the details. A sample rum has been Included along with glossarles describing Input specifications. This should make 1t possible for someone to copy and execute this program. We Intend to send a copy of this program for inclusion in the library at the Argonne Natlonal Laboratory.

The author would like to thank the many people who in one way or another assisted me in this work. The idea of extending the design proceture to cascades was suggested independently by kiton Plessit and A. J. Acosta of the Calffornia Institute of Technology and Julian Frince of United Aircraft. I an deeply Indebted to Palil Garabedian for the aid and encouragement which was glven to me at all stages of development of this work. Eldon MaIntyre has assisted in the preparation of this peper by cerrefully reading an early Uraft of this paper and correcting numerous errors in many of the formulas. Frances Bauer read a later draft and made numerous helpful suggestions. Farntella Graham patiently typed and retyped this manuscript. FInally, I would like to thank wy fanily whose patience and understanding has not gone unotleed. 


\section{Equations of Hotion}

Let $\mathrm{x}$ and $\mathrm{y}$ be Cartesian coordinates and let $\mathrm{u}$ and $v$ be the corresponding velocity components. Then the steady state equations of motion for an inviscid polytropic gas with isentropic, irrotational flow is

$$
\left(\mathrm{c}^{2}-\mathrm{u}^{2}\right) \phi_{\mathrm{xx}}-2 \mathrm{uv} \phi_{\mathrm{xy}}+\left(\dot{\mathrm{c}^{2}}-\mathrm{v}^{2}\right) \phi_{\mathrm{yy}}=0
$$

where $\phi$ is the velocity potential, $\phi_{x}=u, \phi_{y}=v$, and $c$ is the local sound speed.

Let $p$ denote pressure and $\rho$ density. The local speed of sound, $c$, 1s defined by

$$
c^{2} \equiv \frac{d g}{d p}=\gamma \frac{g}{p}
$$

where $Y$ is a gas constant. Conservation of energy is expressed by Bermoulz1's equation

$$
c^{2}=c_{0}^{2}-\frac{Y-1}{2} q^{2} ; \quad q^{2}=u^{2}+v^{2}
$$

where $c_{0}$ 1s the sound speed at stagration velocity. Equation (2.3) shows that $c$, hence $p$ and $p$ are functions only of the speed $q$.

Introducing characteristic coordinates $\xi$ and $n$, equation (2.1) can be written as a systern of four linear equations for $u, v, x$, and $y$ [cf. 2 ]. Cowputing the characteristic directions

$$
\lambda_{ \pm}=\frac{u v \pm c \sqrt{q^{2}-c^{2}}}{c^{2}-v^{2}}
$$

we can write the equations of motion in chamacteristic form as follows: 
$(2.5 a)$

$$
v_{\xi}=\lambda_{+} u_{\xi} ; \quad v_{n}=\lambda_{-} u_{n}
$$

$(2.50)$.

$$
\lambda_{-} y_{\xi}+x_{\xi}=0 ; \quad \lambda_{+} y_{n}+x_{n}=0
$$

We define the local Mach number $M$ as $q / c$. The equations of motion are hypertolic when $\lambda_{ \pm}$are real and unequal which occurs when the flow is supersonic, $M>1$. For $M<1$ the flow is subsonic and the conplex conjugate roots in $\lambda_{ \pm}$mean that the equations of motion are elliptic. The set of points where $M=1$ ls called the sonic line and is a cincle In the hodograph plene $q=$ constant. This constant is called the critical speed, which we denote by $\mathrm{q}_{*}$.

Since we are interested in solutions to these equations in a region of the hodograph plane where both subsonic and supersonic flow is to occur we must use a method applicable to both reglons. The method of complex extension [4] is ideally suited since in the corplex domain there 1s to dfstinction of type, in fact, $\lambda_{ \pm}$need not be real or complex conjugate. The only theoret1cal difficulty which arlses in using complex extension is along the set of points where $\lambda_{+}=\lambda_{-}, 1 . e . M=1$, since equations (2.5b) are cotncident there. It has been shown that this problem is easily treated (cr. $[2,9]$ ).

With the method of complex extension the independent variables 5 and $n$ are each extended into the complex domatn so the solution $u, v, x$ and $y$ must be allowed to take on complex values. Since both $\xi$ and $n$ have real and Imaginary conponents this amounts to enlarging the Independent domain from two dimensions to foum dimensions. We are interested in the solution only in the real hodograph. We would like to conpute the solution in as small a 
subset of the exterided space as posalble in order to obtain the solution In the real hodograph plane. It tums out to be possible to choose characteristic coordinates $\xi$ and $\eta$ so that the set of points $\xi=\bar{\eta}$ Includes the real subsonic nodograph plane. We cell this cholce of characteristic coordinates, conjusate characteristic coordinates as described in [2].

Equations $(2.5 \mathrm{a})$ are Independent of $x$ and $y$ and therefore $u(\xi, n)$ and $v(\xi, n)$ depend only on our choice of characteristic coorilnates, not on the solution to our equations. We may therefore view $\xi$ and $\eta$ as being generalized hodograph variables. We can actually write closed form expressions for conjugate characteristic coordinates in terms of the hodograph variables $u$ and $v$ and thus solve (2.5a) expljoltly. By Integrating (2.4) (cf. [11]) we find that $s$ and $s^{*}$ ere corfugate characteristic coordinates by choosing

$$
s=h(q) e^{-1 \theta} ; \quad s^{*}=h(q) e^{1 \theta}
$$

where

$$
h(q)=R a\left[\left(c-\sqrt{c^{2}-q_{k}^{2}}\right) \sqrt{n}\left(\sqrt{c^{2}-q^{2}}+c\right)\right]^{-1}
$$

where $\mu^{2}=(\gamma-1) /(\gamma+1), \theta=\tan ^{-1} \mathrm{v} / \mathrm{u}$ and $\mathrm{K}$ is a constant chosen so that $h(1)=1$. Note that as the critical speed $q_{\text {n }}$ becomes infinite $h(q)$ approaches q. Thus for incompresstble flow s approaches $w=u-1 v$ and it follows that s Is an extension for compressible flow of the complex velocity. The function $h$ is real when $q$ is real and subsonic so that $s$ and $s$ are complex confugates In the subsortc region. We choose coondtnates $\xi$ and $n$ and consider mapplngs 
of the form

$$
\left.s=F(\xi) ; s^{*}=\overline{F(\bar{\eta}}\right)
$$

Where $F$ is an arbitrary analytie fuction. For any function $F$. $\xi$ and $n$ are characteristic cocrijnates since any function of a characteristic coordjnate is itself a charactertitic coordinate. Also, 1t is clear from (2.8) that whenewer $s=\bar{g}^{*}$ we have $\xi=\bar{n}$ so that $\xi$ and $\eta$ are also confugate coordingtes for any anslytic function $F$. In prevlous work on afrfoil desim we have found it sufficlent to choose a two parameter family of transformations

$$
s=F(\xi)=1-2 \mathrm{~B} \xi-\xi^{2}
$$

for the parameter $B$ wtich is suggested by considering incompressible flow around an elliptic cylinder. Thts led to a class of solutions which had a single branch point in the hodograph plane at $\xi=-B$. Horeover, design in the $\xi-p l a n e$ is simpler than in the $w$-plane because a simple closed curve representing the body streamitne is transformed into the two-sheeted hodograph. Turblne and conpressor blades generally have a high degree of camber and may require more than one branch point. Therefore we have chosen

$$
s=1+C_{1} \xi+C_{2} \xi^{2}+C_{3} \xi^{3}+C_{4} \xi^{4}
$$

which can have as many as three branch points. Locating the branch points can be done by examining their location for incompressible flow around a cambered Joukowskl prof'ile. 
Work is presently underway to Investigate a rational method for the selection of the function $F$ to achieve the desired design objectives. The selection of a suftable transformation $F$ for turbine design will be the subject of a future report $[10]$. 


\section{Singuler Solution for the Cascade Problem}

We epply the method of complex extension to equations (2.5) in order to geremate solutions which represent flow around a cascade. We wlll do this by setting up an appropmate characteristic Initial value problem in the extended hodograph plane.

For the characteristic intital value problem in the extended varisbles we chose two characteristic planes $\xi=\xi_{c}$ and $n=\eta_{c}$ and assien initial data for either $x$ or $y$ along each of them. Equation (2.5b) is a set of ordinary differential equations along a characteristic whlch can be integrated to get the other independent variable. The solution at points not on the characteristic Initial planes can be found by the numerscal techique described in Section 5. The solution will be aralytic as long as the infitial data is analytic.

For flow through a cascade we would like a solution which has an inlet velocity at $\rightarrow$ and an exit velocity at +o in the physical plane. Let w $=$ $u_{B}-1 v_{B}$ and $w_{A}=u_{A}-1 v_{A}$ deriote the corplex upstream and downstream velocities respectively. Let $\left(\xi_{B}, \eta_{B}\right)$ and $\left(\xi_{A}, n_{A}\right)$ be the corresponding values of the characteristic coordinates whlch are found by solving (2.6) and (2.8) once the transformation function $F$ has been prescribed. It follows that $n_{A}=F_{A}$ and $\eta_{B}=E_{B}$ since $E$ and $n$ are confuggte coordinates and $u_{A}, u_{B}, v_{A}$ and $v_{B}$ are real quantities. We require that the solution in the physical plane have Infinities at the two points $\left(\xi_{A}, \bar{\xi}_{A}\right)$ and $\left(\xi_{B}, \xi_{B}\right)$. In other words we have a source at $\xi_{B}$ and a sink at $\xi_{A}$ in the real hodogroph plane. We finther require that the solution be periodic in the physical plane. 
Any closed loop in the hodograph plane sunrounding both $\xi_{\mathrm{A}}$ and $\xi_{\mathrm{B}}$ corresponds to a closed loop in the physical plane enclosing a blade. He will modify this enclosure requirentent for our wake nodel of the trailing edge. one can verify that a solution of the form

$$
\begin{aligned}
& x=\operatorname{Re}\left[X^{1} \log \left(\xi-\xi_{A}\right)+X^{2} \log \left(\xi-\xi_{B}\right)+X^{3}\right] \\
& y=\operatorname{Re}\left[Y^{1} \log \left(\xi-\xi_{A}\right)+Y^{2} \log \left(\xi-\xi_{B}\right)+Y^{3}\right]
\end{aligned}
$$

satisfles the above requirements for sultable cholces of the regular functions $X^{1}, X^{2}, X^{3}, Y^{1}, Y^{2}$ and $Y^{3}$. The assumption that $X^{3}$ and $Y^{3}$ are regular lead to the requirement that $X^{1}, Y^{2}$ and $X^{2}, Y^{2}$ be solutions to the partial differential equations (2.5b) with 1ritial conditions

$$
\begin{aligned}
& \lambda_{-} \mathrm{Y}^{2}+\mathrm{X}^{1}=0 \\
& \lambda_{-} \mathrm{Y}^{2}+\mathrm{X}^{2}=0
\end{aligned}
$$

on $\xi=\xi_{A}$ and $\xi=E_{B}$ respectively. Thls can be verlfled by substituting equations $(3.1 \mathrm{a}-\mathrm{b})$ into $(2.5 \mathrm{~b})$. From this construction we can see that $X^{3}, Y^{\prime}$ and $X^{2}, Y^{2}$ are essentially Flemann functions for equations (2.50).

Equations $(3.2 a-b)$ can be solved with $(2.5 b)$ to obtatn $x^{1}$ along $\xi-\xi_{A}$ and $\mathrm{X}^{2}$ along $\varepsilon=\varepsilon_{\mathrm{B}}$. We must define $X^{2}$ and $\mathrm{X}^{2}$ along the correspondting characterIsties of the other family $n=\eta_{A}, \eta=\eta_{B}$ to obtaln a well-posed characteristic Inftial problem for the determination of $X^{1}, X^{2}, Y^{2}$ and $Y^{2}$ everywhere. We can save conputation if define the data on the other fandly of character1stics by reflection, 1.e. $\left.\left.X^{1}\left(\xi, n_{A}\right)=\overline{X^{1}\left(\xi_{A}, \bar{\xi}\right.}\right) ; Y^{2}\left(\xi, n_{B}\right)=\overline{\gamma^{2}\left(\xi_{B}, \bar{\xi}\right.}\right)$, etc. This is not always posstble stnce $X^{1}, X^{2}, Y^{1}, Y^{2}$ not ne real at 
$\xi_{A}, \eta_{A}$ and $\xi_{B}, \eta_{B}$. However, since equations (2.5b) admit constants as solutions we can find solutions for $X^{1}, X^{2}, Y^{1}$ and $X^{2}$ of the form

$$
\begin{aligned}
& X^{1}=\hat{X}^{1}+1 X_{A} ; X^{2}=\hat{X}^{2}+1 X_{B} \\
& Y^{\prime}=\hat{Y}^{1}+1 Y_{A} ; Y^{2}=\hat{Y}^{2}+1 Y_{B}
\end{aligned}
$$

where $X_{A}, X_{B}, Y_{A}$ and $Y_{B}$ are real constants and $\hat{X}^{1}, \hat{X}^{2}, \hat{Y}^{1}$ and $\hat{Y}^{2}$ are syrmetric solutions to equations (2.5b) satisfying $(3.2 a-b)$ along the initial characteristics.

The equations for $X^{3}$ and $Y^{3}$ obtained by inserting (3.1a-b) into (2.5b) are

(3.4a) $\quad \lambda_{-} Y_{\xi}{ }^{3}+X_{\xi}{ }^{9}=\frac{\left(\lambda-\hat{Y}^{1}+\hat{X}^{1}\right)+1\left(\lambda_{-} Y_{A}+X_{A}\right)}{\xi_{A}-\xi}+\frac{\left(\lambda_{-} \hat{Y}^{2}+\hat{X}^{2}\right)+1\left(\lambda_{-} Y_{B}+X_{B}\right)}{\xi_{B}-\xi}$

$$
\lambda_{+} Y_{\eta}^{3}+X_{\eta}^{3}=0
$$

where the regularity of the right hand side of (3.4a) is assured by the inttal conditions $(3.2 \mathrm{a}-\mathrm{b})$. In order to formulate a well-posed problem for the evaluation of $\mathrm{X}^{9}$ and $\mathrm{Y}^{3}$ it is necessary to assign inftial data along a pair of initial characteristics. We choose initial characteristics, $\xi=\xi_{C}$, $\eta=n_{C}$, so that their intersection is a point in the real subsonic domain. This means that $\eta_{C}=\bar{\xi}_{C}$. To avoid difficulties in the numerical calculation of the right hand side of (3.4a) we choose $\xi_{\mathrm{C}}$ safely away from both $\xi_{\mathrm{A}}$ and $\xi_{\mathrm{B}}$. We asgign

$$
x^{3}\left(\xi_{C}, \eta\right)=G(n) ; \quad x^{3}\left(\xi, \eta_{C}\right)=G\left(\eta_{C}\right)
$$


on the Initial characteristios $E=E_{C}$ and $n=\eta_{C}$ respectively where $G$ is an analytic nmction. The selection of $G$ is the subject of the next section. Since the solution for $X$ and $Y$ uses only the real parts of $X^{3}$ and $\mathrm{Y}^{3}$ we can prescribe many comblnations of initial data which w1] yleld the same real parts. In particular, the symetric set

$$
\text { (3.6) } x^{3}\left(\xi_{C}, n\right)=\frac{1}{2}\left[G(n)+\overline{G\left(n_{C}\right)} ; \quad x^{3}\left(\xi, n_{C}\right)=\frac{1}{2}\left[G\left(n_{C}\right)+\overline{G(\xi)}\right]\right.
$$

has been used to reduce computation in the subsonic portion of the flow.

We have the four real congtants $X_{A}, Y_{A}, X_{B}$ and $Y_{B}$ to determine. Finst we consider the requirement that the solution be single-valued for any real closed peth encircling a blade. We find

(3.7a) $\oint d x=\operatorname{Re}\left[\oint\left(\frac{\hat{X^{1}+1 x_{A}}}{\xi-\xi_{A}}+\frac{\hat{X^{2}+1 x_{B}}}{\xi-\xi_{B}}\right) d \xi\right]=-2 \pi\left(x_{A}+x_{B}\right)$

(3.7b) $\oint d y=\operatorname{Re}\left[\oint\left(\frac{\hat{Y}^{1}+1 Y_{A}}{\xi-\xi_{A}}+\frac{\hat{Y}^{2}+1 Y_{B}}{\xi-\xi_{B}}\right) d \xi\right]=-2 \pi\left(Y_{A}+Y_{B}\right)$

where the path of integration $1 \mathrm{~s}$ around both $\xi_{\mathrm{A}}$ and $\xi_{\mathrm{B}}$ in the plane $\xi=\overline{\mathrm{n}}$. Therefore, $X_{B}=-X_{A}$ and $Y_{B}=-Y_{A}$ if we are to have a single-valued solution. We further require that the stream function $\psi$ defined by

$$
d \psi=(\rho u) d y-(\rho v) d x
$$

be single-valued for gny similar path. Since of and $\rho v$ are real in the real domaln we have

$$
\oint d v=2 \pi\left[\rho_{A} u_{A} Y_{A}+\rho_{B} u_{B} Y_{B}-\rho_{A} v_{A} x_{A}-\rho_{B} v_{B} x_{B}\right]=0 .
$$


Haking use of the closure conditions $(3.7 a-b)$ and $(3.9)$ we have

$$
\left(\rho_{A} u_{A}-\rho_{B} u_{B}\right) Y_{A}=\left(\rho_{A} v_{A}-\rho_{B} v_{B}\right) X_{A}
$$

From $(3.1 a-b)$ we see that the solution is periodie with a period of $X_{B}$ and $Y_{B}$ in $x$ and $y$ respectively. We define the stagger angle $\beta$ and the gap $\mathrm{g}$ by

$$
B=\tan ^{-1} \frac{X_{A}}{\not A} ; \mathrm{g}^{2}=\mathrm{X}_{A}^{2}+\mathrm{Y}_{A}^{2}
$$

G1ven the 1nlet and exit veloc1ties the stagser angle is conputed from (3.11). Therefore, it is convenient to measure the inlet and exit velocity vectors relative to $B$. If we require that the blades be stacled vertically, $B=\pi / 2$, we can prescribe only three of the four parameters for the inlet and exit velocity. For example we may prescribe the inlet and exit Mach numbers and the turning angle, and then determine the inlet and exit flow angle from (3.11) ustin $B=\pi / 2$. To have physical signifucance the gap oust be measured relative to some sultable distance measurement such as the blade chord. Since this Is not known until the solution has been found we have Instead chosen to nomallze the solution by requiring that the gap $g$ have magnitude $\left|\xi_{A}-\xi_{B}\right|^{-1}$ As a result of this nomalization the chord lensth will change slowly as $\xi_{A}+\xi_{B}$. Moreover in the limiting case the 1solated blade will have the same singularity as the one used in our previous work on airfoil design.

The wake model of the trailing edge which was formalated in [ 1 ] to correct for boundary layer displacement can easily be incorporated into this cascade design procedure. This is done by requiring that the residues of (3.7a-b) be non-zero. In fact, they should be proportional to $X_{B}$ and $Y_{B}$ respectively so that the blades will have a vertical gap when stacked verticaliy. The constant of proportionality is the ratio of the thickness of 
the trailing edge outside the boundary layer to the gap and is chosen to be small. It should be noted that equation (3.10) will have to be modified accordingly.

The problem of flow through a cascade of blades can therefore be solved by generating the solution of two characteristic initial value problems for the horlogenous equations $(2.5 b)$, one along $\xi=\xi_{A}, \eta=\xi_{A}$, the other along $\xi=\xi_{\mathrm{B}}, \Pi=\xi_{\mathrm{B}}$, and by solving a characteristic initial value problem for the inhorogeneous equations (3.4a-b) for arbitrary initial data chosen along some initial characteristics $\xi=\xi_{c}, n=\eta_{c}$. The inftial data for the homgenous equations is determined by solving ordinary differential equations along the intisial characteristics reminicent of the Riemarm functions. The four constents $X_{A}, X_{B}, Y_{A}$ and $Y_{B}$ are completely determined by three closure conditions and normalization. The solution for $x$ and $y$ is formed from the solution of these three problems using ( $3.1 a-b)$ and has the singularities necessary for flow through a cascide. 
4. The Selection of Inttial Data

Solutions to the equations of motion of the form (3.1a-b) will have the appropriate singular solution for flow through a cascade but will not necessarily generate solutions with a physical interpretation for arbitrary Initial data assigned along the characteristic initial planes $\xi=\xi_{c}$ and $n=n_{\mathrm{C}}$. Once the transformation from the hodograph vartables to characteristic coordinates has been selected the design problem centers on choosing the indtial data so that the resulting design will achieve as many of the design objectives as possible. Many design objectives, such as boundary layer control, cannot be stated in precise terms within the context of thls inviscid model. Other design objectives may be Impossible to achleve within the class of shokless solutions. Therefore should expect the problem of choosing infitial data to requtre some degree of trial and error.

To find the shape of the blade we generate a solution and exandine the level curve $\psi=\psi_{0}$ where $\psi_{0}$ is the value of the stream finction at stagnation. In general, this shape will not resenthle a blade and in fact does not have to be a closed curve. The shape of this curve will depend upon the Initial data we choose. We now discuss a procedure for selecting the fnitial data which attempts to minimize the chances of obtaining extraneous solutions. To do this we make use of most of the 1deas that have been used for the ainfoll design problem described in $[1,2]$.

We pick the initial characteristic $\xi=\xi_{\mathrm{C}}$ away fron $\xi_{\mathrm{A}}$ and $\xi_{\mathrm{B}}$ to avold complatational difficulties in evaluating the right hand side of $(3.4 a)$. 
The characteristic $n=\bar{\xi}_{\mathrm{C}}$ is selected for symmetry reasons, Since we need only the real part of the solution to equations $(3.4 a-b)$ we can symotrize the equations in a menner that saves half the computation in the subsonic region. Using equation $(3.6)$ the initial data on $n=\xi_{C}$ will be the conplex conjugate of the Initial data along $\xi=\xi_{\mathrm{C}}$ whlch we prescribe. In keeping with the procedure followed for atrfoil design we choose the initial function $G$ on the indtial characteristic $\xi=\xi_{C}$ as

(4.1) $G(n)=\sum_{j=1}^{\mathrm{N}}\left(L_{j I}+1 L_{j 2}\right) \log \left(n-L_{j 3}-1 L_{j 4}\right)+E_{t} n+E_{t t q} n^{2}+E_{t c u^{n}} n^{s}$

The constants that appear determene the resulting solution. The last three terms are polynomial terms while the remaining $\mathrm{NL}$ terms are logarithms located at $\eta=I_{j 3}+\mathrm{IL}_{\mathrm{j} 4}$. They can be placed anywhere inside the blade to stmilate soumces or sints. Their influence is primarily local when their coefflclents are small and can therefore be used to effect small changes without much change to the overall solution.

Selection of the linear parameters has been automsted by a least squares process. Instead of prescribing the linear parameters we select a curve or set of arcs in the hodograph plane there we would like the blade to lie. We choose the linear constants in (4.1) so that the solution it generates mintinzes

$$
\int W \psi^{2} d \xi
$$

where the 1ntegration is taken along the prescribed arcs and where the weighting function $W$ can be chosen to achieve a better fit along any given arc. 
By prescribing the autanation arcs in the characteristic planes we are in effect prescribing the body streamline in the hodograph plane. This 1s very corvemient for boundary layer cortrol since we can select ares for the least square automation whlch have sufficlentiy tmall pressure gradients In order to avoid separation. If we prescribe an arc so that it approaches the trailing edge elong a line of constant speed we can eliminate boundary layer separation or delay it until the last per cent of chord in most cases. In addition we narrow the cholce of Initial data by placing constraints on the solution. We prescribe the curvature at the leading edge and the angle between the inlet velocity and the centrel streanline. We choose a velocity for the trailing edge and require the strean fumction to assure its stagnation value there. We further require that its first and optionally its second derivative vanish. This is our model of the Kutta-Joukowskl condition in the hodograph plane.

The above constratits and the least square conditions greatly reduce the effort in selecting meaningful intital data. It should be noted that we have overprescribed the problem and therefore camot expect good agreanent between the prescribed arcs and the resulting streamline unless they are chosen in a manner consistent with the glven compression and tuming. For a description of how to locate the logarithns the reader is referred to $[1,2]$ since there appears to be little dffference between compressors and airfoils In this aspect of the design problem. 
5. Numerical Method of Solution

The same numerical technique that was successfully used to design atr foils described in [2] has been uzed with minor modifications for the cascade design problem. In the real domain this techufque is often called the mothod of characteristics or Massan's Method [ 3 ] and is essentially a predictor corrector scheme. The method is applied in the complex damatn merely by perforning all operations using complex arithnetic.

In Section 3 we expladned how to construct the appropriate singular solution. In doing so we must find the solutions for $\mathrm{X}^{1}, \mathrm{Y}^{1}, \mathrm{X}^{2}, \mathrm{Y}^{2}$ and $\mathrm{X}^{3}$, $Y^{3}$. The functions $X^{1}, Y^{1}$ and $X^{2}, Y^{2}$ satisfy the equations of motion (2.50) with Intial data given by $(3.2 a-b)$ on the inftial characteristics while $X^{3}$, $Y^{3}$ satisfy the inhomogeneous equations $(3.4 a-b)$ whose right hand side is computed from $X^{3}, Y^{1}$ and $X^{2}, Y^{2}$. Therefore, we will apply the method of Massau to each of these three sets of unknowns. The hodograph varfables may be obtained explicitiy from equations $(2.8),(2.6)$ and $(2.7)$. However, it is faster to use this mmerical method to solve for then as well, using these equations only to generate characteristic inftial data.

The characteristic initial value problen for $X^{1}$ and $Y^{1}$ starts on initial characteristics $\xi_{A}, \eta_{A}$. The characteristic initial value problem for $X^{2}$, $Y^{2}$ starts on initial characteristics $\xi_{B}, \eta_{B}$ and the characterist1c initial value problen for $\mathrm{X}^{3}, \mathrm{Y}^{3}$ uses initial characteristics $\xi_{\mathrm{C}}, \mathrm{n}_{\mathrm{C}}$ along which it is necessary to know $X^{2}, Y^{2}, X^{2}$ and $Y^{2}$ in order to eviluate the inhomogeneous terms. To apply the method of phassau we must select a path along each of the Initial characteristics, as illustrated in Flgure la. Each path starts at the 
point of intersection of the two initial characterjstics. Let $r$ and $t$ be real parameters. We assign initial data along a path $n=n(t)$ from $\eta_{\mathrm{A}}^{\prime}$ on the Initjal characteristic $\xi=\xi_{\mathrm{A}}$ and along another path $\xi-\xi(n)$ from $\xi_{\mathrm{A}}$ on the other initial characteristic. The initial data along these paths deterndne the solution on the two-dimensional surface conststing of the points of intersection $\xi(r), n(t)$. To flind the solution at a given point $\xi_{P}, n_{P}$ we choose a path on $\xi=\xi_{A}$ from $n=n_{A}$ to $n=n_{P}$ and a path on $\eta=\eta_{\mathrm{A}}$ form $\xi=\xi_{\mathrm{A}}$ to $\varepsilon=\xi_{\mathrm{P}}$. The solution at the point $\xi_{\mathrm{P}}, n_{\mathrm{P}}$ will be fndependent of path if the data along the inftial characteristics is analytic. In onder to be able to solve for $X^{3}, Y^{1}, X^{2}, Y^{2}$ simultaneously we choose each initial path on $\eta_{A}$ so that it starts from $\xi=\xi_{A}$ passes through $\xi=\xi_{B}$ and then through $\xi=\xi_{C}$. Similarly the initial path along $\xi=\xi_{A}$ begins at $n=n_{A}$ and passes through $n_{B}$ and $n_{C}$. Thus the values for the right hand side of (3.4a) are avallable as they are needed. This arrangement is illustrated in Fyoure $1 b$.

The solution throughout the four dimensional domain can be conputed by selecting appropriate pairs of paths. We are interested in obtaining the solution only in the real hodograph and would like to do so with as few pairs as possible. It has been shom that by choosing complex conjugate sets of paths we can arrive at one line of the solution in the real subsonic domatn for each set of paths [ 9$]$. One set of paths can be found to find a portion of the solution in the supersonte region bounded by two characteristics and the sonic line. Generelly one pafr of paths can be chosen so that this region contains the full supersonic portion of the flow outside the blade. 
Each set of initial paths is described by the vertlces of a polygonal are and a set of grid points superinposed in such a way that each vertex is a grid point and that the distance between adjacent grid points is less than some prescribed amount. We use the notation $u_{j k}$ to denote the value of $u\left(\xi\left(r_{j}\right), n\left(t_{k}\right)\right)$ where $r$ and $t$ are real paranetric representations of the Initial paths. Wote that $r=0$ and $t=0$ are the initial curves on $\xi=\xi_{A}$ and $n=n_{A}$ respectively. Using this notation we cen write the predictor step of the method of Massau for the solution of equation (2.5a) at the point $\mathrm{J}, \mathrm{k}$ as the two IInear equations

$$
\begin{aligned}
& \tilde{v}_{j, k}-v_{j-1, k}=\left(\lambda_{+}\right\rangle_{j-1, k}\left(\tilde{u}_{j, k}-u_{j-1, k}\right) \\
& \tilde{v}_{j, k}-v_{j, k-1}=\left(\lambda_{-}\right\rangle_{j, k-1}\left(\tilde{u}_{j, k}-u_{j, k-1}\right)
\end{aligned}
$$

for the predicted values $\tilde{u}_{j, k}$ and $\tilde{v}_{j, k}$ whlch are flrst order accurate est Imates of $u$ and $v$. The values of $u$ and $v$ along $j=0$ and $k=0$ are determined explicitly from the hodograph transfomation $(2.6-2.8)$.

For the corrector step, we use the values obtarned in the predictor step to compute first order accurate midpoint values for $\lambda_{ \pm}$given by

$$
\begin{aligned}
& \vec{\lambda}_{+}=\frac{1}{2}\left[\left(\lambda_{+}\right)_{j-1, k}+\lambda_{+}\left(\tilde{u}_{j, k}, \tilde{v}_{j, k}\right)\right] \\
& \tilde{\lambda}_{-}=\frac{1}{2}\left[\left(\lambda_{-}\right)_{j, k-1}+\lambda_{-}\left(\tilde{u}_{j, k} \tilde{v}_{j, k}\right)\right]
\end{aligned}
$$

and solve

$$
\begin{aligned}
& v_{j, k}-v_{j-1, k}=\tilde{\lambda}_{+}\left(u_{j, k}-u_{j-1, k}\right) \\
& v_{j, k}-v_{j, k-1}=\tilde{\lambda}_{-}\left(u_{j, k}-u_{j, k-1}\right)
\end{aligned}
$$

for $u_{j, k}$ and $v_{j, k}$ to obtain second order accuracy. 
A stintar set of equations is solved to obtatn $\mathrm{X}^{1}, \mathrm{Y}^{4}, \mathrm{X}^{2}, \mathrm{Y}^{2}$ and $\mathrm{X}^{3}, \mathrm{Y}^{3}$ to second order accuracy. Equations (3.1a-b) are evaluated at points in the real hodogreph to obtain $x$ and $y$ to second order accuracy. The value of the strean function is obtained by applyting a second order accurate difference approximation to (3.8). Points on the blade are Identifled by the streanilne passing through the stagnation point. They are computed by perabolic interpolation along the paths.

The least square gutomation discussed in Section 4 is acconplished by repeatedly solving equations $(3.4 a-b)$ along the prescribed autometion arcs with varying initial data. For egch automated parameter of function 0 given by (4.1) we assign initial data which has that particular parameter set to one and all the others set to zero. This set of solutions determines the coefficlents of a linear system of equations for the automated paraineters as described in $[2]$. The function $G$ as defined by these autcmated parameters is then used as inltial data which detenines the shape of the blade.

The systems of two simultaneous linear equations $(5.1 a-b)$ and $(5.3 a-b)$ becons 111-conditiloned whenever $\lambda_{+}$and $\lambda_{-}$are nearly equsl, 1.e. near points on the complex sonit line; therefore, we expect our langest errors to occur in the vicinity of the sonic line.

A thind order accurate method can be obtained by doing the calculation with two different grid sizes and using Richandson extrepolation to the limit. We have incorporated this option into the computer program in order to obtain more accurate resolution in the vicinity of the leading and trafling edges. We cannot expect improvement near the sonic line because of the singularity of the hodograph transformation there. 


\section{Refinements to the Desiog Procedure and Results}

A number of 1 mprovements have been made in the cascade design program that have not as yet been incorporated in the alrfoll design procechure $i$ (cf. [ 2 ). These modifluations fall into three general overlapping categories.

The first set of modifications was intended to decrease execution time. The cascade design program should take longer to execute than the airfoll design progran since each path must comect the inlet and exit velocities In the Inttial plane. Since the gap to chord ratio varies inversely with the distance between these singularitjes we expect blades with low gap/chord to take longer to compute. Automation generally takes most of the computing time since the solution for $\mathrm{X}^{3}$ and $\mathrm{Y}^{*}$ along each automated path mist be conputed ance for each autontated parameter. Welghting for the least squere automation was achleved by choosing additional mesh points in the corresponding Interval for the alrfoll design program. Since the exectution time is proportional to the square of the muber of points on the initial path, a highly weighted least square autamation is very time consuning. In the present progrem the weight Ing is achleved by multiplying the value of $\psi$ at the wejghted point by the ingut wejght factor. A signifleant reduction in execution time can be achteved if we complite $X^{3}$ and $Y^{3}$ for each automated parcmeter at the some point in the program. The right hand side of (3.4a) and $\lambda_{t}$ would only be computed once. To achieve this we would require storage of the set of conplex arrays for each $X^{3}$ and $Y^{3}$. For fine grias with many autamated paremeters the required storage would make this procedure prohibitive. $A$ compramise, which allows for a fixed nuber of solutions of $X^{3}$ and $\mathrm{Y}^{3}$ 
at each pass has becin incorporated. A typlcal run for the solution with ten automation parameters obtained at each pass has decreased execution time for the autamation by a factor of about five using less than twlce the storage.

A second set of modifications was made in order to frprove accuracy. The gutomation procechure was modifled to ensure that it was second onder accurate. The integration for least squares (cf. (4.2)) was modified so that only half the prescribed weight was used at the endpoint of each given interval. The automation near the leading edge was made second onder accurate by adjing an extra point on the path to the leading edge beyond the stagnation point so that central differences could be used for derivative approxtmations.

An optional third onder accurate scherme is provlded which has been achteved by repeating the calculation at a finer grid and using Fichertson extrapolation. Finaliy we note that the definition of $\lambda_{ \pm}$(See equation 2.4) has been changed from reference [2] and so have the ensulng equations. This change awolds the Inaccumacy which occurs when the denominator is small since for the flows considered $u$ is greater than $v$ throughout the supergonic zone.

The final set of modifications was made to make the program easier to use. Some of these modifications have been achleved by more sophisticated computer codins such as the free-form tnput. Other modifications have been added so that more of the input parameters have a physical meaning. For example, Instead of glving the values of $x_{u}$ and $y_{u}$ at the stagnation point we now supply the leading edge radius of curvature and the angle between the 
central streamline and the Inlet flow vector. Slmilarly the location of the trailing edge in the hodograph can be specifled by prescribing the Mach nimber and the angle relative to the ext velocity vector. A number of changes have been inoorporated in an effort to allow more general transformations for the hodograph plane as discussed in Section 2. An inproved technique for the location of cuts of the logarithms in the intitial plane removes the distinction between nose logs, tall logs, and side logs that was made in [ 2$]$.

A computer program for cascade design has been written which incorporates these ideas. It has been used to generate a few destgons. Fach design required many rums in order to succeed but the time for each run is mall so that computing time is not pronsbitive. It takes about half a minute of central processer time on the CDC 6600 for a coarse mesh mu. An intermediate grid and fine grid take about 2 and 8 minutes respectlvely. The third order option increases conputing time by a factor of about 5 .

Figure 2 is a calconp plot of a blade whtch has been designed with this program in about 50 Inuns. All but the last few runs were made on a coarse grid. The inlet flow angle, measured relative to the vertical stacking direction, is $45^{\circ}$ and the turning angle is $29^{\circ}$. The gap chord ratio 181.07 . The Mach number distribution over the blade and the characteristics or Mach lines in the supersonic region have been plotted. Whth this Mach number distribution no separation 1s predicted for Reynold's number 1.6 million.

The corresponding inftial plane is illustrated in Figure 3. The input paths and sonic locus have been plotted. The plus signs represent the preinages of points on the body and the arrows 11lustrate the location of logarithic singularities in the inftial function and the direction of their 
cuts. An asterisk is placed at the points corresponding to the inlet and exit velocities. We point out the similarity between this figure and those we have obtained previously with the airfoil design program (cf. [1, 2]).

A number of experiments performed on airfoils designed by this procedure (cf. $[5,6,7,8])$ have proven the usefulness of this method. In the near future we expect a blade designed by this technique to be tested in a cascade wind tunnel at the Pratt and Whitney Division of United Aircraft. This test should verify the relevancy of this theory in this lower Reynolds number regime.

Work to simplify the design procedure is in progress. A more detailed report on cascade design with an emphasis on turbine design should appear shortly $[10]$.

25 


\section{Bibliography}

[ 1 ] F. Bauer, P. Garabedian, A. Jameson and D. Korn, Sugercritical Wing Sections II, A Handbook, Lecture Notes in Economics and Mathematical Systems, vol. 108, Springen-Verlag, New York, 1975.

[ 2 ] F. Beuer, F. Garabedian and D. Korrl, Superciftical Wing Sections,

. Lecture Notes in Ecanomios and Nathematical Systems, vol. 66, Springer-Verlag, New Iork, 1972.

[ 3 ] G. E. Forsythe and W. R. Wasom, Finite Difference Hethods for Partial Differential Equations, Wlley, Hew York, 1960

[ 4 ] P. R. Garabedian, Partial DifferentiaI Equations, Wiley, New York, 1964.

[ 5 ] L. A. Graham, R. T. Jones, and F. W. Boltz, "An Experimental Invest1gation of Three oblique-wing and Body Camblnations at Mach Whmers between 0.60 and 1.40," NASA TM X-62, 256, Ames Research Center, 1973.

[6] I. J. Kacprzynskd, "A Second Serles of Wind Mumel Tests of the Shockless Lifting Airfoll No. 1," Project Report 5x5/0062, National Research Counctl of Canada, Ottawa, 1972.

[ 7 ] J. J. Kacprzynsk1, WWind Turnel Test of a Shockless Lifting A1rfołl No. 2," Laboratory Technical Report IHR-HA-5x5/0067, National Research Coumeil of Canada, Ottawa, 1973.

[ 8 ] J. J. Kacprzynski, L. H. Ohman, P. R. Garabedian, and D. G. Kom, "Analysis of the Flow Past a Shockiess Lifting Airfoil in Design and Off-Design Conditions," Aeronautics Report LR-554, Nat Ional Research Coumc1l of Cenada, Ottawa, 1971. 
[9 ] D. G. Korm, "Transonic Design in Two Dimensions," Lecture Notes in Mathemat1cs, vol. 430, Springer-Verlag, New York, 1975.

[10 ] - E. McIntyre, "Design of Iransontc Cascades by Conformal Transformation of the Complex Characteristics," Thesis, New York Univergity, 1975.

[11] W. R. Sears, GeneraI Theory of Hitgh-Speed Aerodymanics, Princeton University Press, Princeton, 1954. 


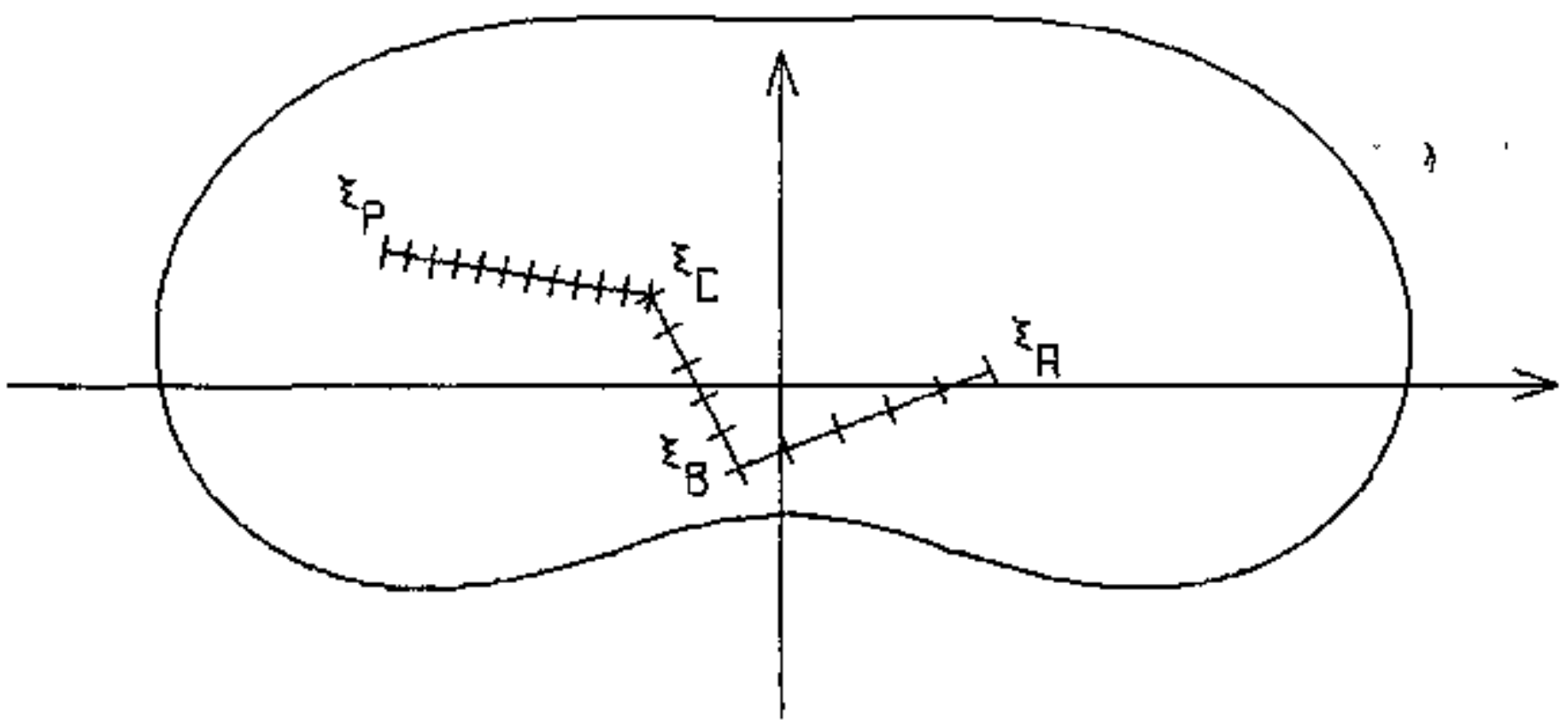

CHARACTERISTIE PLANE $\eta=$ CONSTANT

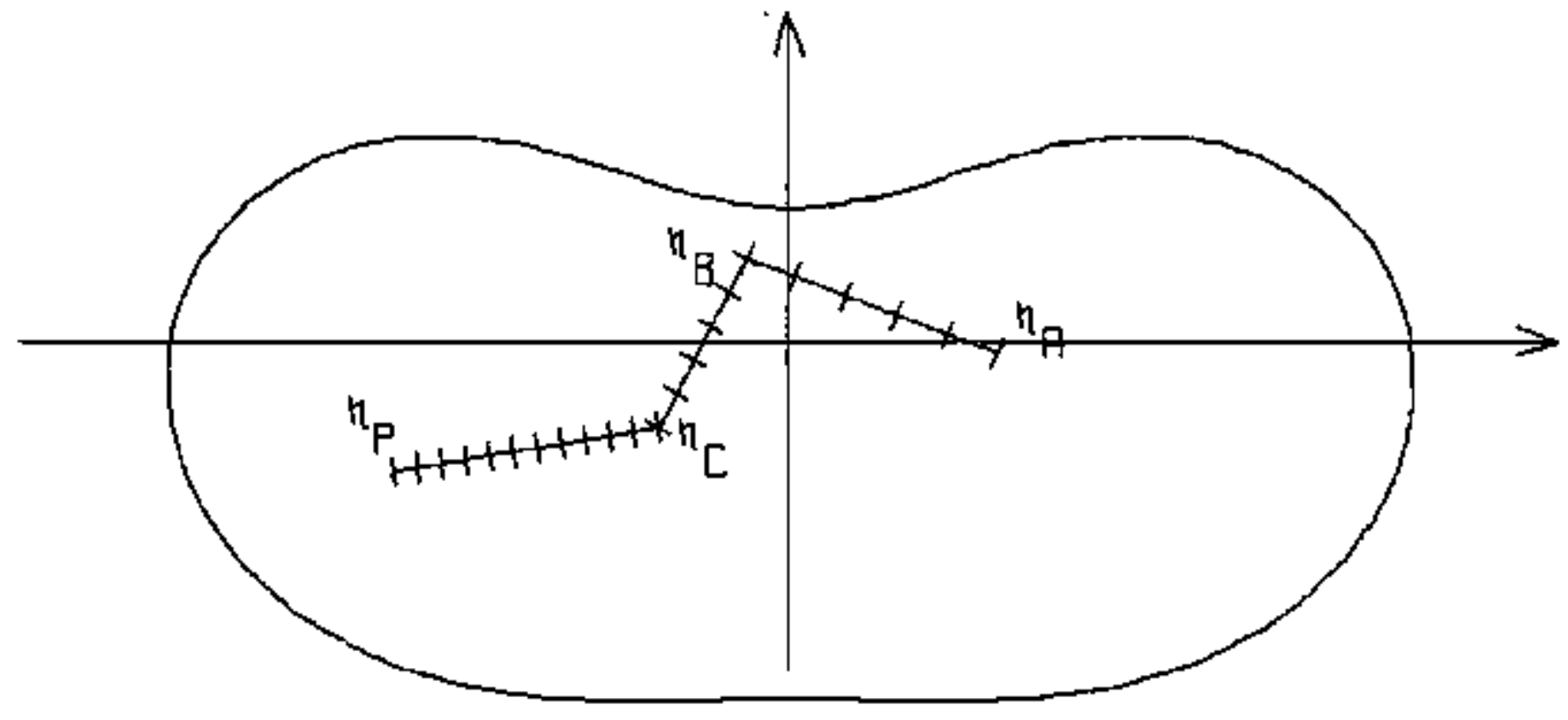

CHARACTERISTIC PLANE $\xi=$ CONSTANT

FIGURE 1A 


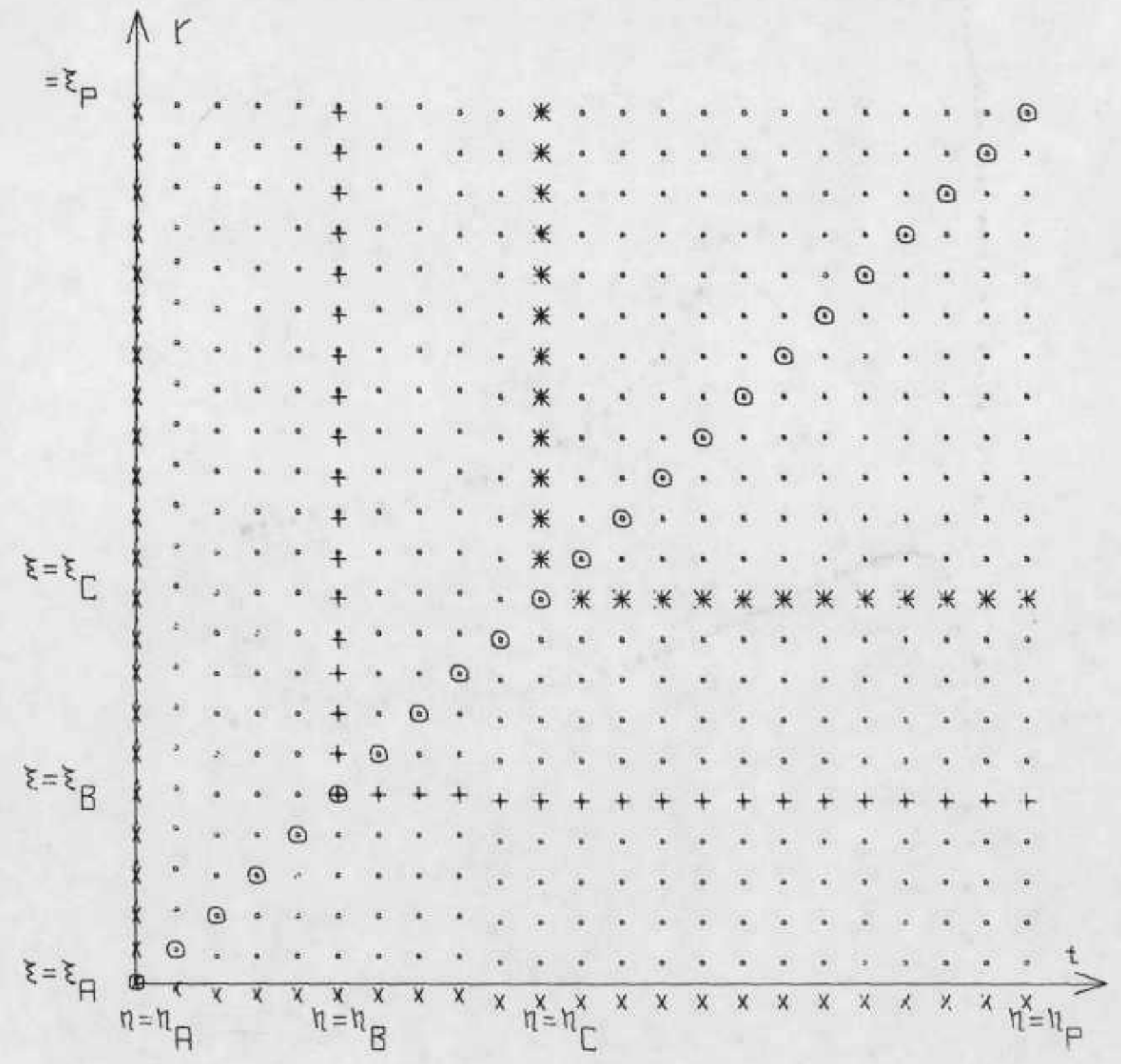

PIINTS DN THE FINITE DIFFERENCE GRID

$x$ POINTS IN THE INITIAL CHARACTERISTICS FOR $x^{1}$ AND $y^{1}$

+ PQINTS IN THE INITIAL CHARACTERISTICS FOR $x^{2}$ AND $Y^{2}$

* POINTS IN THE INITIAL CHARACTERISTICS FaR $x^{3}$ AND $Y^{3}$

- PQINTS IF SOLUTION IN THE REAL DOMAIN

FIGURE $1 B$ 
1.2

1.0

8

4

6.

2

0.01

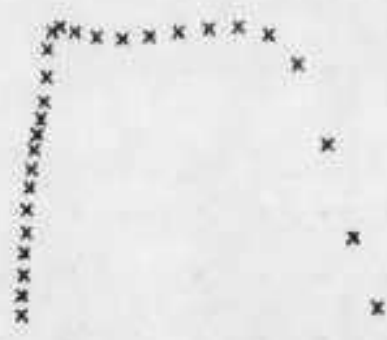

x

$x$

$x$

$x$
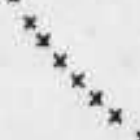

$\times \times$

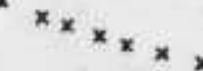

$f^{f}$

$+$

$+$

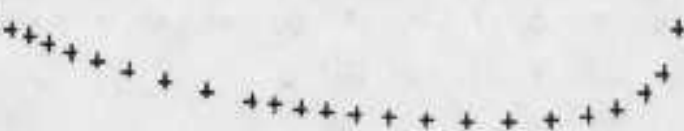

$+$

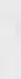

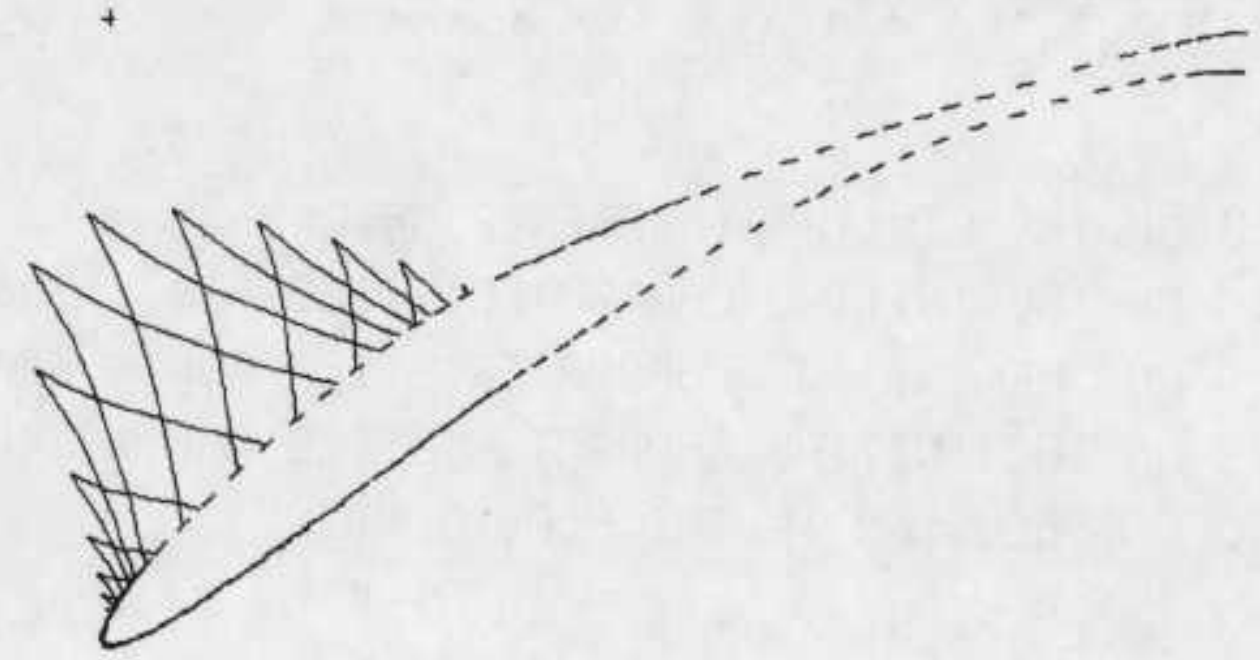

$M 1=.780$

$M 2=.480$

DEL TH $=29.00$

$G / C=1$. 


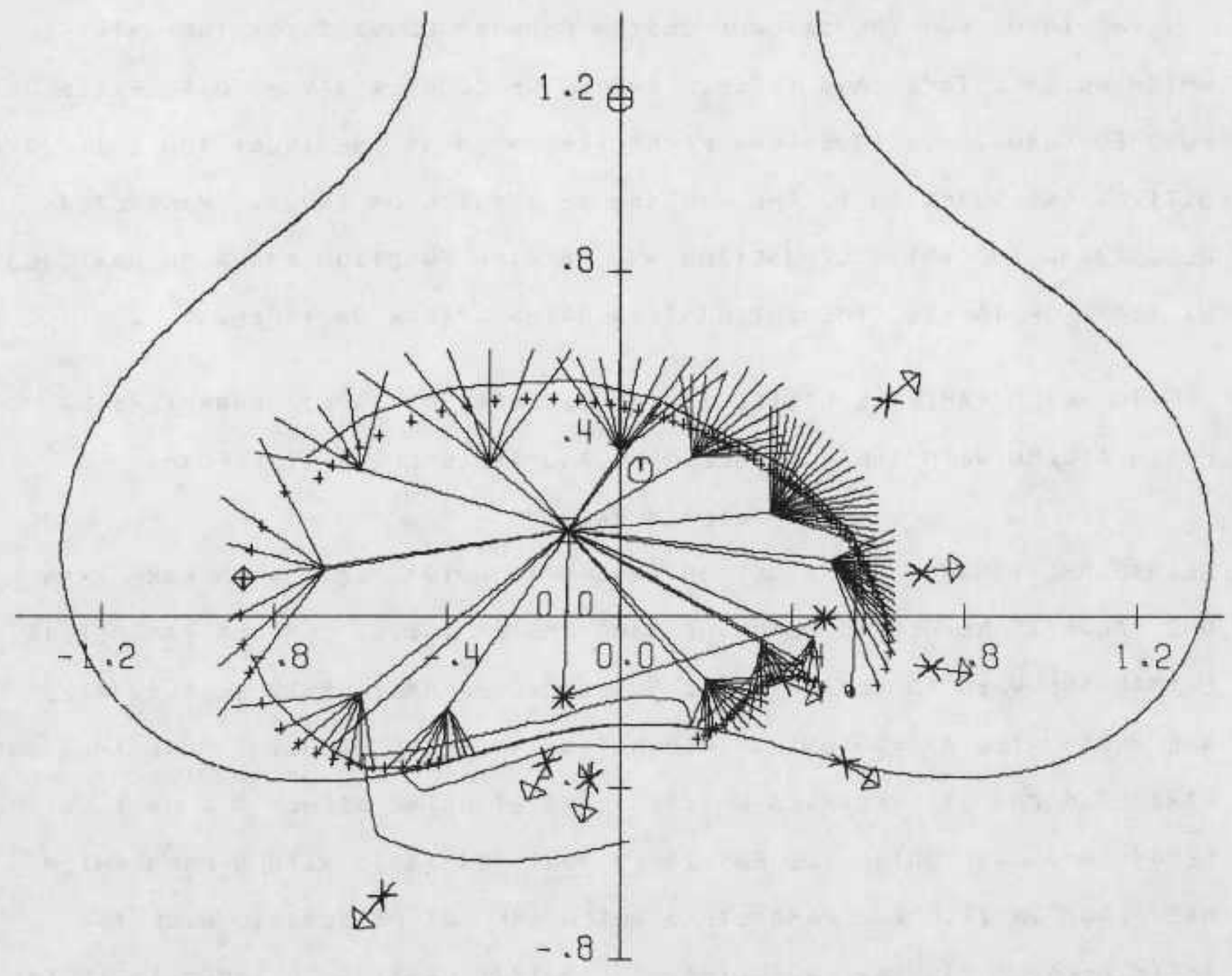

$M L=.780 \quad M 2=.480 \quad D E L \quad T H=29.00 \quad G / C=1.07$

FIGURE 3 
THE INRUT FUR THE CASCAUE JESIGN PROGKAM LONSISIS OR TWO UAIA FIG WHICH WE CALL IAPET ANJ TAPEG. THESE, CF COUKSE, MAY DE UISC FILES JR PUNCHEO CARUS. VARIUUS FLOW PARAMEIERS SUCH AS ITE INLEI AVU EXII LONOITIONS ARE SUPPLIEU TO THE PROGKAM AS INPUT rROY TAPE7. PAKAMETERS OESCRIBING THE INITIAL FJNCTION AVD MAPPING FUNCIION ARE ALSO AOSIGNEU BY MEANS OF IAPE7. THE INTEGRAIION PAIHS APPLAR ON TAPEG.

TO SET A VARIAELE LISTED IV IHE GLOSSARY UF IAPE7 PARAMETERS WE PUNCH A CARU WIIH THE VARIABLE NAME ANU IIS VALUE OF THE FOQM:

$$
\text { PARAMETER = VALUE }
$$

BLANKS ARE IGNOKEO ANU MOUE CONVERSION IS AUTUMAIIC, WHEN MURE THAN ONE VALUE IS NELUEO TO OESCRIBE A PARAMEILR, I.E. COMPLEX PARAMEIERS, COMMAS ARE USEU TO SEPARATE THE VUMGERS. PARAMETERS TO GL AUIOMAIEU ARE UESIGNAIED BY ASSIGNING THEM ANY NONONUMEKIC VALUL. MOKE IHAV JNE PARAMETEK CAN BY SPECIFIED ON EACH CARO BY USING EITHER A $\$$ OR : AS A SEPARATUR. THE DATA FILE FOR TAPET MUST IERMINATE WITH A CAKO WHICH HAS ENU = ON II. ALL PARAMETERS WHICH ARE NOI PRESCRIBLU WILL TARE THEIR DLFAULI VALUES. NOTE THAI IHE OUIPUT LISIIVG OF IAPL7 IS IV ITE CORRECT FORIMAT IO BL USL) AS INHUT TO KEGLNERAIE IHE RUN.

TAPES CUNTAINS THE PATHS OF INTEGRATION. THE FIRSI RAIH LEAJS TU THE STAGINATION PUINT IHE SECOND IO IHE IRAILING LUGE FOLLUWEU BY IHE NP AUTOMAIIUN HATHS ANO AS MANY INIEGRATION HATHS AS DESIREU. THE FIRST PATH WILL ALWAYS EE AUJUSIEU SO IHAT IT TERMINATES AT SIAGNAIION. IF THE MACH NUMBER AT THE TRAILING EOGE IS PKESCKIBEJ THE ENOPOINI OF IHE SECOND PATH WILL BE ACCORUINGLY ADJUSTLD. ALL THE PATHS ARE PKLSCRIBEO IN THE HLANE EIAEEIA(A). FOR SUSSONIC PAIHS IHE NATH IN IHE XIOPLANE 


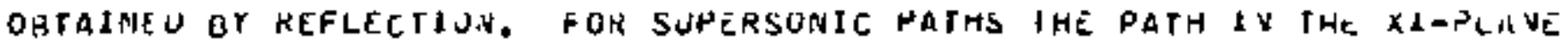
S JdTALNEU HY COHJUGATIVG IHE r OLLUNIVG PATH.

EACH PAIH IS OESLKIDẼ GY CAKOS DF IWO I YHES. 1HE FIKST ITHE JH

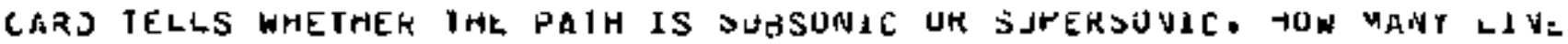

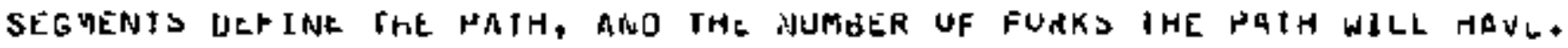
CAROS OF THE SLEORD IPPE CONIAJW THE ENUPOIVI FOR EACH LINE SEG IE WF IV THE ETA-PLANE ANO A NUMGEN WHICH IS USED TOR LEASI SGUATE WEIGHIIVZ UR FOR LOCHL YESH KEFINE MENI WI HH HN-AUIUMAIEU HAI HS.

CARUS UR TRPE ONE COVIAIN IHE FULLJWLIVG INFURMAILUN:

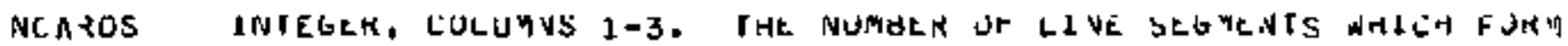
IHK PATP. THIS WLL $d=$ THE NUMBER UF CAROS DF TYOE IWO WIICH FULLUW.

NTYPE INIEGER, CULUMVS 4-6. IF NIYH<O A STEY FULLUHS ANU -VIYPL IS THE AJMLEA JF FORKS ISSUIVG FROY I1. IF WIYPE =U A FUR JR GASE STEA FULLOWS. IT NITHE>U A SUREKSOVIE PATH FULLONSI IF ITYPE=1 THIS PATH IS PLOTTEU: IF VTYPE=2 TRE SINGULARIJIES OF RHIS PATH ANE PLOTTEO; IF IIYHPS RAIA IS NOT HLOTIEU.

GARUS JH TYPE TWO COVTAEN THE FULLUWLNE INFORMATIONA

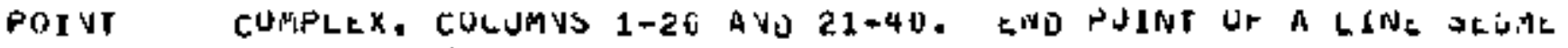
JN THE PAI UH UR FOKK.

WG+1

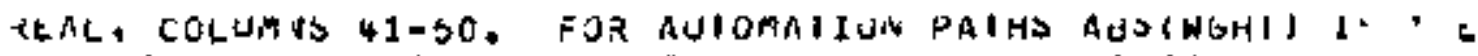

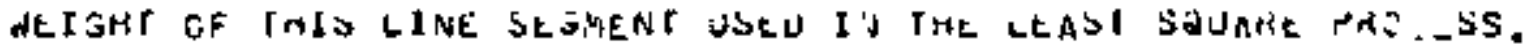

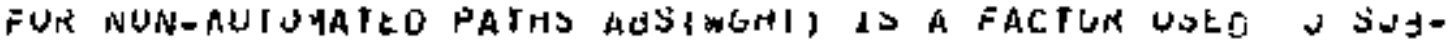
JIVIUE THE rINITE DIFHERENCE GHIO JW THIS LINE SEGMEVI. WOHT

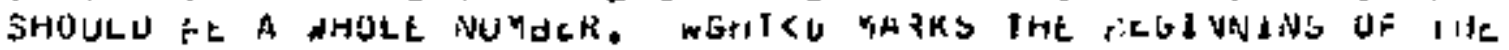

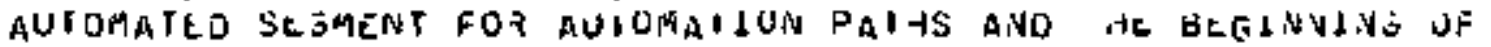
THE PAHT UF IHE PATH ALJVG THE SOVLL LJWL FUK A SJPEKSJVLG PATH. 


\begin{tabular}{|c|c|c|}
\hline NA "L & UEFAULI & UtFIVITION \\
\hline KUN & 1 & KJW NJMGtK \\
\hline MKP & $k$ & $\begin{array}{l}\text { McSN PLF INE MLVT } \\
\text { HARAMEIER }\end{array}$ \\
\hline$M P$ & $\mathbf{b}$ & $\begin{array}{l}\text { NUMdEz OF AUIU- } \\
\text { MAIIOV PATHS }\end{array}$ \\
\hline NCR & 7 & $\begin{array}{l}\text { NUMBET UF CUNE } \\
\text { STRALVTS }\end{array}$ \\
\hline PLTSIZ & 1. & RLJT SIZt \\
\hline IPLT & 057 & $\begin{array}{l}\text { INWEX FOA PLUI } \\
\text { CUUTRJL }\end{array}$ \\
\hline
\end{tabular}

CUNAEVIS

AUS(KUN) IS IHL RWN NUMBER, VLGAIIVE VALJES NILL PRJUULE A WIIt PAHEK PLOI ON THE LلL GSUO AI I TL AtC LOMPUIIVO CEVIES AT IUY.

UUUELING IHIS PARAYETER CUIS ITE GRIU IN HMLF. A NEOATIVL VALJE IS UStL FOR I HI SJ URUCK ACCUKACT.

SlNCE THESE PATHS UCTERTINE IHE RESULTIVG JESIGN THEY ARE PREVIEJ.

USt MLR=S FOR \$NGLE CRIILZAL PJINT AT IHE IAAILIVG EOLE.

USEU ID SLALE IHE PLUT OF IHE $X_{t}$ PLANE.

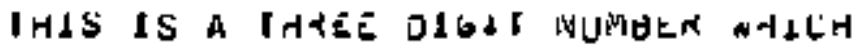
CUNTKULS THE DLOTILVE. THE FIRSI U1GII CUNIRULS THL PIFTY IVG PLUT AINJ IHE PLJT JF THL KLAL CHAREEJERISTIL PLAIE AS FULLJAS:

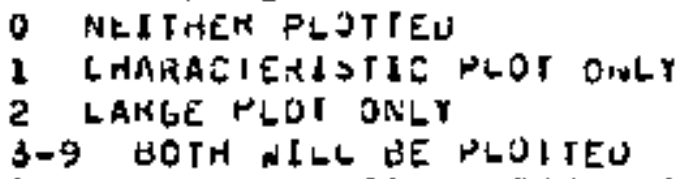

THE MIUOLE JIGII CUYTRULS THE PLJT

UF IHE RATSLEL PLAVE AS FULLJNSI

0 NO PLOI GEVERATEJ

1 MACH NUYGCX UISI\$LUTION UNGY

2 BLADE AUD MACH DISTRILUTIOY

3-9 SAME AS 2 FLUS GAARACILRISIICS

IHE LEAST SIJVIFICAHI UIGII IS USEO

TO CUNIRJL I HE PLJE Or THIE XI-DLAVE

AS FOLLOAS:

o XI-PLANE VOT PLUIJEU

1 SONIC LOEJS, BOUY POINIS+ LOSS, UNANCA PUI $\forall T S, x \perp A, x \perp d, x \perp=$, HULE, NJSE AND IALL ARE PLUTICD.

2 SAHE AS 1 PLUS W 1 RCLES OKANV AT AUIOMAIED POINES.

3 SAME AS 1 BLUS AJTUMATEJ HATHS

4 SaMe as 1 PLUS NJiv-aUTOMATEJ PAI HS

5 SAME AS BJIH 2 AVU 4

6 SAME AS BUIT 3 A.NU 4 WIIHUJI SUPERSUVIE PAIHS

7 SAME AS BJIH 3 A.VU 4

B-g SAME AS 7 HLUS CUNTUUR CJRVES If IPLI IS NEGAISVE IMEN IHE FLUW COMFUTATIUN IS SKLPNEJ. 


\begin{tabular}{|c|c|c|c|}
\hline NA YE & DEF AUL T & y化 $\perp * 1 \mathrm{TION}$ & EJ门酒上 VIS \\
\hline$n C-1$ & .63 & MAL_- VUNBEK & $\begin{array}{l}\text { THE FLOW IS VJRMALILEU } 3 \text { Y ASSLSWLVG } \\
\text { IHIS VALJE AI XI = V. }\end{array}$ \\
\hline RN ${ }^{-}$ & ¿. & KET VOLUS NUMUER & $\begin{array}{l}\text { IU SKLH BUSNJART LAIEK IUIEGNATIUV } \\
\text { SET RN }=0 .\end{array}$ \\
\hline TRAVU & .05 & $\begin{array}{l}\text { TKAUSITION ON } \\
\text { UPREK SURFACL }\end{array}$ & $\begin{array}{l}\text { THE VALUE OF X AT WHICH WL SIARE } \\
\text { IHE IUFBJLENI JUUNUARY LAYEN } \\
\text { INIEOKATIUV. }\end{array}$ \\
\hline TRAVL & .10 & $\begin{array}{l}\text { THANSI } 1 \text { IUN DIV } \\
\text { LUNER SUAFACE }\end{array}$ & $\begin{array}{l}\text { IHE VALUE OF } X \text { AT WIILA WE STAZI } \\
\text { IHE IUROJLENI GUJNUARY LATEN } \\
\text { INTEGRAIUV. }\end{array}$ \\
\hline KC & .009 & $\begin{array}{l}\text { KAUIUS OF CUK- } \\
\text { VAJJKE. }\end{array}$ & $\begin{array}{l}\text { IHE KADIUS UF EURVAIUKE AI STAS- } \\
\text { NAIION JASED OV UNII CHOKD LEVGIH. }\end{array}$ \\
\hline ANG VOSE & 20.00 & ANGLE AT NOSt & $\begin{array}{l}\text { IHE ANGLE DETAETN IHE INLET FLON } \\
\text { VECTOK ANU THE CENITAL STREAMLINE. }\end{array}$ \\
\hline MTA1L & & $\begin{array}{l}\text { MALH YUVGER AI } \\
\text { THE TZAILING } \\
\text { KU'SE }\end{array}$ & 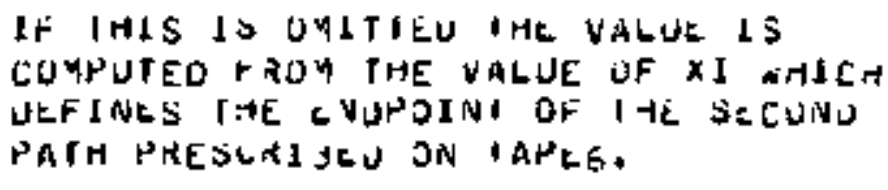 \\
\hline ANGTAIL & -14.00 & $\begin{array}{l}\text { ANGLE AT THE } \\
\text { TRAILING EOGL }\end{array}$ & $\begin{array}{l}\text { IHE ANGLE JETHELN IUL IRALLIVO EUGE } \\
\text { ANJ THE EXIT FLOW VECTOP. }\end{array}$ \\
\hline $\mathbf{I} \mathrm{k}$ & .03 & $\begin{array}{l}\text { TKAILING EOSE } \\
\text { HAIIO }\end{array}$ & $\begin{array}{l}\text { THE HATIU JF IHE IHICKIVESS UF I HE } \\
\text { TKALLLNG JOGE TO IHE GAP }\end{array}$ \\
\hline WLS & 2. & $\begin{array}{l}\text { WLIGHIING FOK } \\
\text { LEAST SQUARES }\end{array}$ & 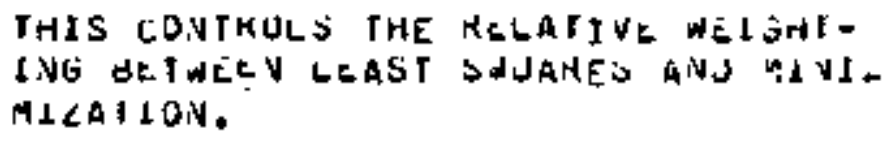 \\
\hline GAMYA & $1+40$ & GAS CONSTANT & $\begin{array}{l}\text { GAMMA IS I.4 FOK AIX. GAMYA IS } \\
1.07 \text { FOR URA IUH HAXIFLOKIJE. }\end{array}$ \\
\hline GRIO & De & $\begin{array}{l}\text { GKIO SHACING } \\
\text { PARAMETER }\end{array}$ & GRIU/MAP IS I tE MAALMJM theSrl $>1<L$. \\
\hline A INLET & & MALE SNLEI & 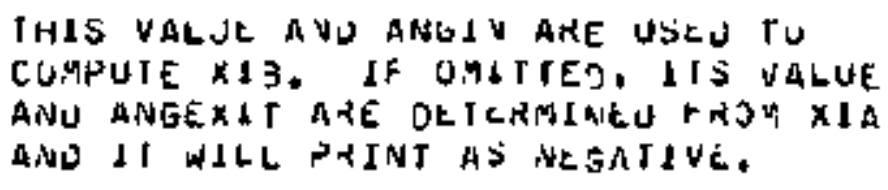 \\
\hline ANGIV & 7.00 & ANGLE AT INLEI & 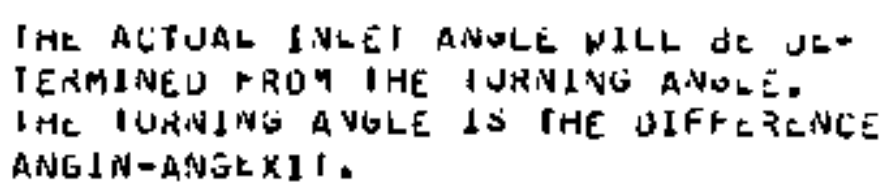 \\
\hline
\end{tabular}


MAYE DEFAULT UEFIVITION
MEXIT MALA EXIJ

ANGEXIT -10.00 ANLLE AT EXIT
XIA
.47 .003 XI ATH

X19 $-.14-.19$ XI Al

XIC $=.12,+20$ XI AtC

POLE PULE LOCATIJN

BP .05..34 BRALCन PUIN1

ET O.0. O. COCFFICEENT OF $\pm 1 \Omega$

trso 0.40.

ETCJ $0 ., 0$.

ETFO 0.00 ,

LOG

LUtFFICIENT UF $E Y \wedge * 2$

COEFFLCIENT UF $k+1 a * \$$

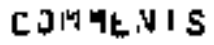

IHIS VRLUL AVJ ANGEXIT AKE USLU COUPUTE XIA. IF UAITTEO, HS VAI AND ANEIV ARE JETERAREO ANO 11 WILL PIINT AS NEGAIIVE.

USEU ALUNG WIIH ANG THE IUANING AVILE AVU EXII ANOLE.

IHE NUINT IS IAT XI=PLANR COATESPONUING TU THE EXIA VELOCITY, IF MEXII IS SOEEIFIEU IHE VALUE JF XIA WILL BE CUMFJIEU OY THE PROGRAM.

IHE HOINT 15 I HE XI-HLANL CURAESPONBLNG TU THE INLET VELUCIIY. IF MINLE I IS SPECIFILJ I HK VALUE JF XId NbLL UE COMPUIEU.

THIS UEFINCS THE CHARACTERISIIE INIILAL PLANE FOR XS AND YS.

IF OAITILU TAE TAANSFUMMAIUV FNUM THE XI-PLAVE IO THE HUUOGRAPH PLANE WILL BE JEIE\&MINEU SULEL AY 1 dS LOCAIION UF IHE ERAVCA DUIVIS.

THE MAPPING FTUF THE XIMLANE TU THE HUDOGKAPA PLANG IS DEJENYIVEO dY PKLSCRAJIVT ITS JKALEC PJIVIS ANU UHTIONALLY A POLE, NS YAVY AS TEN GHANCM PJINTS MAY UE SPELIFLEO.

UEIEKMINES LIVEAR IERM FUA IHE DNIIIAL FUVCIIOV. THE REAL ANU/JR IMAOLNAFT PATIS CAN JE ALIDYAIEJ.

UE JEKMINLS QJAJRAIL IERM IN IHE INIIIAL FUNCTIJR. IHE REAL AWJ/UR IMAGINAAY PARTS CAN JE AUIONAIEU.

DETERMINÉS CJJEC IERM FOIS THE INIIIAL FU.WCIIUV. THE KEAL AVUJJZ IMAGINAHY PATIS EAN BE AIJIMAIEO.

DE IEHMINES OJARIIC IEKM IN THE INIILAL FUVCIIJN. IHC ZLAL AVJJJA IMAGINARY PAATS CAN DE ALTOMAEN.

KACH LOS 15 JEFINEU SY PKL\$LRLSIIVG FOUR NUAdKRS SEPARAIEU EY COMHAS. IHE FIRST TWJ SHELAPY THL REAL ANU IMAGINAKY PATIS OF IHE WLIGHT ANJ EIIHER JR UUIH MAY dE AUIUMAIEJ. IHE LAST 1 NO SPECIFT IHE LOCAFIOV OF IHE LOS $1 N$ THE $X 1-P L$ MIJE. AS MAN AS 12 LOGS MAY BE PKESCNIJEU. 


\section{IApe 7}

8

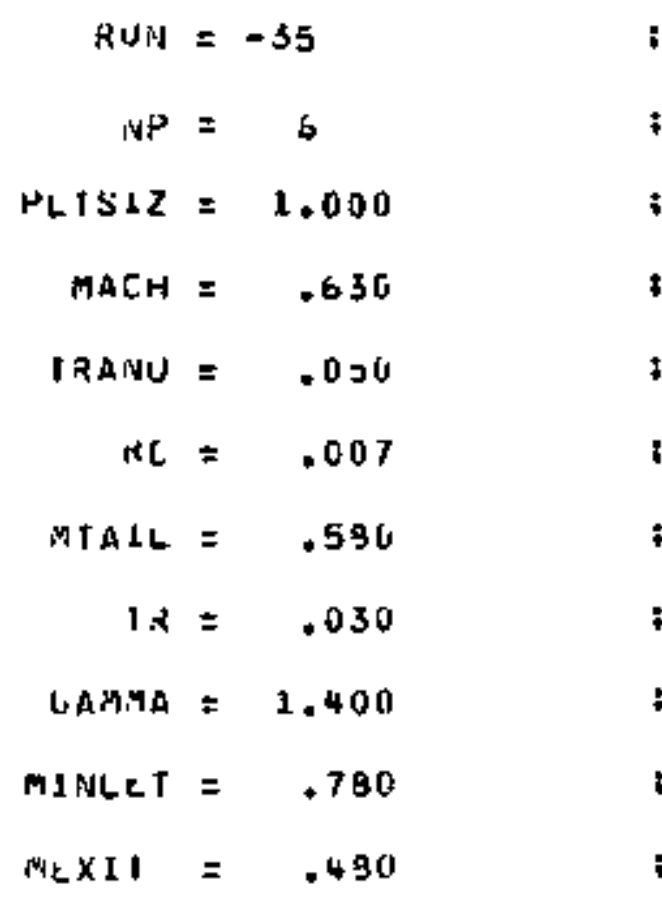

$X I A=.475 .-.003$

XIL $=. .120, .200$

$+$

4

$\mathrm{H}^{\mathrm{H}}=0.000 \quad 1.20 \mathrm{0}$ :

$E+=.043 \times . .246 *$

ETCU $=.106 * . .020 *$

LOS $=.285 *,-.568 *$

LOS $=-.996 .+-.724 *$

LOS $=.005+.043 *$

LOQ $=.0010 . . .062$

LOO $=.055 * .1 .035 *$

LOG $=0.000 . .181 *$

LOG = .062... .174*

$\log =-.085 * .0 .064 *$
;

;

;

;

t

i

;

;

$$
\begin{aligned}
\text { MRP } & =2 \\
\text { VCK } & =7 \\
1 P L T & =357 \\
2 N & =1.600
\end{aligned}
$$

IKAVL $=.10 \mathrm{~J}$

ANS VOSE $=25.0 \cap 0$

ANOIAIL $=+15.000$

$$
\text { NLS }=2.0 \mathrm{nU}
$$$$
\Delta+10=.020
$$

AYOIN $=9.000$

ANOEXIT $=-20.000$

$$
\begin{aligned}
& x 13=-.132, \quad-.158 \\
& d p=.050 . .540
\end{aligned}
$$

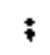

$E T S Q=.312 * . .021 *$

LTrO=0.000 . 0.000

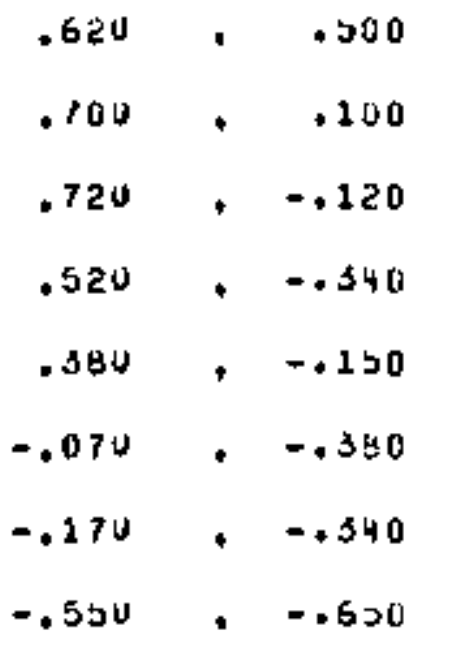




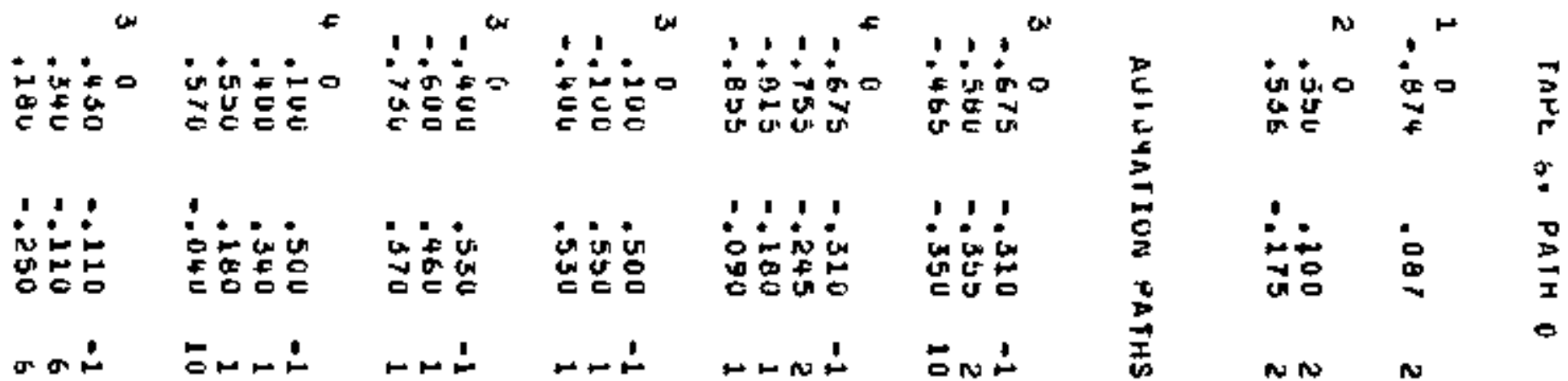


$G_{A P} P$ CMUKU $=1.06 \%$
INLE I MALH VUYUEN= .780
INLET FLUN ANBLE $=45.03$
EXII MACH WUYdEK
EXIT FLON AVtTLE= 74.03

TUKVIVG AUGLL $=29.00$

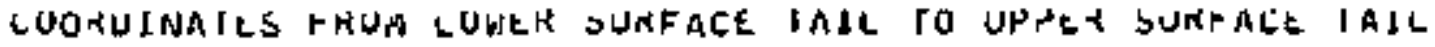

$x$

$\mathbf{r}$

ANo

K

$$
\begin{array}{rr}
1.0 & 14.15 \\
-.4 & -2.95 \\
.5 & -3.58 \\
3.1 & -3.14 \\
3.5 & -2.37 \\
8.7 & -1.90
\end{array}
$$

.64554

.82363

.79444

.76100

.72680

- 6944 A

.66491

.63793

.61436

.59395

.57217

.55374

.51937

.41491

.45573

.43078

.40965

.33150

.37627

. 36) 72

.34375

.32756

.31445

. 30206

.29042

.27954

.27303

. 26250

. 25390

.24544

.23697

.22564

.21614

1215

1053

.18146
.43864

.40023

$.45 / \mathrm{fi}$

+456y8

.43559

- $4+007$

.44576

.43516

.42470

$.40<59$

. $3 \neq 1 \in 9$

. 34154

.37251

.3621 .2

.35293

.35427

$.31>51$

- ग9R5A

. 28354

+2 I 1014

. $256+1$

.24834

.25953

- 22660

.21554

- 206́1

- 1 y 71

- 1 9y

$.131 \leqslant 3$

. 17545

. 15932

16318

. 15703

.13092

- 144 RE

$.13 \bigcirc 82$

.12564

.11759

.11007
.41356
$11.1-1.45$

$13.5 \quad-1.19$

$13+3=1.02$

$16.0 \quad-.92$

$14.9 \quad-.87$

$21.4 \quad-.01$

$24.7 \quad-.79$

$25.9 \quad-.77$

$24.7 \quad-.76$

$23.7 \quad-.73$

26.8

28.4

34.3

31.0

51.9

32.5

35.1

35.5

33.9

34.3

34.7

54,7

35.1

35.3

3b. 5

35.5

50.1

3.8

15. 9

35.9

36.0

36.1

36.1

$\$ 6.1$

उ6. 0

$y$

THE IA

SEP

.5800

.4912

.4430

.4069

.3711

.3784

.3726

. 35, 95

.3682

.1635

.3696

.3714

.3737

.5761

.3786

.3118

.3449

.3521

.4003

.4035

.4164

.4237

.4503

.4361

.4416

.4491

. $\$ 560$

.4616

.+671

.4723

.4773

.4812

.4852

.4893

.4933

.4974

.5014

.5075

.5144

.5200

.5240
.0010

$$
\begin{array}{r}
.00104 \\
.00166
\end{array}
$$

$.002<1$

.00219

. Ousug

.00335

.00343

.00347

.00345

.0030

.00350

. v0s<U

.00310

.00500

.00240

$.00=79$

.00257

$.0024 \mathrm{e}$

. $00<27$

.00208

$.001 \geqslant 1$

$.001 / 7$

.00165

.00156

.00147

.00136

- $001<5$

. 0119

.00112

. 0ulus

. c01vo

.00095

.00072

.00067

.00043

$.000 / 9$

.00075

.00070

.00064

- D0057

. 00053
$-.08674$

-.0260

.01578

.00765

.00417

$-.0021 \mathrm{~s}$

$-.00000$

$-.00027$

.00001

$.0002 y$

couty

.00060

.00071

- UDusa

. OnOFy

- volus

. O0lat

.00151

.00134

.00153

.00127

$.001<+$

.00214

.00115

$.002 u 5$

.00201

$.0009+$

. Ucists

.00us4

.00030

.00015

.00072

$.0006 y$

.0006 b

.00065

- Housu

. v00st

.00002

$.0004 t$

.00042

.00035

.90275

. yula

.09061

08519

. 47007

. 94713

$.12+47$

. $t$ †טगs

.76231

- 12529

.

- D6s6s

- $05+72$

- U1619

. 9502

. 7406

. J5532

.02025

+86b1

.45744

.45253

+1115

.39305

.31764

.26305

.34527

- य287 


\begin{tabular}{|c|c|c|c|c|}
\hline & 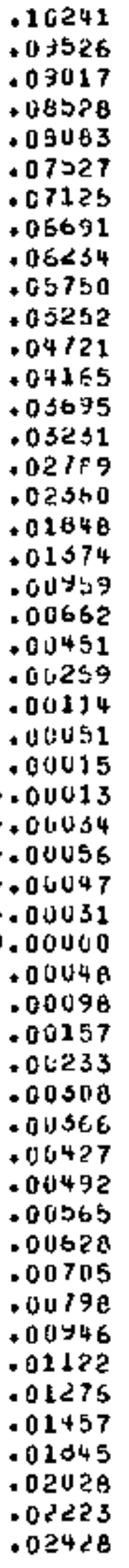 & 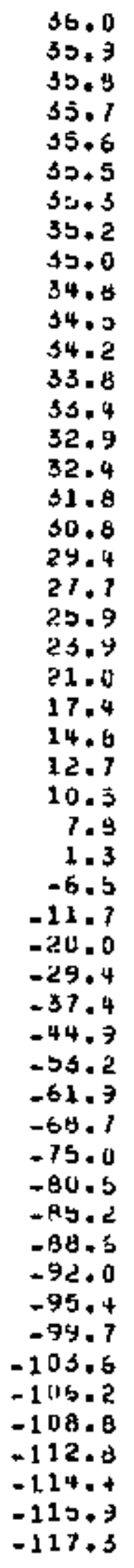 & $\begin{array}{r}.12 \\
.16 \\
.20 \\
.23 \\
.27 \\
.31 \\
.35 \\
.40 \\
.45 \\
.52 \\
.60 \\
.70 \\
.82 \\
.97 \\
1.15 \\
1.39 \\
1.77 \\
2.43 \\
3.44 \\
4.96 \\
6.95 \\
9.88 \\
14.48 \\
19.77 \\
23.95 \\
28.54 \\
34.03 \\
44.93 \\
56.95 \\
87.58 \\
138.60 \\
143.85 \\
154.07 \\
146.06 \\
145.66 \\
169.14 \\
186.37 \\
172.58 \\
141.42 \\
112.98 \\
92.78 \\
77.84 \\
64.00 \\
50.58 \\
37.55 \\
28.35 \\
23.32 \\
16.97 \\
13.94 \\
11.96 \\
10.55 \\
9.74\end{array}$ & 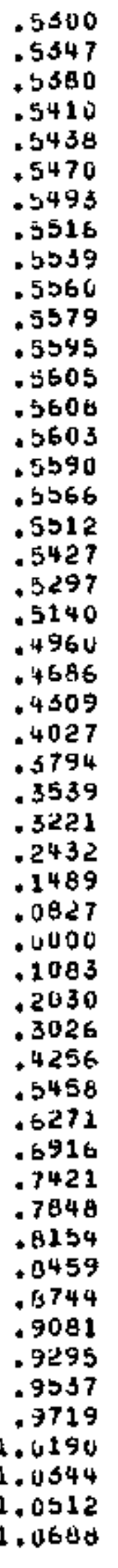 \\
\hline
\end{tabular}

$\begin{array}{ll}.00050 & .00053 \\ .00045 & .00051 \\ .00044 & .00020 \\ .00041 & .00020 \\ .00059 & .00025 \\ .00056 & .00020 \\ .00054 & .00018 \\ .00052 & .00015 \\ .00043 & .00015 \\ .00047 & .00110 \\ .00024 & .00001\end{array}$

I ZANSITION

STALNATION
$.170 / 2$

.160ts

.15375

.14670

.14075

.13293

.12745

.12110

.12458

.20761

.20041

- एบ2 25

$.08+20$

. $/ / 13$

.07005

$.06 \$ 14$

- 40662

.04787

.03971

. vsals

. 02627

$.021 / 5$

. 017 us

.01243

.01075

. $109 \times 9$

.00796

. 00603

. v04us

. 00202

.00100

0.00000

.000103

$-.00178$

$-.00246$

. .10309

$-, 00358$

- 10306

$=.00405$

$-00419$

$-.004<8$

$-.00451$

. .00450

$-.130424$

.00404

-.003/2

-.00327

- v0269

.00120

.00040

. vU0⿰1

.00204
11.

, 09597

.09075

- 10382

.08134

.07574

.07159

.06755

.06273

.05795

.05235

.04721

. 04165

.03675

. 03231

.02739

. 02350

. $018+8$

. $01 \leqslant 74$

.00959

. 0066z

.00451

- 4025

. 00114

- vevol

. 00015

$=.00013$

.00034

.00056

$-.00047$

. onjos 1

0.00000

.00043

.00098

- 0015I

- 0 C 233

- 00s0B

- Ousso

. 00427

. 00472

. 00565

.00628

.00705

.00738

. 00746

.01122

.01276

- 01457

- 01945

$.0202 \mathrm{r}$

$.02^{n-}$

.02 


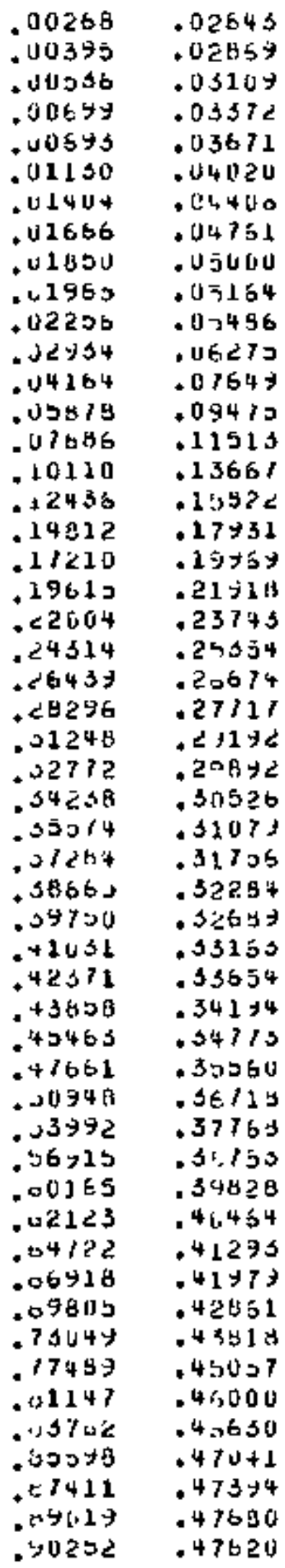

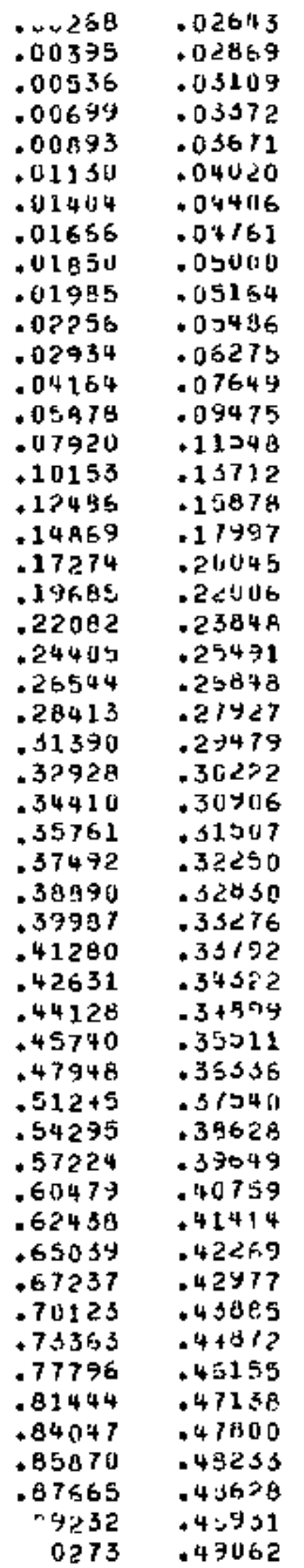

0273

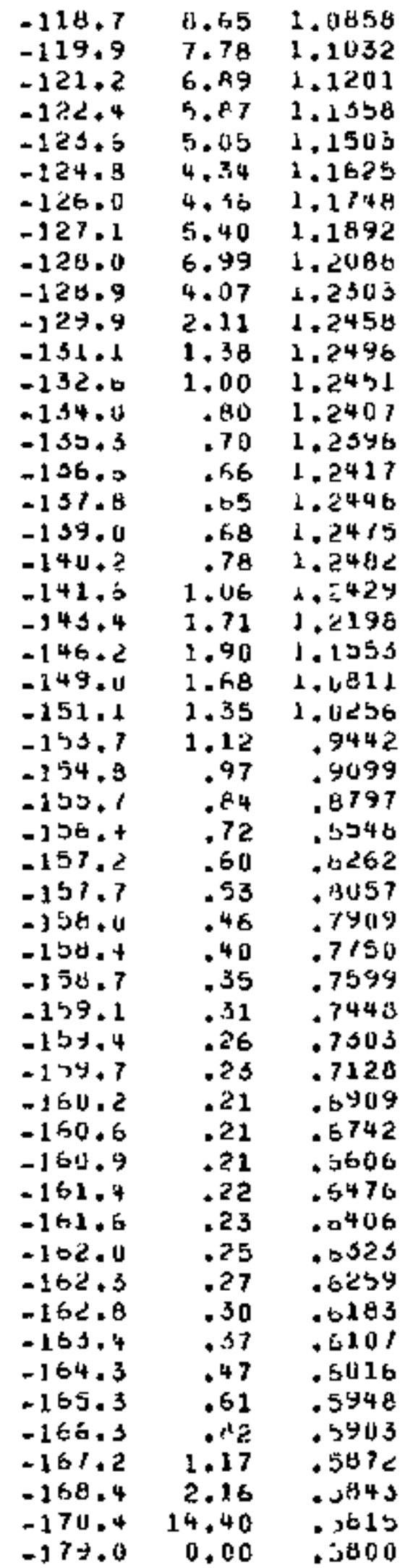

- $00 \mathrm{~d}<3$

- Guvor

.00045

. 64054

. 00002

. U⿺辶⿸广 3

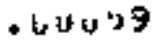

- v0104

. 0105

- 00151

. Gu1b7

. 00136

- U0z 10

- [102<9

- 00245

- 04263

- 64243

- 6. 544

- $005 \times 7$

- 00508

- 13549

- 00434

. 00466

- 0050

- 60519

- C0543

- 00563

- 0 U otg

- UU61

.00547

.005/4

- $006 y 3$

$.007 \cup 6$

- 100713

- 6471

- 04753 . c0usu

.00042

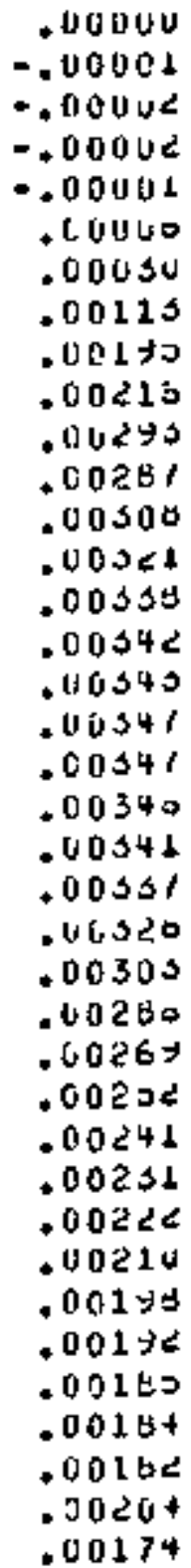

(1)

$13 \mathrm{H}$ 


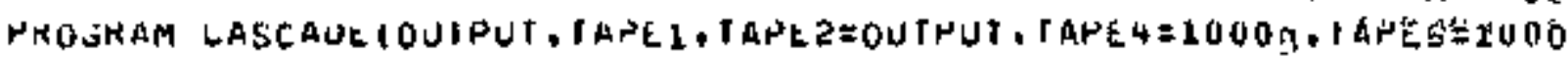

1 S, TAPE $7=102 B,[A P E S\}$

UIMENSIDIV LARUIBII

COMYOH J LUMnUN/G/N1+N2,N6,N7,N3, V4,M1

C SECONU IS A tUC G6I0 CENTBAL PROCESSOR IIVIVG ROJIIVE

GALL SECUNUAILME)

$r I=3.14159260357969$

6 LHAVGE LUM WHEN CHANGING IHE UIMENSIOV SILE

LUM $=200$

C GHAVGE KOM WHEN CHANGING JHE DIMENSION $51 \angle E$ UF XO AND YS

$K$ MM $=10$

$M 1=N_{1}$

KEW INU N4

$\operatorname{MKPFAC}=1$

2 KENINU NI

KEWINJ NG

KEWINO N7

[

KEAJ IN IHE TAPET UAIA

20 KEAD (NT.120) (CARO(J),

Ir $($ INCOUE (CAKU), VE, 0 ) 60 TO 20

C

MKP IS NEGATIVE WHEN CHOUSING IHE IHIKU OKUER ACLURATL HELTOU

MKPJLU = MRP

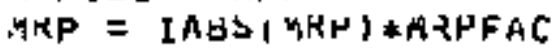

If (MKPOLU,LT.O) पKPFAC = MRPFAC+1

IF $(N P, G E, C) \quad N 4=N_{2}$

$A P=1$ AASS (NP)

GALL INII

NATIE $(N 2,60\}$ VIN

If (1PLT,L1, I) GO 1010

LALL AUTU1 (N2,KBY)

JU $40 \mathrm{~J}=1,9 \rightarrow$

MUDE $=-J$

LALL MAINIJ)

IF (MOOE.LQ.99) 6J TO 45

WhIt (Na, SO) J

40 LUNBINUE

45 NKIB $(\$ 2,130) \mathrm{J}$

CALL SECUNO III

IIATE $=11-1[$ Hit

Writt $(N 2+110)$ II UE

的1 $=N_{3}$

It (MRPFAC,EO.2) 60 TO?

If (MRPUEU, $[1,0) \quad V_{1}=M 1$

$M+P=I A O S\{M R P L O U$

10 LALL TITLE

IPLI $=$ IABS (IPLT)

$\forall X=0$

LALL BOOYPI (mX)

(ALL HLAUET WX)

IF (IPLT.EG.O) CALL EXIT 
LALL HOGKF ( $4 X)$

LALL CPLUT(10.+0.1.9\%9)

LALL EXII

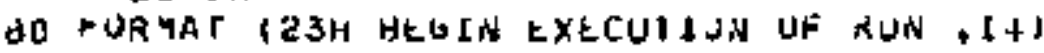

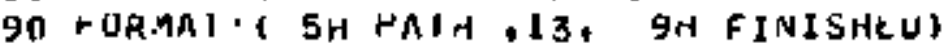

210 PORYAT I17H TOIAL CP TIVE IS,FG,1,8H SECOVJS)

120 HURAI (BQAJ)

130 FORMAT $(+3 H$ UUI UF PATHS/ 28 LONGEST PATH HAS I $13,7 H$ NUINIS,

END

PUNCIION INCUUE IJATAS

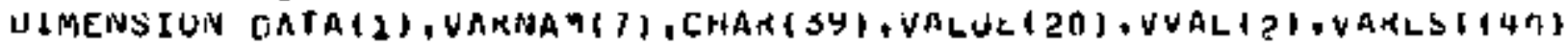

1 - LJCV\{ 401, ARRAYTII, IARPAY(1)

KEAL MACH,LOGS

LUIAMUN /AI GAMMA, YACH.ROUI (4)

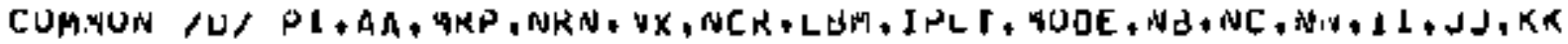

COMPLEX EIJ

COMMON $/$ L LUUS $(4,12), E T J(4), X K, N L U G S, N A, W, N J, L L(32)$

CUMPLEX XIIAIL, BP,HOLE, X\A,X10,X1C

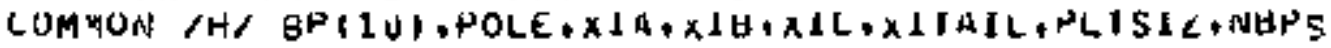

HEAL MACHA, MACHB, MIALL

LUM MUIV /K, RN, NCHJ,PCHL, MACHA, ANGLA, MIAIL, ANGLI, WACHA, A YGLI, RE,

1 ANGLN, IR

EHUIVALENCE (ARRAY (1). IAKKAYTI)

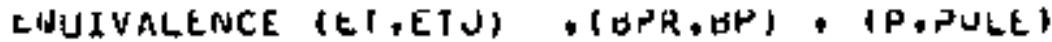

UATA CHAR, IHA, $1 H 3,1 H C, 2 H 3,1 H 2,1 H F, 1 H G, 1 H H, 1 H I, 1$ J, 1HK, 1HL, IHY,

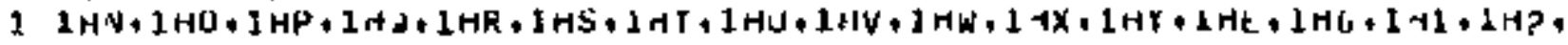

2 LH3,1H4,1H5,1H5,1H7,1HB,1H9,1H+, 1HE, L11,

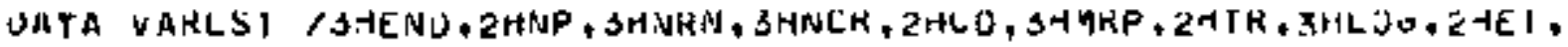

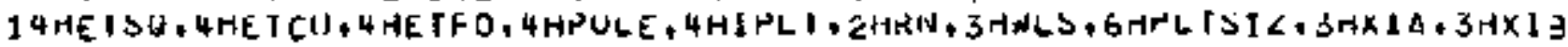

? JHXIC, 7HANG TAIL, 5HMTAIL, 2HRC, 7HANG VUSE, כHGAMMA, 2MLY , 4 MAACA,

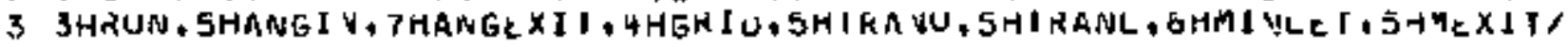

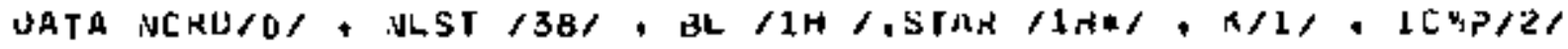

$L U C V(N L S I+1)=$ LOER (LOCV $(V L S I+1)$

in $x=1$

$K x=1$

NoDE $=1$

IF INCRD,NE.D) GO 104

LUCV(2) $=-\operatorname{LOCF}(\mathrm{VP})$

$N F=6$

LUCV (S) $=-$ LOLF ( VRV $)$

UHN $=1$

LUCV $\{4\}=-\operatorname{LOCF}($ NCR)

$\mathrm{NCR}=7$

$\operatorname{LDCV}(5)=\operatorname{LOLF}([K)$

$\mathrm{IH}=.03$

LUCV ( G) = -LUCF MRP

TKP $=1$

LUCV 7 ) = LUCF (IR)

$L U C V I B)=L U C F(L J G S)$

$\operatorname{LUCV}(9)=\operatorname{LOLF}(E T)$

LUCV(10) = LUCVt $y+$ ICMP 


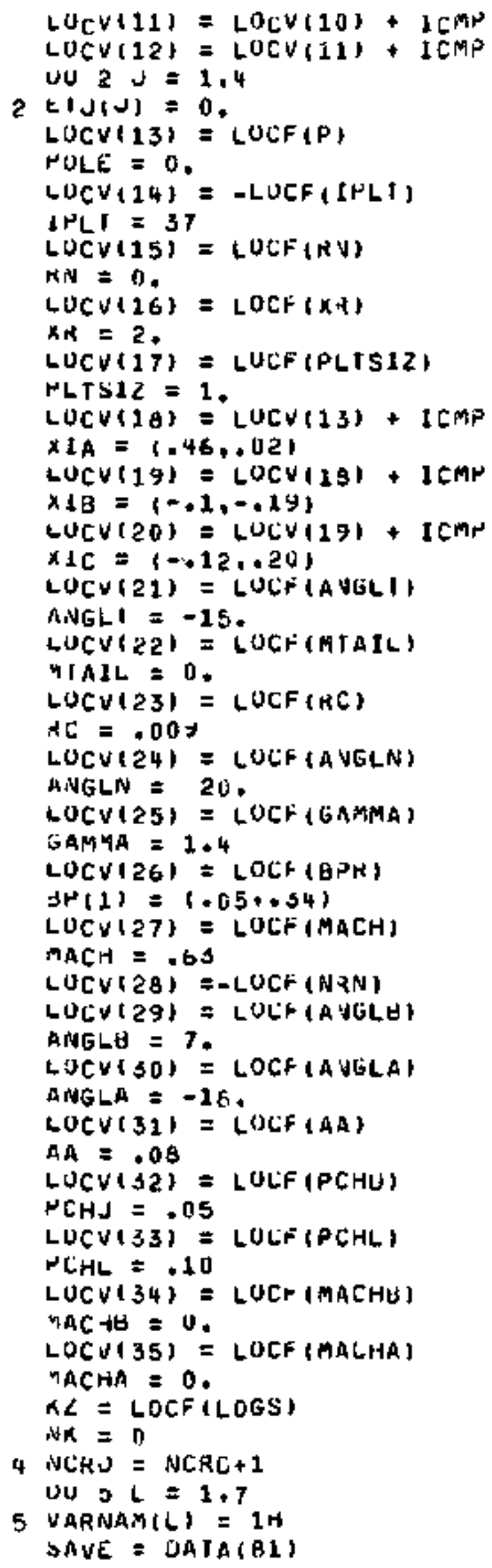




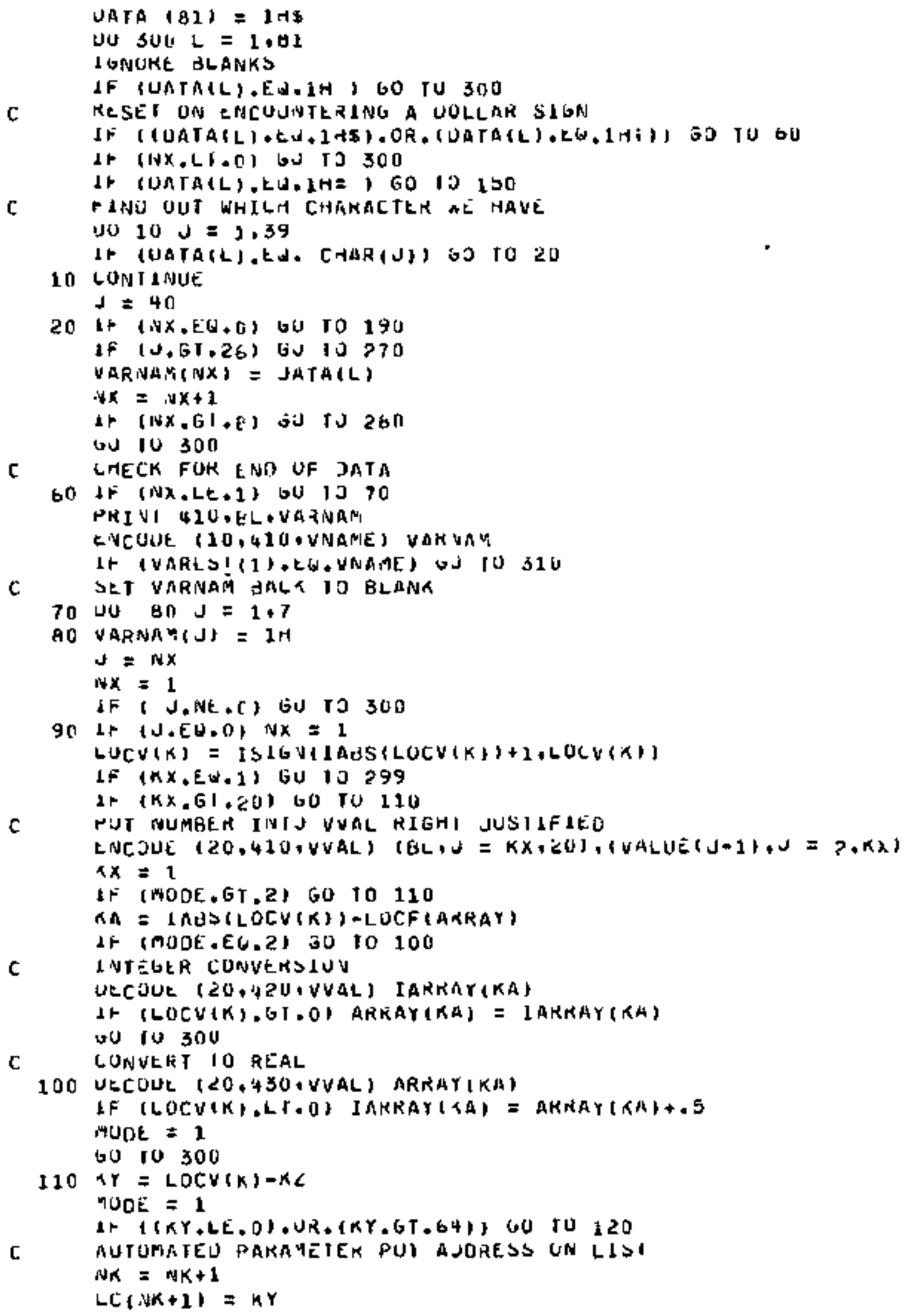




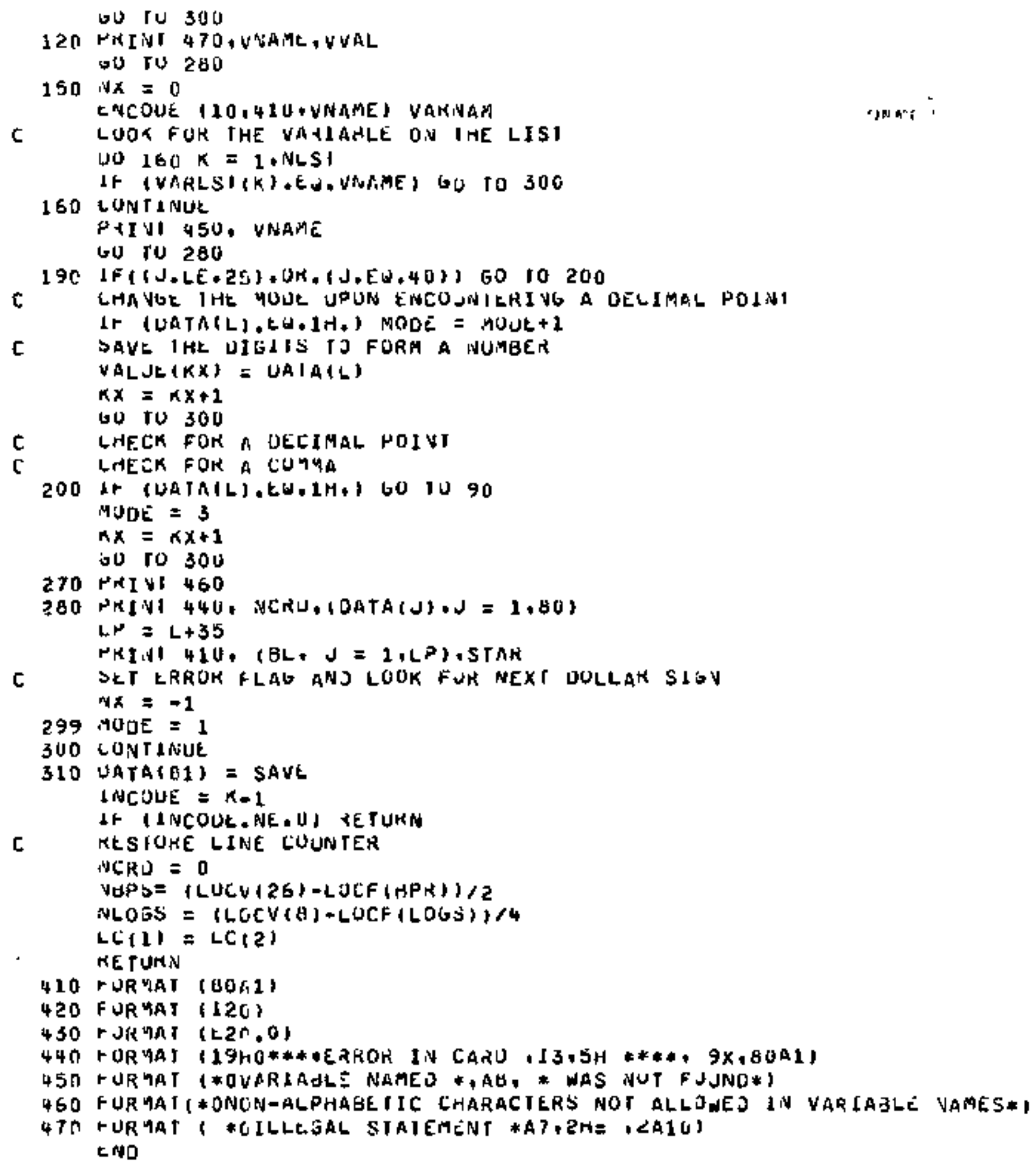


SUBROUTINE INII

JU INITSALIZAIION

REAL TALH

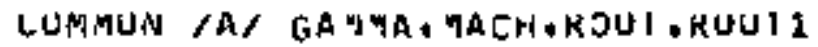

LUAYUN $/ L$, XARLAL, XA1HG, YAREAL, YAIMG, XUIIU, YBIMU, IPIZ

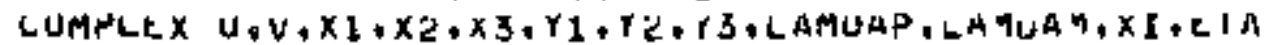

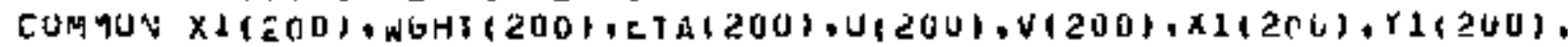

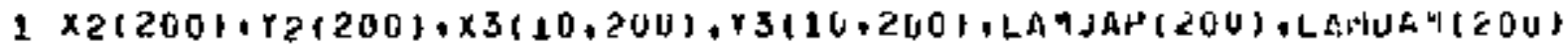

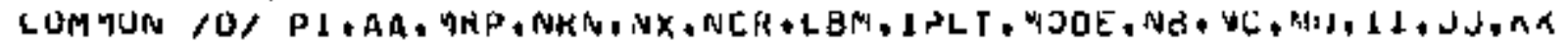

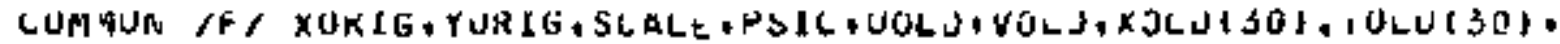

1 NS1OLOT30)

LUMPLEX XIMAIL, AP, POLE, XIA,X1B,XIC

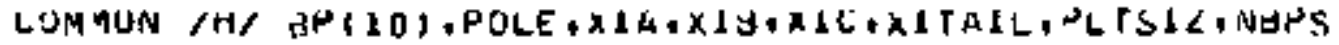

$M \leftarrow A L$ MALHA, MACHS, YIALL.

LOAYUA $/ K /$ RN, HCHJ,PCHL, MACHA, ANGLA, MIAIL, AVGLI, MALHS, ANGLJ, ML.

J A YGLN,IR

CUMPLEX I.S. H SOFXI,X1DFM,HOUF,KUUII

JATA I / O., 1.1/

$\triangle C A L E=1$.

$X \cup R 16=0$.

YURIG $=0$.

rSIC $=0$.

NUOI $=10,1,1$

KUOTL $=11, \ldots 0.1$

C LAY JOWN PATH FROY XIA IU XIB IO XIL IN EIA-PLATL

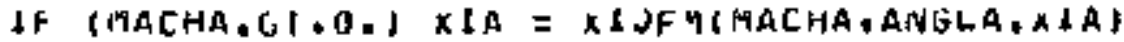

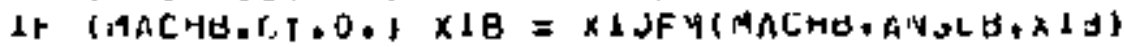

$x \perp(1)=X 1 A$

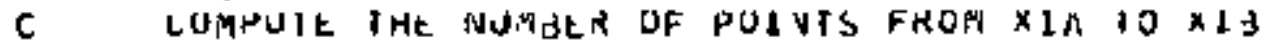

$M, n=L A B S(X \perp B=x \perp A) / A A+, 9$

पन $=$ YAXU\{1, Yप*MRP

।जs $=M+1$

$I=(X I B-X|A| / R=D A \mid\{\eta Y)$

C LAY UOWIS GKIO IJ $\mathrm{AlB}$

UU $10 \mathrm{~L}=\mathrm{S}$, No

$20 X \perp[L]=X[(L-1)+H$

c

LUMPUIE IHE NJWJEt DF PJIVTS FROM XIS IJ XIC

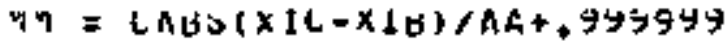

$M, M=M M * M R P$

$V L=M_{M} M+i V_{0}$

C

$H=(X \perp C-x) B) / F L U A T(M H)$

LAY UOWH GRIU FROY XIA TO XIC

MUP $=N d+1$

No $20 \mathrm{~L}=N B P, \mathrm{VE}$

C

$20 \times(L)=A I(k-1)+H$

LAY UOWH REFLELIEJ GKID IV THE X JU SOL $=3$, NC

$30 \mathrm{LIA}(L)=$ CUVJG(X)(L))

TAU $=P 1 / 110$.

OAP $=(6 A M M A-1+) / 2$.

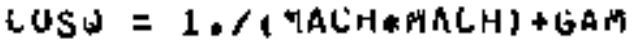

IF IMAEHU.CT\&U.1 GU 10 40

C

IINJ BACH NUHOLR AND AHSLE AI INLEI

$S=S C F X+|\lambda I U|$

$U(N)=1$. 
$V(N \Delta)=J$.

LALL GETUV (S,LONJG(S), Ji\$3), VINGJ)

UQ = REALIUINGJI

$V B=$ KEALIVINBH,

$\triangle S B=U B * U B+V B * V_{B}$

TACHU $=$ - SURI(USD/ICUSG-GAMQGSO)

MNGLB = ATAN2IVG, JB)/RAU

Go IU 45

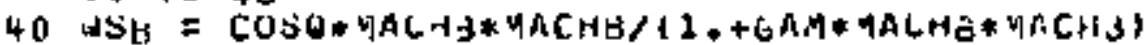

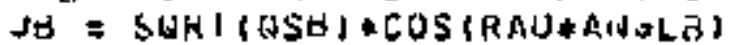

$V B=S G H(G S B) * S I V(R A U * A N O L B)$

$U(N)=U A$

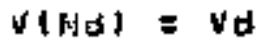

45 IF IMACHA.GT.U.) SO TO SU

C

FINU YACH NUMULR ANG ANGLE A LXII

$v(1)=1$.

$v(1)=0$.

$\checkmark=S O F \times I(\lambda I A)$

LALL GETUV (S.CDAJG(s), J(2), V(1))

$J A=R E A L(U\{1)$

$V A=F E A L(V(1))$

$\triangle \triangle A=U A * U A+V A * V A$

$4 A C+M=-S G R T(W S A / \operatorname{COS} G-6 A M+0 S A 1)$

$A N G L A=A I A V 2(V A, J A) / K A D$

ou ru $5 b$

$5 C$ 1 $\$ A A=\operatorname{COS} Q * 4 A[H A * 4 A C H A / 11 .+6 A M * M A C H A+4 A C H A]$

UA = SURTIUSA, *LOS \{RAIJ *A IVISLA

$V A=S U R I(O S A) * S \downarrow V(R A U * A N G L A)$

UII) $=$ UA

$V I 1 J=V A$

55 AHOJ $=$ RHOQOSL

KHOA $=$ RHO(GSA)

IF (MIAIL,GT,U,) XITAIL = XIOFM,AIAIL,AVGLA+MNGLI, XIA)

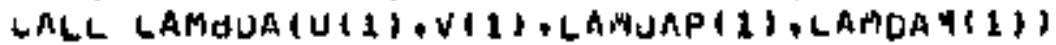

$X 1 A S S=1, / C A Q S(X \backslash B-X \perp A)$

PAC $1=12,-T K\} *\{H O A * V A=R H D B * V B$

$r A C 2=(1,-\{K) * R H J A * U A-\{H J B * W B$

YARLAL = FAL2-FACI*REALILAMOAMII)

IF (FACI + NE. O,) YAREAL = YAREAL/IFACI*AIHAGILAMUAMIII))

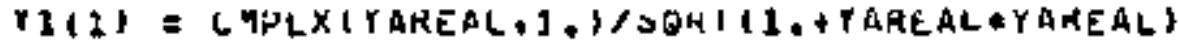

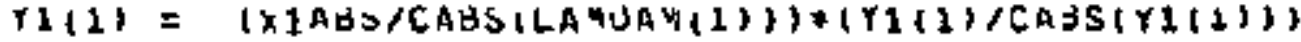

$A 1 \mid 1)=-L A N O A H(1) * Y 112)$

IF (REAL(X112)).LT.0.) GO IJ 60

$X 1(1)=-X_{1}(1)$

$\left.r 1(1)=-r_{111}\right)$

60 LUNT 1 NUE

XAREAL = REAL $\{X 112\}$

TAREAL = KEAL $(Y 111)$

XAIAG $=A[P A G(X 111)$

YAI मG = ADUAG (YI11)

$X_{B I I G}=-X A 1 M G /(1,-T R)$

IUIDG $=-Y A I M G /(1,+T h)$

IHTK $=2, * P I * I+T$

Kt TUKN

END 


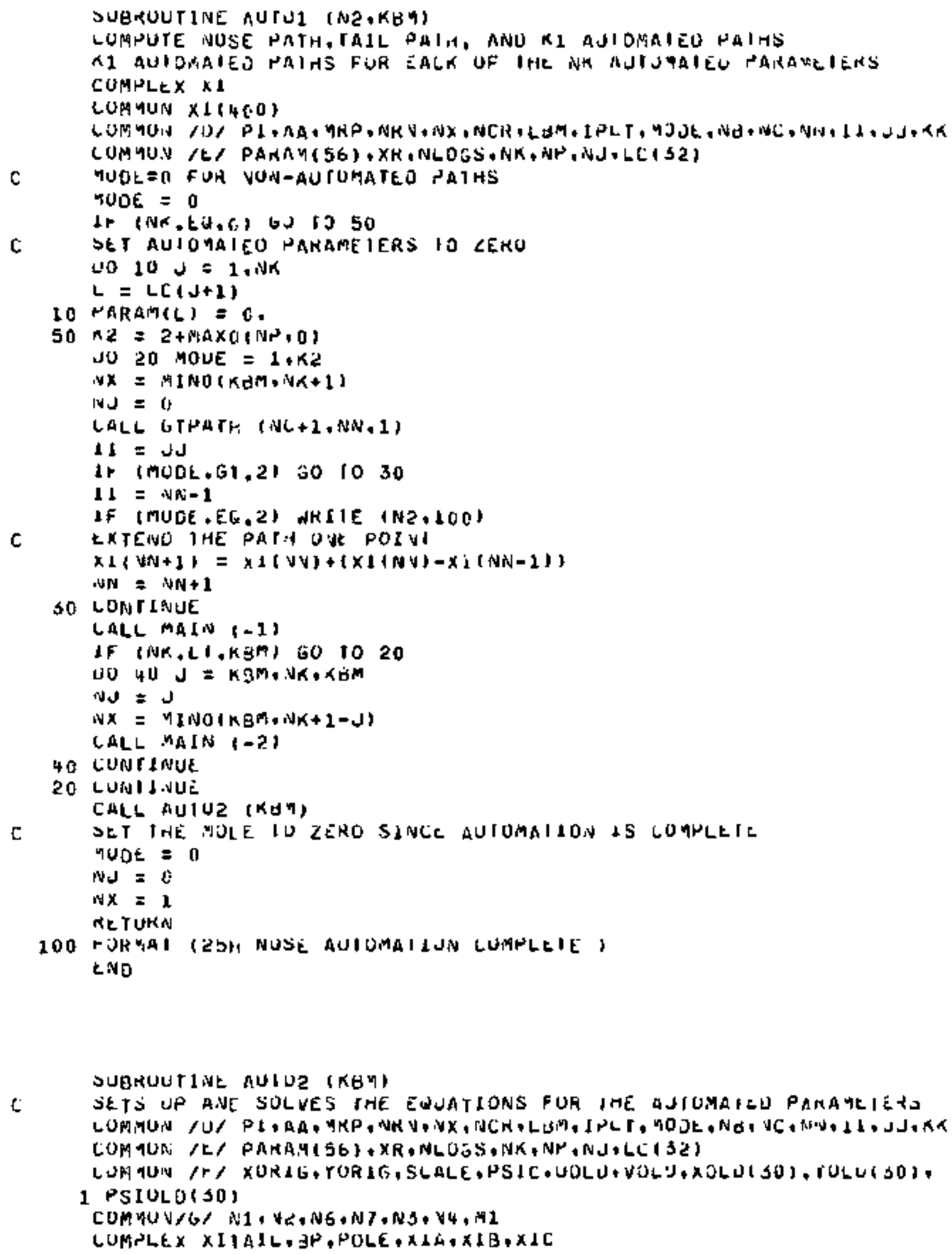




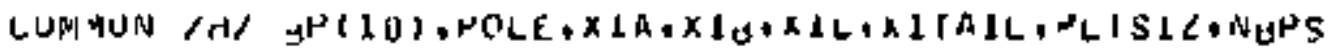

KEAL MACHA, YACHB, YTALL

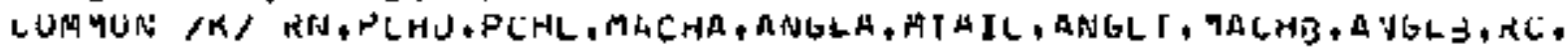

1 A VGLIV,IK

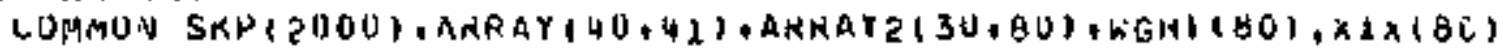

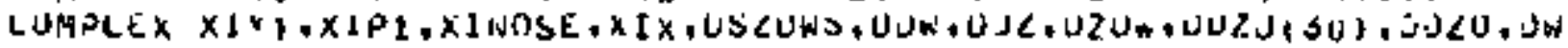

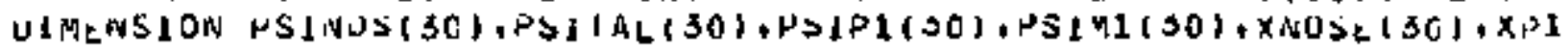

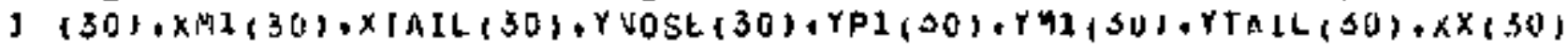

UATA $X U, A V / 0 .+1,1$

NAO $=18 \mathrm{U}, / \mathrm{PL}$

UELTA = AA/FLOATI YHPS

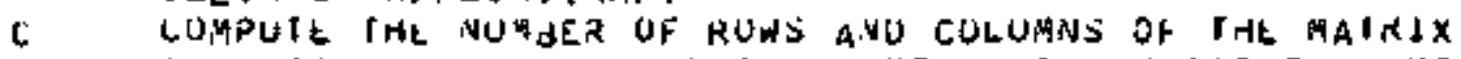

C IHE KIGHE RINJ SIJE UF IHE STSTEM OF EUJAIIJNS IS SIOKEJ IV

L LULUMV NSIZP

WSIL $=N K+M C K+2$

$N S I Z H=N S 1 Z+1$

NSI $\angle N O=N S I \angle H+I$

6

SET WHE LEFY ANU TIGIT HAVO SIUK UF THE AAAIXIX IJ LERU

UJ $10 \mathrm{~J}=1$, NSL 12

UU $10 K=1$, NS $1 \angle P O$

10 ARKAY $\{J, K\}=0$.

aRRAT $(N K+2, N S I \angle P)=1$.

ARRAT $[N A+2, N S 1 \angle H O)=1$.

IF INCR.LE.3) OD TO 1S

AVGL $=2 *$ * ANISL,V+ANGLd\}/RAD+P\{

$X U=\operatorname{COS}(A \cap G L)$

$A V=D I N$ IANGLI

C

15 AKRAY $(N K+7, V S I Z P)=1$.

KEAU IN IHE UAIA FUR MOSE MUIUMAIIUN

KEWIWU WI

VKP $=N K+1$

JU $20 \mathrm{JJ}=1, N K P+\angle B M$

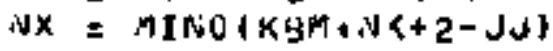

WJ $=J J+N X-1$

(KA) $1 N 1+200) \times 1.42$

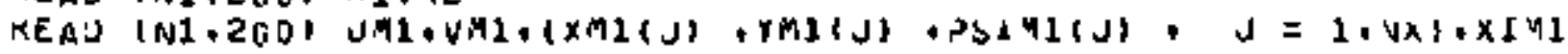

KEAJ (NI, 2OC) U,V, XXNOSE(J), YNOSE(J),POINUS(J), J = JU,VJ),XLUSE

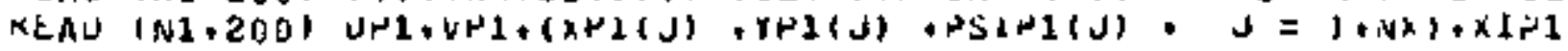

UU $24 \quad k=1,4 x$

$J=J J+K-1$

AKRAT $(N K+2, J)=1$.

C LUMPUIE XU ANU XV

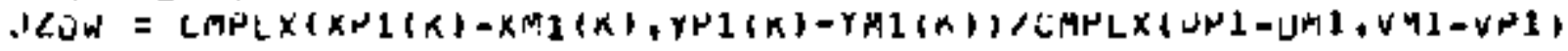

$A R B A V(N K+6, J)=X V * R E A L(U(O W)-X U * A \perp M A J(O Z U N)$

ARRAV (NK+7.JI = XJAREAL (UCDW) +XV*AIMAG (DLJA)

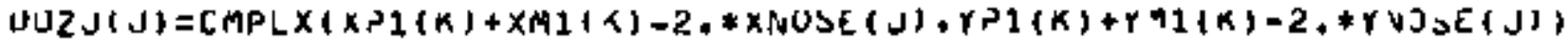

20 CUNI INUE.

$U W=C M P L X(U P 1-J A L 1 \cdot V+1-V P L)$

$U_{W}=C M P L X(U N 1+J, W 1, V P I+V M 1)$

C KEAD IN ODAIA FUN IAIL AJILIAAION

NO $30 \mathrm{JU}=1+\mathrm{N} \times \mathrm{P}+\langle 84$

$W X=M I N U\{M B M+. N\langle+2-J J\}$

WJ $=J J+N X-1$

HEAJ $(N 1,2,1, \times 1,42$

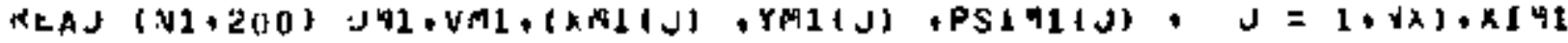




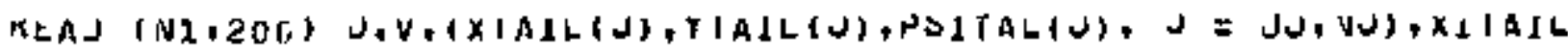

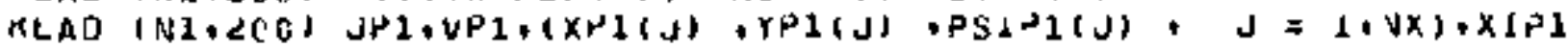
DU $30 K=1, N X$

$J=J J+K-1$

AKRAT (NK+S,J) $=$ PSITALIJ)-PSINOS(J)

ANRAY $(N K+4, J)=(X P 1 \mid K)=x$ I $1(X)) / U E L) A$

ARAAY (NK+S,J) $=(Y P I(K)-Y \eta I(K)) / U E L I A$

$\operatorname{Ar}(R A Y+N K+B, J)=(X+1\{K)+X+2(K)-2 * * X I A[L(J)) /(D E L \mid A * U F L T A)$

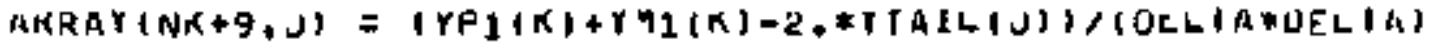

30 LONIINUE

WPT $=0$

1. (INH.LL.OO) 60 TJ 95

c

KEAU IN LEAST SUUAHE RESULIS

$4 J 5 \mathrm{~J} J P=1, \mathrm{VP}$

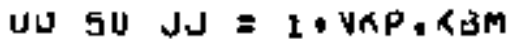

$N X=M I N O(K B M+V A+2-J J)$

KEAD \&N1 $2001 \times 1,<2$

uU $=0 K=1, K<$

KEAJ $(N 1+20(1)(x \times(J), J=1+N X), W G H T(K)+X I X(K)$

Uo $50 \mathrm{JX}=1, \mathrm{~N} X$

$J=J J+J x-1$

ARRATद्व $(J, K)=A X(J X)-P S I N O S(J)$

SO LUN IINUE

t

WURYALIZL ANU WEIGHT RONS

$1055 \mathrm{~L}=1, \mathrm{K2}$

$S U M=0$.

JU $60 \mathrm{~J}=1$, NKF

GO SUM = SUM + AKHAY $2(J, L) * A K R A Y 2(J, L)$

WOHI(L) = KGHI ILISSUM

65 LUNA I I I LE:

JU ju $K=1$. NKP

vo BU $J=K, N K r$

J) $70 \mathrm{~L}=3, n_{2}$

AHRAT $(J+K)=$ AKRAY J,KI+WSHILLIFAKKAYZIJ,LJ*ARKAT2IX,L)

BO LUNTL UUUE

ANTS = NHI $5+<2$

55 LUN 11 NUC

UU $70 \mathrm{~K}=1 . \mathrm{NRF}$

FRCT $=4$.*XR/FLJATIMKPI

UU $70 \mathrm{~J}=\mathrm{K}, \mathrm{NAR}$

ARRAJ $(J, K)=F$ ACI *HRKATIJ,K)

TI LUNIINUE

95 WrIIE (N2, 2501 NPIS

山U $96 \mathrm{~J}=1, \mathrm{NS} \perp L$

Ju $16 \mathrm{~K}=\mathrm{N}, \mathrm{N} D 1 \mathrm{~L}$

Y6 MRRAY $[J, K\}=$ MKKAY $\{K, J\}$

UU $40 \mathrm{~J}=1$, NK

UNE $=1$.

40 AKRAY $J J+1+J+1)=$ AKRAY $(J+1, U+1)$ + OME

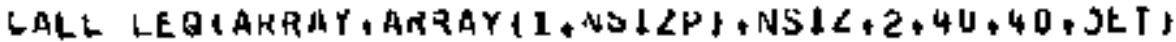

WRIIE (N2, 240$)$ UEI

$X I L=0$.

$\mathrm{r} I \mathrm{~L}=0$.

DU $+=(1,10,1)$

C IHE SUFF IX O KEPKESENTS I HE VALUES FOR ABSUZUW=O, 


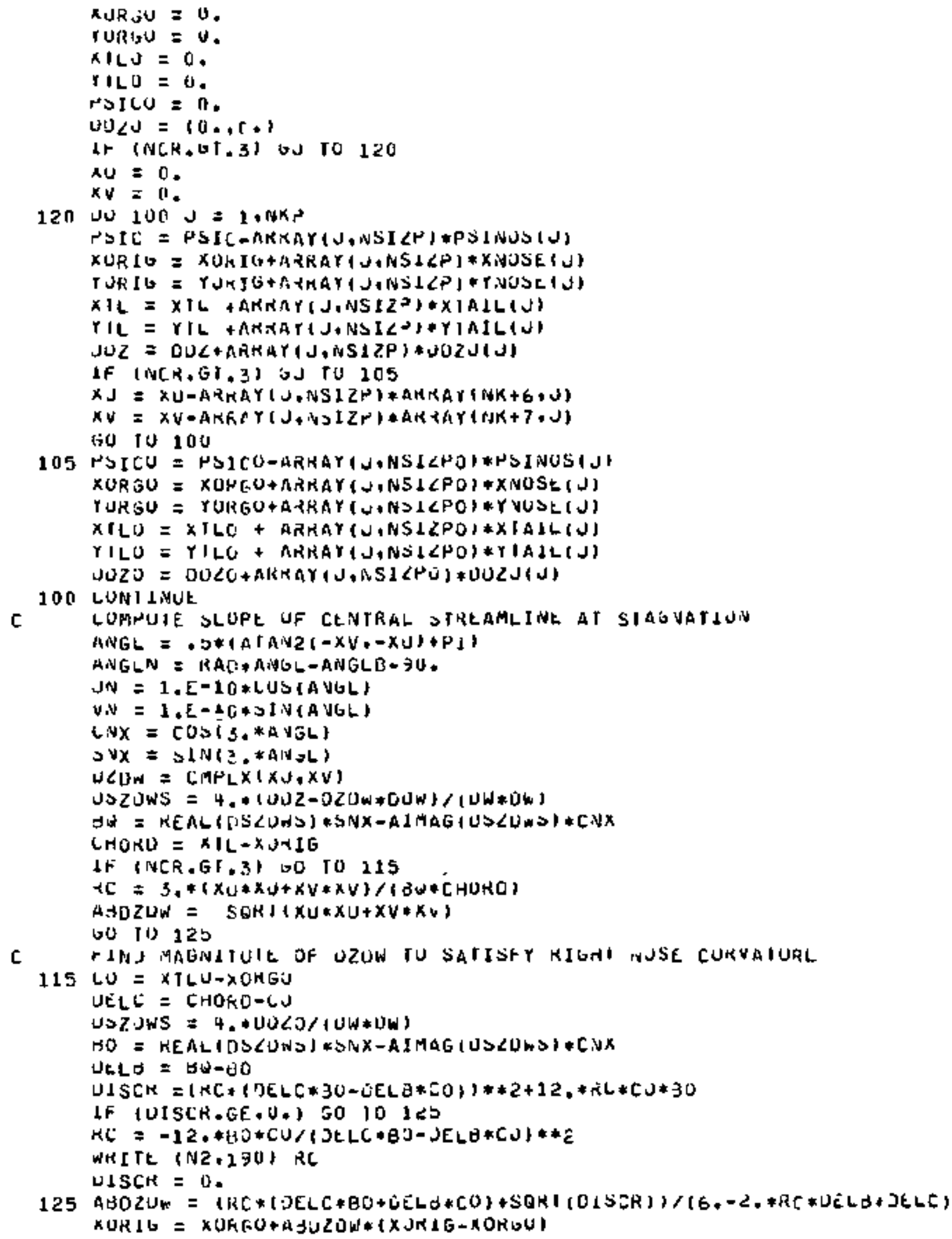


TUR IG = TORGO+AAUZUW* (YUNLG-TOHGO)

$Y I L=Y T L O+A B U \angle O W *(Y Y L-Y 1 L O)$

PSIC = PSLLU4ADULDW*\{PSIL-PSICO)

CHOTU $=C O+A B U \angle U W * O E L C$

SCALE $=1 . /$ [HONO

RSIL = PSIC/CHURO

TIL = TIL-YOKL TI/LHUKD

C

SIORE THE VALUES OF THE AUTOMAIEO PARAMEIETS

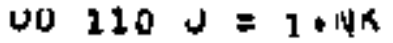

$L=L[(J+1)$

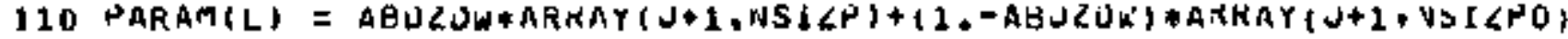

TEWINU NI

WTITL (N2, 2CD) (PAKAYIL), L $=1,56$ )

HIITL (VI, 200$) \mathrm{W}, \mathrm{V}$, TTL

WHITL (V1, 20U) JN, VN, XIVUSE

KET JKN

190 RURMAI (50HO**IHIS VALUE JF HC CAMMOT OE ACHIEVLJ*\# USIVG YCEFG,3)

200 PUR YAI 140201

240 FOR IAT (24H OEIERYINANT $=$,E12. T)

2SO TURMAT TIIH THEKE AKE, $14,30 H$ POINTS USEJ FOR LCAST SWUANES I LNO

SUBRUUTINE MAINAITYP)

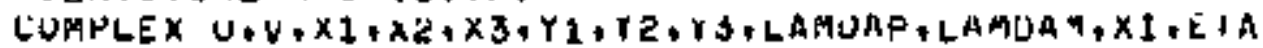

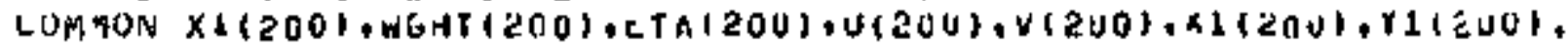

] $\times 2(200), Y 2(200), x 3\{10,200), Y 3(10,200)+L A Y J A P(200), L A Y U A N(200)$

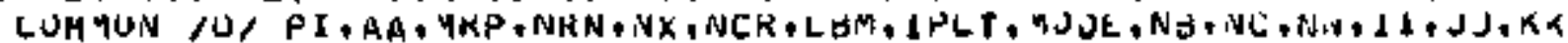

LUM HUN $/ G / N 1, N 2, N G, N 7, N 3, N 4, M 2$

LOM MUN $/ L, X A K L A L, X A I M G, Y A R E A L, Y A \perp M G$

CUM YUN IF, XURIG, YURIG, SCALE, HSIC, UOLO, VULJ,XJLUI3O , YULUISOH.

1 PSIULOQSOS)

LUMPLEX UNN, VNN, XINN, YINN, TEMH

LUGICML ISW

JATA ISW I,FALSE,A

IF (1SW) 60 IO 10

ISW $=$. IKUE.

$U A=$ REALIU(1):

$V A=$ NEAL (VI)

LALL SAVE $11,1,1$ )

$c$

NEAL IN IHE WEXI PATH

I0 IF IIIYP, GE, OI CALL GTPAIHINL+1,NNI1)

IF (MOOE,EG,9Y) RETUR,

C

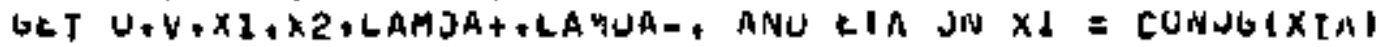

$U(1)=U A$

$V(1)=V A$

$X 1(1)=X A R E A L$

$11(1)=$ TAREAL

CALL GETXYO $(2$, NN $)$

it 11[YH.GE.01 $11=\mathrm{JJ}$

Ju $40 \mathrm{~L} X=\mathrm{J}, \mathrm{A} X$

$c$

40 rSIOLU $(L X)=$ PSIC

LHECK FOK SUPLRSOVIG PATH 


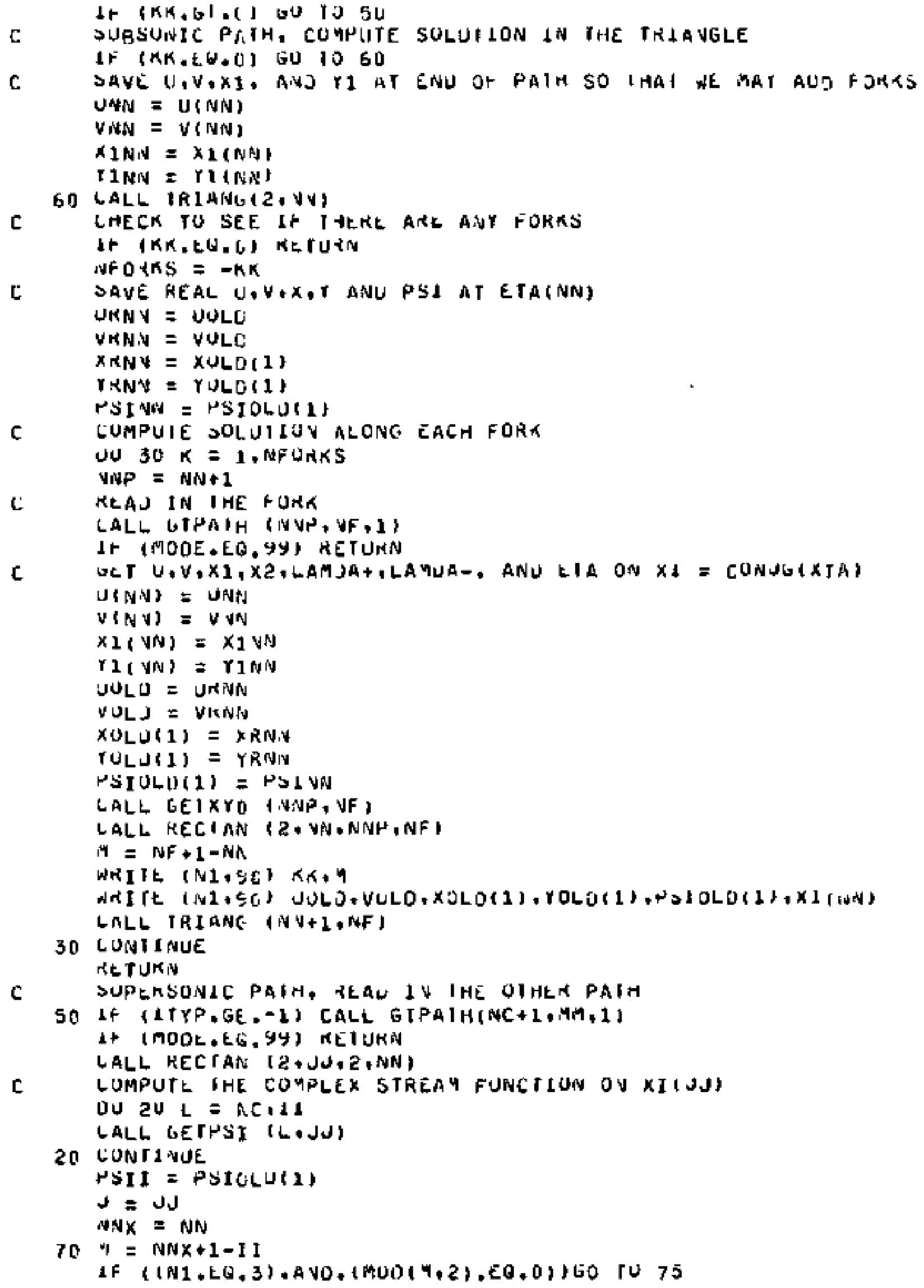


WITt $(N 1.50) \mathrm{BA}, \mathrm{Y}$

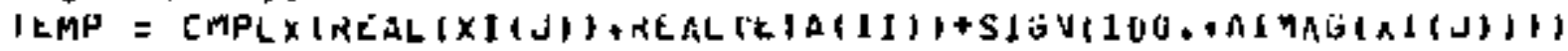

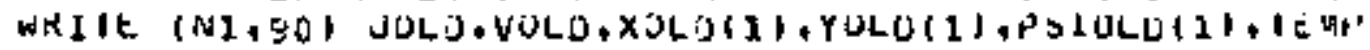

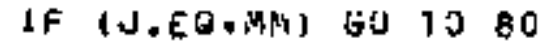

LALL SAVE $(11+2+N N X+J)$

75 WN $=N N-1$

$J=J+2$

CALL RECIAN $(J \cdot J, 2, N(N)$

HSIJUULI) = NSII

LALL GEIPSI 11 I)

HSII = PSICLUA1)

is 1070

BO LUNILNUE

BO FURTA1 (405(:)

KETUNN

t vo

SUBRUTINE TKLAVG $(K 1+K 2)$

C

LUMPUTE IHE SOLUTION IN IHE IRIANGGE XI XIMKI), XI EIA,

C EIATK1) EIA ETATM2)

LUM YUN /A, SKHI2S,KOOT

LUMPLEX U, V,X $1, \times 2, \times 3, Y 1,12, Y 3, L A M U A F, L A Y U A 9, X I, E H A$

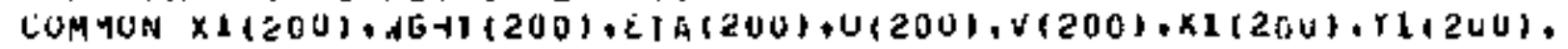

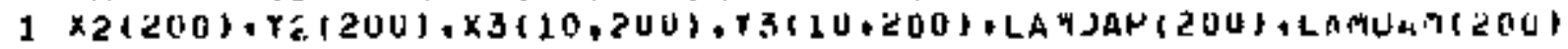

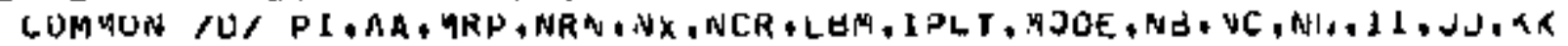

LUMPLEX HENP, NOJ

UU $30 \mathrm{~J}=K \mathrm{~K} \cdot \mathrm{K} 2$

C

SET IHE DRANEH FOR THE SWUARE ROOI IN LARJA+ ANU LAMTHE.

KDO $=(0,1,1,1$

C

GET VALULS Gr J,V,X1, X2,LAMDA+,LAMUA= AT $X 1(J), E I A(J=1)$ OY

c

KEFLECTIUN OF THESE GUAVTITIES AT XI JUIILEA(J)

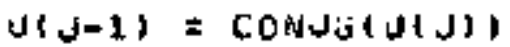

$V(J-1)=$ CONJG $(V(J))$

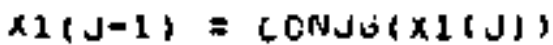

$Y 1(J-1)=$ CONJGIY1(J))

ILMP = [UISJGILAMUAPTJ),

L. AMUAP $(J-1)=C U$ J $J$ G $(L A M U A T(J))$

LAMJAM $(J-1)=$ IEPP

C

LHECM IO SEE IF WE AKE HAST XITINU

IF (J,LE. NH) GO TO $1 U$

C

GLT $\times 2$ ANU $Y 2$ SY REFLECTLUN

$x Z(J-1)=$ CONJO(X) $x(J))$

$(2(J-1)=\operatorname{coNJG}(r 21 \mathrm{~J})$

C

L'HECK TO SEE IF WE AKE PASI XIINC)

c

10 IF (J.LE,NC) GU TJ 20

GLT XJ ANU Y S SY TEFLEETIJN

UU $15 L X=1$. VX

$X . S\{L X, J-1)=$ CUNJS(X) $(L X, J))$

Y $3(L X, J=1)=\operatorname{LUNJG}(Y 3(L X, J))$

15 LUNI I nitue

C

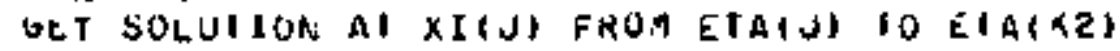

2n (ALL IIIULU,J*J,K2) 


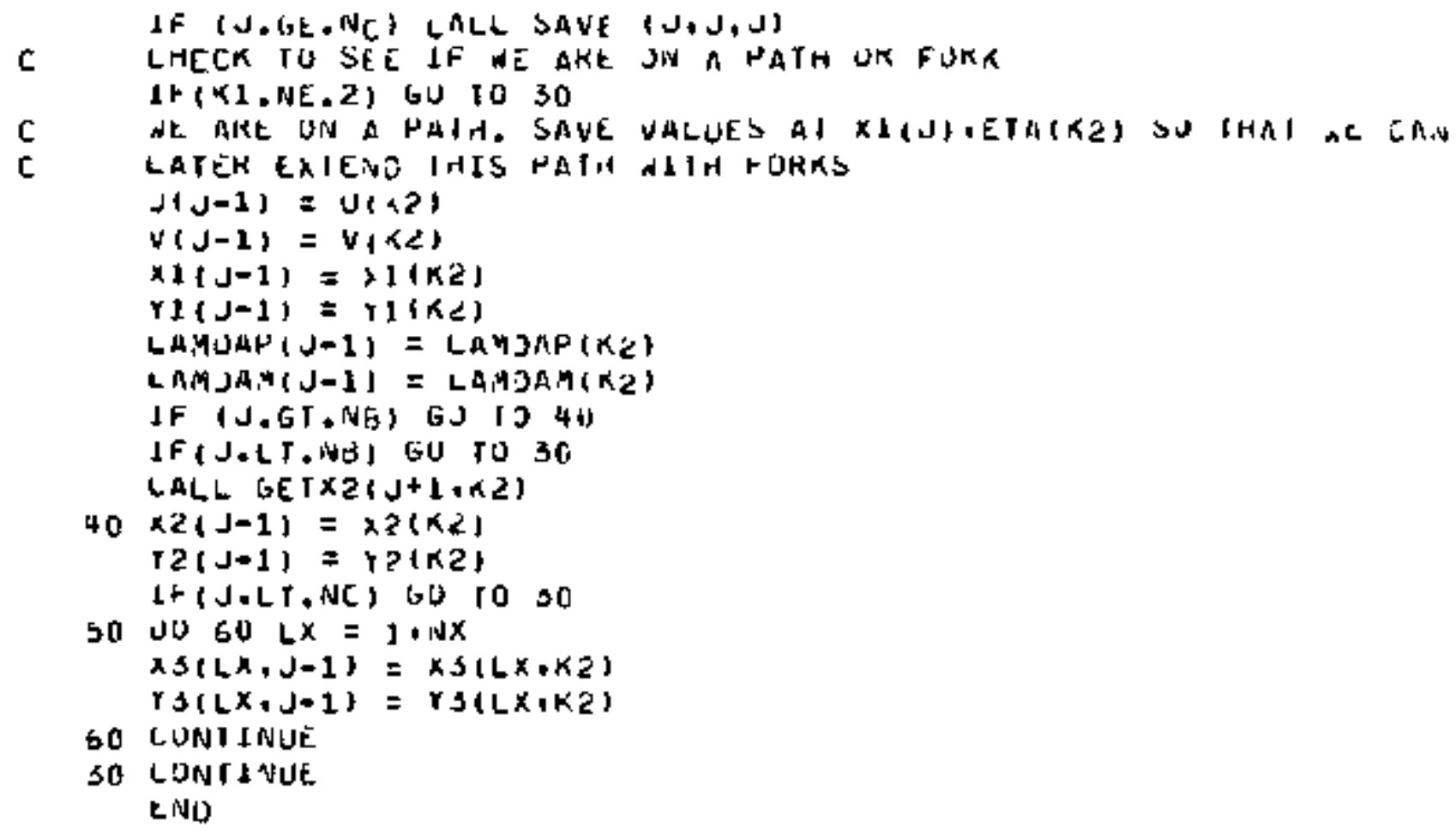

SUB \{UUTINE RELIAN (KI,Kล̂, A3,K4)

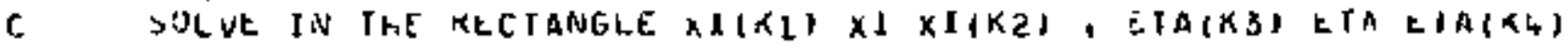
LUMWUAN $/$ A SRIP(Z), KOUI

LUMALE $U, V+X 1, X 2+X 3, Y 1, Y 2, Y S, L A N U A P, L A Y U A \eta, X I, C$, A

LOM पUA $X 1(200)$, WG

$1 \times 2(200)+Y 21200), \times 3(10,200), Y 3(10,200)+L A Y J A F(200), L A M U A Y(20 U)$

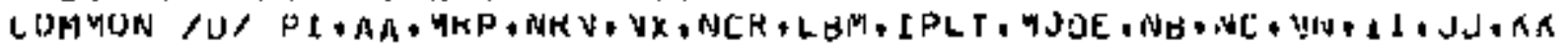

LUMPLEX KOUI? + KOOI

IJ $20 \mathrm{~J}=K_{1}, K_{L}$

$\mathrm{C}$

GLT IHE VALUE UF THE SOLUIION AI XI(J),EIATK3)

1. (KK.LL.CI bU TJ 20

C

A SUPERSUNIC HAIH GEI U,U.X1+X2,LAMOA+ILAMJA- ONEIA $=\lambda 1 A$

LALL GE IXY1 IJ)

ou ru 30

$20 U(K 3-1)=U(J-1)$

$v(k 3-1)=v(U-1)$

$x 1(K S-1)=x 1(J-1)$

$r 1(K S-1)=Y(1)-1)$

LAMJAP $\{K B-1\}=$ LAMUAP $(J-1)$

LAMOAM $K K 3-1)=$ LAMOAM $(\mathrm{J}-1)$

$x z(x s-1)=x 2(J-1)$

$x(15-1)=Y 2(N-1)$

wo $25 L X=1$, VX

$x J(L x, K 3-1)=x_{3}(L x, J-1)$

$Y S(L X, K 3-1\}=Y S\{L X, J=1\}$

25 CUNIINUE

C

KLEH IRACA OF THE BRANCH JF THE SUUARE RUJT FOR LAPUA++LAYJA-

3 hOOTL = KOOI 
LALL LINGA [., AS, R4]

IF (J.EQ.NB) CHLL GE1X2(MAXO(NB+1,M3),N4!

KUOI = ROOJ

SUPEKSONLC PAJA, COMHUTE PSI UW ETA = LDNJGXXIA)

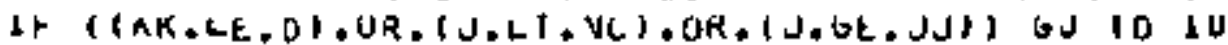

IF IJ,GI.NC, GO 1040

(ALL GEIHSI I-VC,J)

bU IO 10

40 LALL GETHSIANC, J)

10 LONTINUE

RETUKH

CND

SUGRUUTINE LINEJIJI,KI,KL\}

SOLVE IHE EGUAIIONS ALOVG THE [MARACIEKISTIC XIIJ) FRUA EIA(NI)

IO EIA(N)

COMMUN $C$, XAREAL, XAIMG, TAREAL, YALMG, XOIHS, TBIMG, IPIR

LUMPLEX U, V,XI,X2,X3,Y1,Y2,YS,LAMUAP, LAMOAY,XI, LJA

COMNUN $x+12(, 0), W G+1(200), E T A 1200), U(20 U), V(200), x 1(20 U), Y 11200)$.

$1 \times 2(200), Y E(200), X 3110,200), Y 3(10,200), L A+J A F^{2}(2 U U)+L A M U A M T<0 U 1$

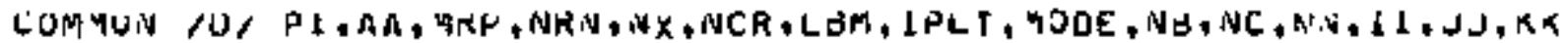

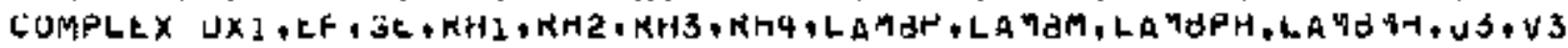

1 I, IIH,EIAH,XSNET3U, JLAMI,OY,EIGE

UATA $1 / 10.11 .1 \%$

$\checkmark=J_{1}$

LF I IJ.NE.NCI,OR, (K1.GT,NCH GO TO 5

Ju $2 L X=1, i X$

(ALE INITFN(ETAINC), X, SNC (LX),LX)

$Y S(L X,\{N C)=10.00 .1$

$X S(L X, N C)=X S N C \mid L X\}$

IF $(K K, G T,(i)$ GU to 2

$A S(L X, N C)=$ REALIXJNC $(L X))$

2 LUNTINUE

$5 u \times I=x(1)+x(d)=1\}$

$x \perp H=.5 *\{x I(J)+X I(J-1)\}$

UQ $B O L=K J, K 2$

C

SULVE FON U ANU $\checkmark$ TO FIASI ORUER ACCUBACY

$N H_{1}=V(L)-L A . M U A P(L) * U(L)$

$A H Z=V(L-J)-L A M O A M(L-1) * U(L-1)$

$U_{3}=\{K H 1+R H 2\} /$ LAMOAM $\left.(L-1\}-L A M O A H(L)\right\}$

VS $=R H 1+L A M U A N\{L I * U 3$

C

LUMPUIE LAMDA+ ILAMUA- TO FIASI

CALL AMEUACUS,VS,LAMBP, LA YGMJ

C LUMPUIE MIUPULNI VALUES JF LAMBUA+ ANU LAMBJA-

LAM $3 H H=.5 *\{L A M B P+L A M U A H(L)\}$

LAM $3 M H=.5 *(L A H U V+L A M L A M(L-1)\}$

C SULVE FUR U ANU $V$ TO SECUVU URUER ACCJKALY

$T H_{1}=V(L I-L A M \triangle P H * U(L)$

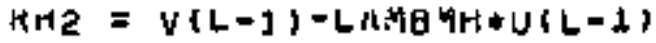

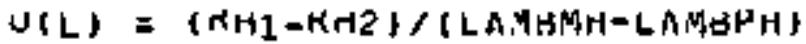

$V(L)=R H I+L A: A$ SPH $* U(L)$

IINJ LAMDOA+ ANU LAMUUA- AT XI(J)+EIA(L) 
GALL LAMLUA (UCL), VIL), LAMGP, LA.YBM)

LUMPUIE MIDPULVT VALUES UF LAMUAH AN) LAMBJA-

LAM $\triangle P H=-2+(L A Y B, D+L A M U A P(L-t))$

LAMAMH $=\$ 2+(L A Y B Y+L A M C A M I L)$

C SlOKE THE IQEW VALJES DF LAYJUA+ ANU LAMBUA-

LAMUAPIL) = LAMAP

LAMJAMILI = LAMBM

C CUMPUIE XI ANU YI AT XIUI,ETAIL)

$K-1=X 1(L)+K A+d M A * Y_{1}(L)$

NH2 $=X I(L-1)+L A, M B P H+Y 1(L-1)$

$11(L)=(K H 1-H-12) /(L A M H A H=L A M B P H)$

$\left.X_{1}(L)=K H\right]-L A M \rightrightarrows M-Y 1$ (L)

$C$ LHECK TO SEF IF WE HAVE KEACHEO $X \backslash b$

LF(AJLE.NG) OOR. (L.LT.NB), GO TO YO

C. LUMPUIE $\times 2$ ANU $r_{2}$ AT $X I(J), E T A(L)$

$H+3=x 2(L)+L A M A M-Y * C(L)$

IF (L.GT.NG) GU TO 20

$c$

CJMPUIE $\times 2, Y 2$ UN EIA $=X 10, X 1=x(5)$

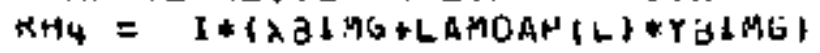

$T(L)=\mid R H 3-K H+H /$ LAME.MH-LAMOAPILJ)

$x \in(L)=K H 3-L A M S H+Y Z(L)$

bo 1090

$20 \mathrm{KH} 4=X 2(L-1)+L A M 3 P H+Y 2(L-1)$

TZ\{L = (RHS-KH

$\times 2 \mid L=K H 3-L A Y d Y-1 * Y 2$ (L)

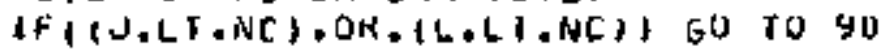

C LOMPUTE $1 \mathrm{HE}$ LNHOMJGENLOUS TEKM

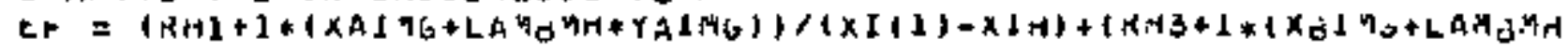

$1 * Y j \perp(M G) 1 /(x \perp(V a)-x I H)$

IF (L, EU, NC) GU TJ 40

LE $=10.0,1$

C CHECK FUR SUHSUVIC PATH

IF $\{K M+G I .0\} 60$ IJ 10

C RATH IS SUBSONIE, GEJ STMMETKIC EF ANU GE

Lt $=.5 * t F$

LIAH $=.5 *(E \mid A(L)+E T A(L-1)$

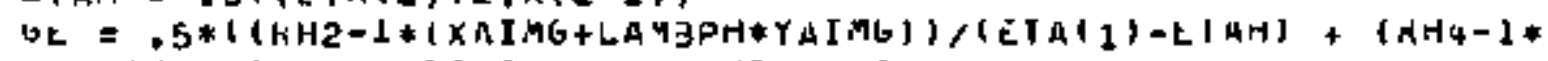

$\left.1\left(X 31, B G+L A v_{1} B P H * Y B I N C\right) /(E|A(N B)-t| A H)\right)$

C

$101+1, N E$. NEJ GJ TS 30

C GET X3,YS CN INIIIAL CHANACIEKISIIC XI = XIC

LIGE = IETACL)-ETA(L-1) I*GE

UU $50 L X=1$, NX

LALL INITFN(LTA(L), XSILX,L),LX)

IF $(K X, L E, O) X S(L K, L)=+3 *(X 3(L X, L)+C U V J=(X \operatorname{SN} C(L X)))$

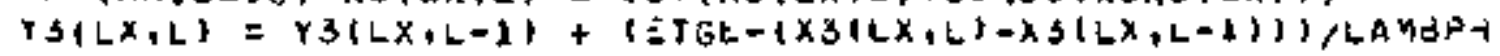

50 LUNI LNUE

$\rightarrow 0$ TU 90

40 Ir\{(KK,LL.O).JK, (J.EW.NC) $\}$ GO TO 90

$U Y=$ COX $\$$ *EFH/LAMBNH

U. $S D L X=1$, IV

YSILX,L) $=Y 3(L X, L)+$ Or

60 LONTINUE.

OU 1090

C

LUMPUIE $x_{3}$ ANU Y3 AT XIV),ETARL

$30 . \psi r=U \times I * E F$ 
LIGE $=$ ILTAIL)-ETA(L-1) *GE

ULAYL $=1 . /$ (LAMBYH-LAMBPH)

UU $70 L X=1$, WX

$\left.\left\langle H_{1}=X S(L X, L)+L A Y B H H * Y 3\right| L X, L\right)+0 Y$

$K H_{2}=X 3\{t X, L-1\}+L A N A P H E Y 3\{L X, L-1)+E l G E$

$Y S(L X+L)=(K+1)-R+2) * O L A M 1$

$X S(L X, L)=R H 1-L A Y B M H+Y 3\{L X+L)$

70 LUNTINUE

$\triangle C$ CUN 11 NUK

BO CONIINUE

NETUKH

LNO

DUBRUITINE SAVL $\{11, \times 2, \times 3\}$

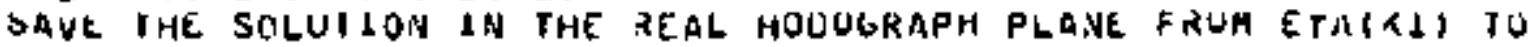

CIAIK2) ALCVG XI (KS) UN IAPE

COM TUN $/ L /$ XAKEAL, XAIMG, TAKEAL, YAIMG, KUIMS, YHIMG, IPIR

CUMPLEX U,V,XI+X2,X3,Y1+YZ,YJ,LAMOAP, LA YUA $4, X I, E I A$

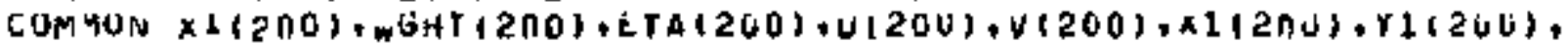

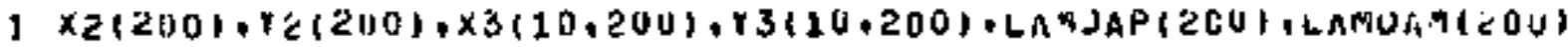

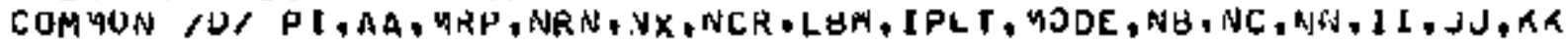

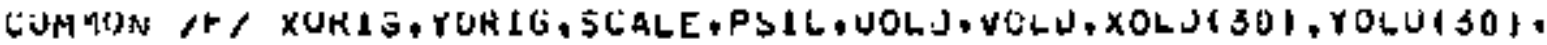

1 PSIOLOL3OR

LUM4ON/G/ N1+N2, NG,N7+N3, V4, 1

CUMPLEX XITALL+ BP,POLE+ $A L A+X I B, X I C$

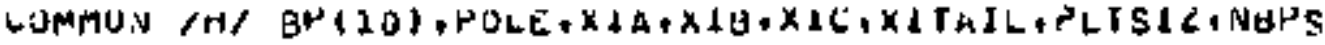

KLAL LUG $1+L O G L$

LUMPLEX TE,

LUGJCAL ISW

UATA ISW/ F ALSE, , TOL /1,E-G/

It (LSW) 60102

$\downarrow S W=$ IKUE.

US = REAL(UINU) ,

$V$ i] $=$ KEAL ( VINA)

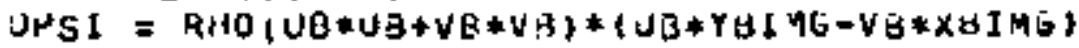

RCTUKA

2. IF (LABSIXI(K3)-XITMLL).LI, IUL) GO IU 4

$I E M P=\operatorname{CLOE}(1 X \perp(K 3)+X I T A L L) /(X I(K S)-X I A))$

ALPF = ALVAG (T七HP)

4 LUNI LNUË

ICMP $=$ CLUG $(\{\times 1(\times 3)-X 1 B) /(\times 1)(K 3)-X 1 A)$.

LUL1 = REAL (IE.MP)

I HE IA $=$ MIMAGITSIMP)

IF (K).EG.AC) IAETAZ = O.

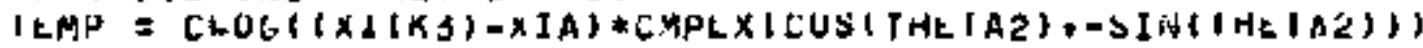

LUG 2 = REAL (TEMP)

I HEIAZ = AIHAG (IEMP) + THEIA2

DU $20 L=K 1+K 2$

UNEN' = RLAL $(U(L)\}$

VVEW = REAL (V(L)

$X X T=5 C A L E *(Y L A L(X 2(L)) * L O G)+(K L A L(X 1(L))+R E A L(X 2(L))) * L Q G L$ $1-X 3 \perp M G * I H E T A-(X A I M G+X \$ 14 G) * T H E I, A 2-X U 2 I G)$ 


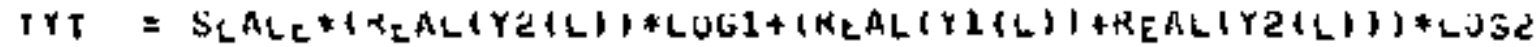

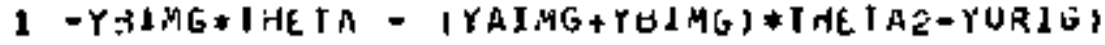

UU $5 U L X=1, N X$

$X N E N=X X T+S C A L E * R L A L(X S(L X, L))$

YVEN = YYT+SCALE*ZEAL $\{3(L X, L)\}$

If IL.EQ, NC, bU 1020

$U_{i}=-5 *\left(U_{N} \in W+U \supsetneqq L J\right)$

$V+t=.5 *(V+E, w+V D L 3)$

$U X=X$ XNEW-A JLU $(L X)$

UY $=$ TNEWTIOLJILX)

SHOA = AHUIUH*JH+VH*VH)

PSIJLL $(L X)=$ PSIULG $(L X)+H H O H *(U H \# U Y-V H * J X)$

IF (ABS(ALPH-ALP+O),LT,PI) GO IO 25

c

WE HAVE JUST CROSSEO LIVE JOINING EXIT VELJEITY IO TRALLNG EDGE. PHINI $90, \times 1$ (KS)

GR FURMAT (* CHUSSIMS CUI AI *2E15.4)

RAC = TPIR* SLUV(SCALE, ALPHP)

GU IU 5

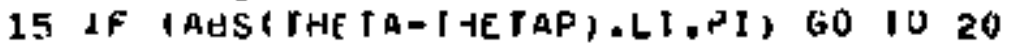

C

dL TAVE UUSI ENOSSED THE TUT, ADUUST PSI

$r A C=S I G N(2 * * I * S C A L E, I H E T A P)$

5 PSIULU $(L X)=P S \& J L O(L X)+F A C *(D H S I-K H U H *(U H * 13\{M G-V-4 * X B T H G))$

$20 \times O L J\{L X)=X N E W$

TOLUALX) = TNEW

50 CONILWUE

UULU = JWE

VULO = VNEK

it (L.LI,II) OU TO 10

IEMP $=\times 1(K 3)$

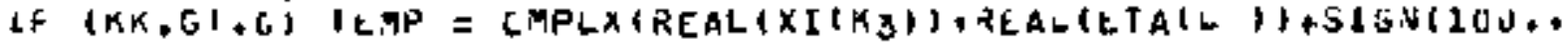

I AIMAG( $x \perp(k 3)))$

$N=N+1=11$

IF (L.E.,II) WEITE (\$1, 4U) KK, M

Lt (14OOE.GT, 21 GO TO 30

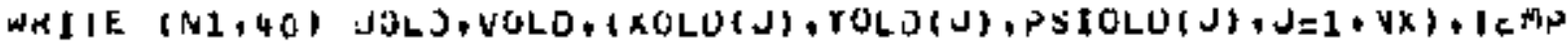
GO TU 10

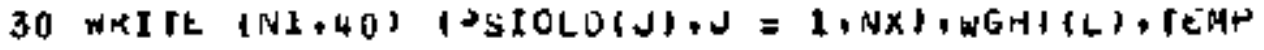

10 LUNF 1 AIUK

ALP-AP = ALPH

I HEIAP $=$ THETA

METUKY

40 PUR MAT (40EO)

LNO

SUGRUUTLNE GEINSLILSLGNIS)

MLAL MACH

LOMMUIN $/ A /$ GAMMA, MACH

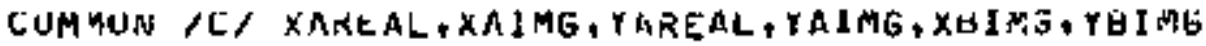

LUMFLEX $U, V, X 1, X 2+X 3, Y 1, Y 2, Y 3, L A M U A P, L M Y U A 4, X 1, E I A$

CUMYUN $\times 1(2) n)$, WGHT (200), ETA(200),U\{200\}, V(200),X1(200), Y1 200$\}$,

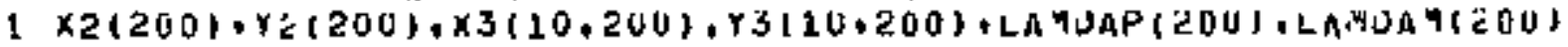

COMYUN /J/ PI + AA, MKP, NRN, NX,NCR +LdM, IPLT, MJOE, Nd, NC , NJiv, I1, wJ, KK 


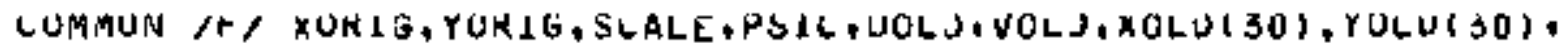

1 PSIULOL\$O)

LUMPLEX XIIAIL, BP, PQLE, XIA,XIB,XIL

COMYUN /H/ BP(1O),POLE, XIA,X1B,X1C,X1TAIL,PLTS1L,NAPS

LUMPLEX CUNEW, CVNEK, CXNEW, CYNEW, UX, OY, UH, VH, CS , C THU, CLUGE, $, \angle, C L O$

1 , CWULO, CVELO, CXOLU, CYOLU,LOG1, LOGL

UATA $1 / 10,1,1$, ISW $/ 0 /$

$c$ COMPUIE IHE COMPLEX LOG JF 2 AND CMOOSE IHE BRANLH WHOSE AKGUMEMI

t. IS CLOSEST TU IH

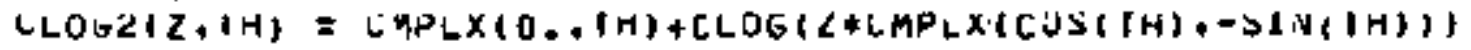

IF I SW, NE. O BO TO 10

$L \gg W=1$

GAM $=\{$ GAMMA-1.\}/2.

COSW $=1,2($ MACH*MACH) + GAY

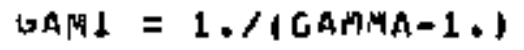

KHOINF $=($ MACH*MACH) *

10 IF ILSIGN.GT.O) GJ TU 15

LOGL $=(0, \ldots$,

LDG $=(1 ., 0.1$

$15 L=$ IABS (LSIGN)

LUNEW = UIL!

LVNEW = VIL)

$L U G 1=C L D C 2\{X 1(J\}-X I(1)+A I H A G(L O G 1))$

LDG2 = CLOG2 $(X \perp(J)-X \perp(N+), A I M A G(L U L 2))$

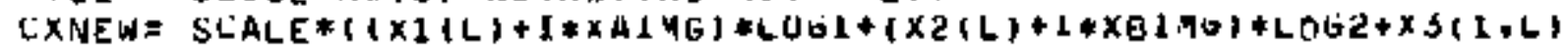

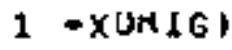

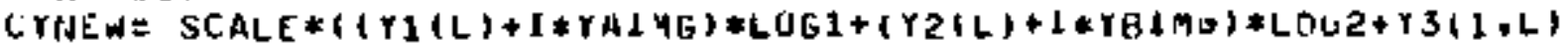

1 - rOK(G)

IF ILSIGN,LT.DI GO 1020

$J H=.5 *(C U O L U+C U N E W)$

$V H=.5 * 1 C V O L J+C V V E W$

$U X=C X N E W-C X U L D$

$U Y=C Y N E A-C T U L U$

$L S=\operatorname{COS} Q-6 A M *(J H * U H+V H * V H)$

LKHO = KHOLNR *LEXP(GAMI*LLOE (CS) )

PSIJLO(2) = FSLOLD(1)+CKMJ*IUHWLY-VH*OX)

20 CUOLU = CUNEW

LVULL = LUNEW

LXOLU = LXNEW

LYOLD $=$ LYNEW

If (tU,LI+JJI,UR, LL,LT, IL) REIUKN

$U U L D=$ KEAL (CUULD)

VULU = REAL (LUOLO)

XOLJII) = REALICXOLD)

TULUI1: = REALICYJLOI

nETUN

L VÜ

FUNCIION RHOLOS

C CUMPUIE JEASIIT HHO AS A FUALTIUN OF THE SIJARE JF THE SPEEO, US KLAL MACH

LUMYUN /A/ GAMMA, HACH 
LOGLLAL I\$W

JATA ISW /,FALSE,

IF ILSW LO TU 10

$I S W=$ IRUE.

GAH $=$ (GAMYA-1.) $/ 2$.

CUSO $=1 . /$ (MACH*MACH) + GA

GAH I $=1 . /$ (GAMMA-1.)

RHUIWF $=$ (HACH*MACH) **GAML

10 LS $=$ COS $O-$ LAM $* U S$

$K H O=K H O I N F * C S *$ SAMI

REt TUKN

LNU

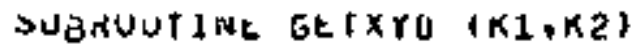

GET U.V,XI ANU TI ON $X_{1}=X 1 A$ FRUN EIAIKI) IJ ETA(K2)

LUMPLEX U,V,X1,X2,X3,Y1,Y2,Y3,LAMUAP, LAMUA,$\times 1$, LI A

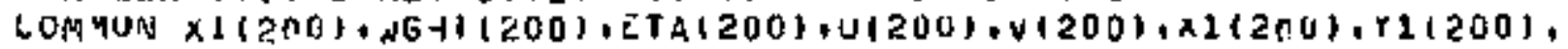

$3 \times 21200), Y 2(200), \times 3(10,200), Y 3(10,200)+L A 4 U A B(20 U), L A M U A Y 1<0 U)$

LOMYUN $/ L, X A K L A L, X A I M G$, TAREAL, YAIMG

LUAPLEX $1, S, 1, L A B 3 P H, N H 1$, KHE, SOFXI

UATA I $110.1,1,1$,

C

LOMPUIE $\triangle$ AT $X I=X I A$

$s=\operatorname{SUF} X+(X 1)(1))$

LALL LAMBOA U (KA-1, , V(K1-1), LAMOAN $(K 1-1), L A M O A M(K 1-1)]$

C LOPPUIE I (E.TATLJ)

$1=\operatorname{conj}(\operatorname{sor} \times 1(x[(L)))$

$E I A(L)=C D N J G(X I) L)$

$J(L)=U\{L-I\}$

$V(L)=V(L-1)$

ENLL GETJVIS, $1+J(L,, V(L)$

CALL LAMUUA(U(L), V(L) ILAMUAP(L) LAMOAY(L))

c

IINW $X I$ AND YI ALONG $X I=X I A$ AT ETALL

$C$ LUMPUIE LAMDA- AT MIUPOLIII

LAMSHFI = E* (LAMOAN $(L)+L A M O A P(L-1)$

$\left.K H_{1}=X\right]\{L-1\}+L A M 3 P H * Y\{(L-1)$

KM2 $=-I *(X A I M G+L A M D A N(L) * Y A 1$ MG)

$\left.Y_{1}(L)=\{K H\}=K A 2\right) /\{L A M B P H-L A M U A Y(L)$

$X_{1}(L)=K H_{1}-L A M B R H * Y_{1}(L)$

100 LUNTINUE

RETUKN

ENO

SUERUUTIAE GE IXYI IKI)

C

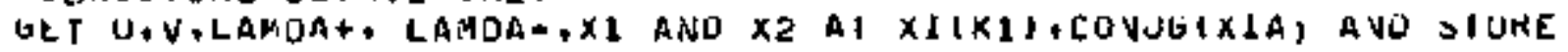

IHE HESULTS IV THE FIRST ELEATIN OF THE RESPECIIVE ARRATS

IHE + IRSI ELE AENT OF THE RESPECTIVE ARKAYS WILL LJNIAIN I HEIK

VALUES AI $X I(K I=1\}$ +CONJG(XIA)

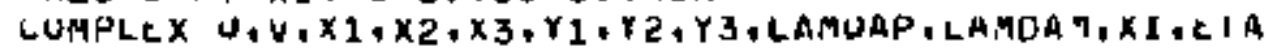




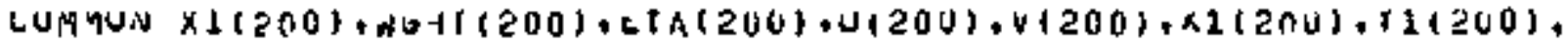

$1 \times 2(<10)+Y 2(200)+X S(10,200), Y 3110,200)+L A Y U A P\{20 U), L A M O A 4(\angle C U)$

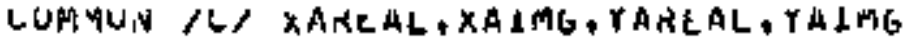

LOMPLEX I, S, 1, NAI + KHE , LAMBM, LAMBMH, SUFXI

DATA $1 / 10,1,1 /$

C

LUMPUIE O ANU $x 1(41)^{\circ}$

$s=$ SUF $\times I(\times I(\times 1))$

$C$ LUMPUIE $T A T E f A=$ CONJG(AIA)

$1=$ CONJGISOFXI(XI(1) I)

LALL GETUV(S+1,U11), V121)

LALL LAMHUA (U $(1), V(1)$.LAMJAP $(1)$. LAMBY)

C

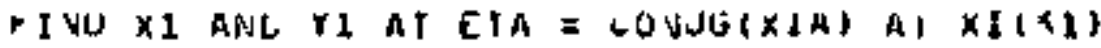

C CUMPUIE LAPDA+ AT MIOPOLNI

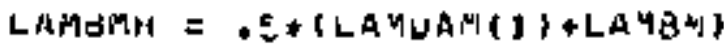

$\mathrm{HH}_{1}=\mathrm{X}_{1}(1)+L A M B H A Y_{1}(1)$

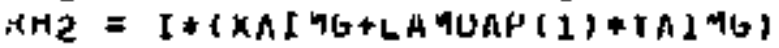

$1\left\{(1)=\left(K H 1-R H_{2}\right) /(L A M B Y H-L A M O A N(1)\}\right.$

X111 = HHJ * LAH3HH*Y1(1)

C SIOUE HEN LAMUAT

LAMUAM(1) = LAMDM

KE TUK,V

cWO

SUARUUTENE Gt, T $\times 2(K 1, K 2)$

C

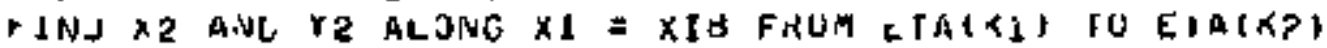

LUMPLEX U+V,X1,X2,X3,Y1,YL,Y3,LAMUAP,LA4UAV,XI,EIA

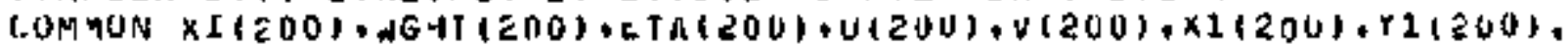

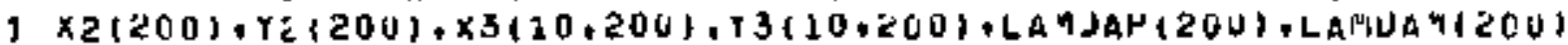

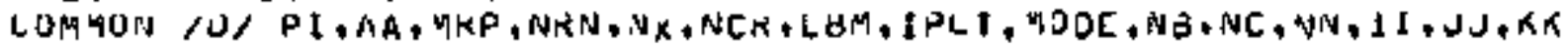

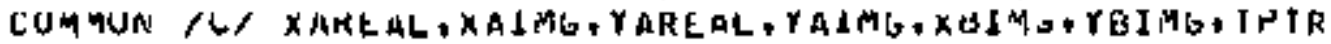

LOMPLEX KHJ +KH2,LAHEFH, I

UATA I $/ 10.11 .1 /$

C CHEEK TU SEE IF WE ARt AI $x$ IU

it $\{K 1, G), 1 \mathrm{VB}+1\})$ GO TO

C FINJ X2 ANL, Y2 AI ETA = CUNJGIXIZI

TH1 $=1, / L A M U A M(N 3)$

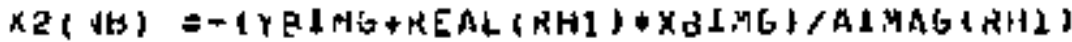

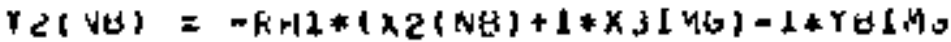

5 LONIINUE

ND $10 L=K J, K L$

C LUMPUIE LAVOA- AT MIUPULNI

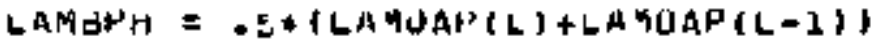

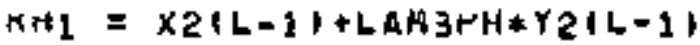

t+2 $=-I *\{X B I M G+L A M U A Y\{L\} *$ TAIMG

$r 2(L)=(K+I I-K H 2) /(L A M B H H-L A M O A Y$ ILI)

$X_{L}(L)=\mathrm{RH}+\mathrm{LAHJHH}$ - LZZLL

10 LUNTINUE

TET JKES

END 


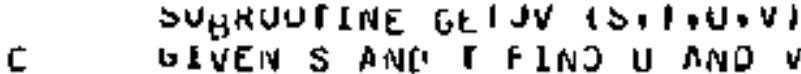

LOMYOH/G， N1, N2,NG,N7+N3+V4, M1

LUMPLEX $O, T, U, V, O S+W, W S T K, I, H S D, H S U P R, U S N E N, S T$, LOSRK

EXTENTAL CSGHI

JATA I / TO..1., TOL / T.E=10/

is $s=U * U+V * V$

$w=s$

NSTH = T

$\$ I=S * I$

If ILASSISII.GE, TJL) GD 1025

LALL GETHSO (10.०0, I, HSU, HSUPK)

$W=W / S G N I$ (REAL (HSOPNI)

WSTR = WOIK/SDRTIFLALIHSWPRI)

SOO 10100

C UO AI MOST 2D NEWTON ITERATLUS

$25 \mathrm{LO}$ SU $\mathrm{L}=1,2 \mathrm{O}$

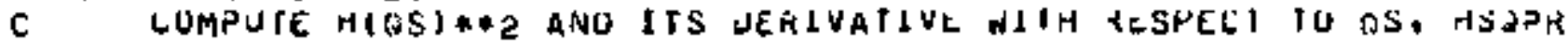

CALL GEIHSW(US, HSU, HSUPA)

JSNEW = US- $1 \mathrm{HSW-STH/HSQPK}$

IF (CABSIUSNEW-US).LI.IUL) GU TO 90

$80 \mathrm{WS}=$ GSNEW

WIIt $(\$ 2,110)$ \$I

CALL EXII

SO JS $=$ iNSNEW

$W=L>Q H(1 Q S *(D / T), W)$

NSTK $=W *(1 / S)$

$100 \mathrm{U}=.5 *\{W+W S \mid R\}$

$v \quad=.5 * 1 *(W-N S T K)$

KLTURiN

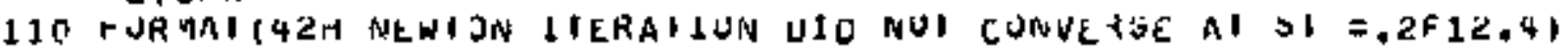

ENO

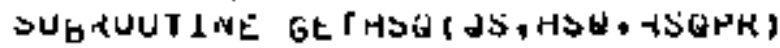

c

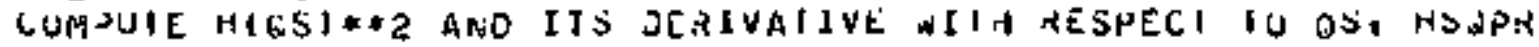

NEAL ฯACH

GUMMU,N /A/ GAMITA, YACH,RR, ROOK

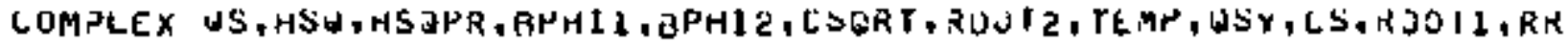
EXTEKVAL CSQKK

LUGILAL ISW

UATA ISW /.FALSE* , CONSI 1.1

It \{LSW\} GO TO 10

GHM $=($ GAMNIN-1.1/2.

LUSU $=1 . /$ (MALH* VACH) + GAY

WSTSG $=(2, / 16 A M A A+1+1)+C U S$ iे

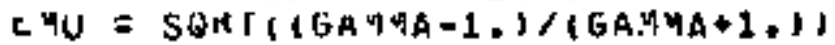

$r A C=E M U / G S T K S$

$\forall \leq x=G s$

$w s=(1,10,1$

$10 \mathrm{LS}=\cos \theta-6 A M * d S$

BPHII = ICS+CSI/USIRSO-I.

$\therefore H+2=(C S+C S)=[S$ 


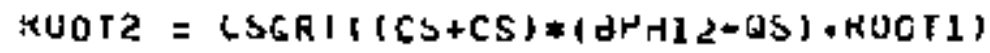

KUOTI = FAC NUJT2

I ENP = CKXP(LLJU(3PHI1-RUUTI)/L\#U)

I LMP $=$ CONS $[/(1 E M P *(B P H 12+20012)]$

C IEM ls $\mathrm{H} * 2 / \mathrm{E} / \mathrm{S}$

$H S O=W S * I E N P$

It ISW tio To 20

ISW $=, 1 R \cup E$,

C SET CUNSI SD IHAT HILI $=1$

LUNSI $=1 . / \operatorname{REAL}(H S O)$

ds $=u s x$

GU TU 10 ,

c

COMPUIE IHE DENIVATIVE DF ISO WIIH RESPECI TO US

20 HSQPK = ILNP*RUOT2/ ILS+CSI

KE. JWN

END

C

SUBRUUTINE LAMUUA IUL, VL, LAMUAP, LAMUAY,

C LOMAUTES LAMHUA+ AND LAMBUA- GIVEN U AIJDV

$N E A L$ MACH

LOMYUN $A A /$ GA THA, VACH,KOUI

LUMPLEX UL, VL, LAMPAP, LA AUA,M, V,CS, US, U, LSERA, KOO

LNTEKARL LSGH

LOGILAL ISI

UATA ISW I.FALSE.'

if (ISW) GC IO 20

$I S W=$ TKUE.

GAM $=(G A M M A-1) /$.2 .

LUS $=1 . /$ MALH*MACH) + GAM

$10 U=U L$

$V=V L$

US $=U * U+V * V$

LS $=\cos \theta-$ GAM

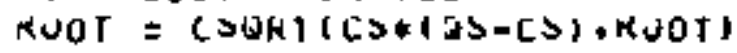

LAMOAV $=(U * V+K O U T) / C C S-V * V)$

LAMUAM $=(U * V-K O O T I / L S-V * V)$

RET JKN

LNO

SUBRUUTIIFE GIRATH [K] K Ká, ‘3]

$c$
$c$
$c$

MEA JS IN IHE PATHS ON IHE COMPLEX LHAKACIETISTILS ANG SEIS JP THE

IVIIIAL GKIO

HATHS AKE PRESLNIBEU DV IHE PLANE XIELDNJOIXIA) ANU IHE

GKIJ IS SEl UP IN 1 HE PLAVE ETA=XLA

LOMPLEX $U, U, X 1, X 2, X 3, Y 1, Y 2, Y 3$, LAMUAP, LAMDA $1, X I, E I A$

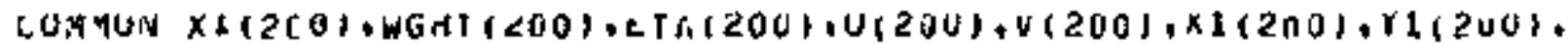

$1 \times 2(200), Y E(200), \times 3(10,200), 13110,200), L A Y J A P(200)$, LAMUAMT $20 U)$

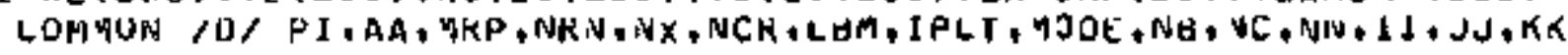

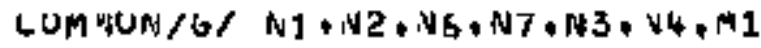


LUMPLEX XIVALL, QP,POLE, XIA,X1E,XIL

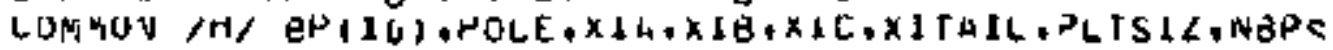

KEAL MACHA, MACHb, MTAIL

LOM,HONE $/ K /$ RN, PCHJ +PCHL, MACHA, ANGLA, MTHIL, ANGLT, MACHE, AVGLB, RC,

1 I VULH, IK

CUMPLEX FUINT, H, XIUTS

JATA KA) /.01/, L2MAX/U/

KEANJ (NG,ION) NCAROS,KK

C

****CHECK FOH EVU UF *ILE****

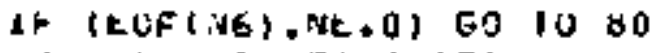

HAROS = IABST:VCAROST

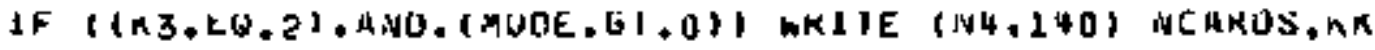

ASWTCH $=K K$

$n=K 1-1$

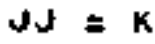

ISWTCH $=0$

LSW $=$,YOUE

IF $(\{M 0 U t+E G, 2)$. AVU, (MIAIL.LE.0.) LSW = U

UD GO $L=1$, NCATUS

READ ING,110) PDIVT,WGHTX

LL $=$ WGHTX

C JSE XIIAIL IH MIAIL HAS BEEV KLAU IN

IF (ILSW.EQ.2).ANU.\{LEG.NCAROS), POLNT = X1TAIL

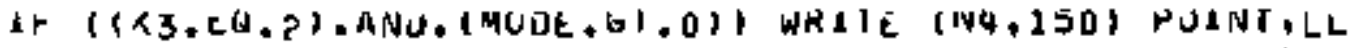

C AUJUSI PATH IU THE NOSE SO THAI IT ENDS AI A SIAUNATIUN RJIVI

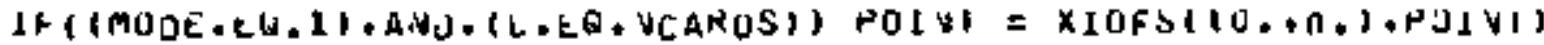

IF (KSWTCH.GT.U)

$10 d x=1$

LALL AUJUSTA $I X, i x, P O I N T)$

IF $(1 x, E(\alpha+1)$ GJ IJ 20

HOINI = HOINI $+K A I+1 X I(K I-P O I N I)$

601010

20 In $=C A B S(P O \perp N 1-X I(K) / A A+.999$

$x N=K+1$

IF (LL,EL,O) LL $=1$

$M M=M M * M R P$

IF (ISWICH.LI,S) $M M=M M$ IADS(LL)

IF (LL.6I.G) GO IO 50

$J J=K+. M M$

ISWTCH = MUOE

KSWILK = - I

$L L=-L L$

IF (KX.GI.O) EMLL ADJUST 11,1 ,POINT)

$50 H=(P O I N I-x)(K)) / F \operatorname{LNT}(4 \pi)$

$x=M+M M$

DU $60 J=K N+K$

WHOH(J) = FLOAI(LL) *FLOAI ILL)

$60 \times[(J)=X I(J-1)+H$

IF (ISWTLH.LT.3) 601060

It (K.LE,JJ) GJ TO GS

$K N=\rfloor J+2$

IF $\left(K N, G E^{-}, K\right)$ GU TJ 64

UD $52 \mathrm{~J}=\mathrm{KN}, \mathrm{K}$

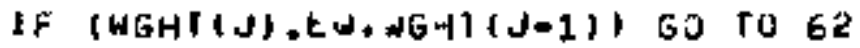

$W(O H I(J-1)=.5 *(W G H T(J-1)+W G H T(J))$ 


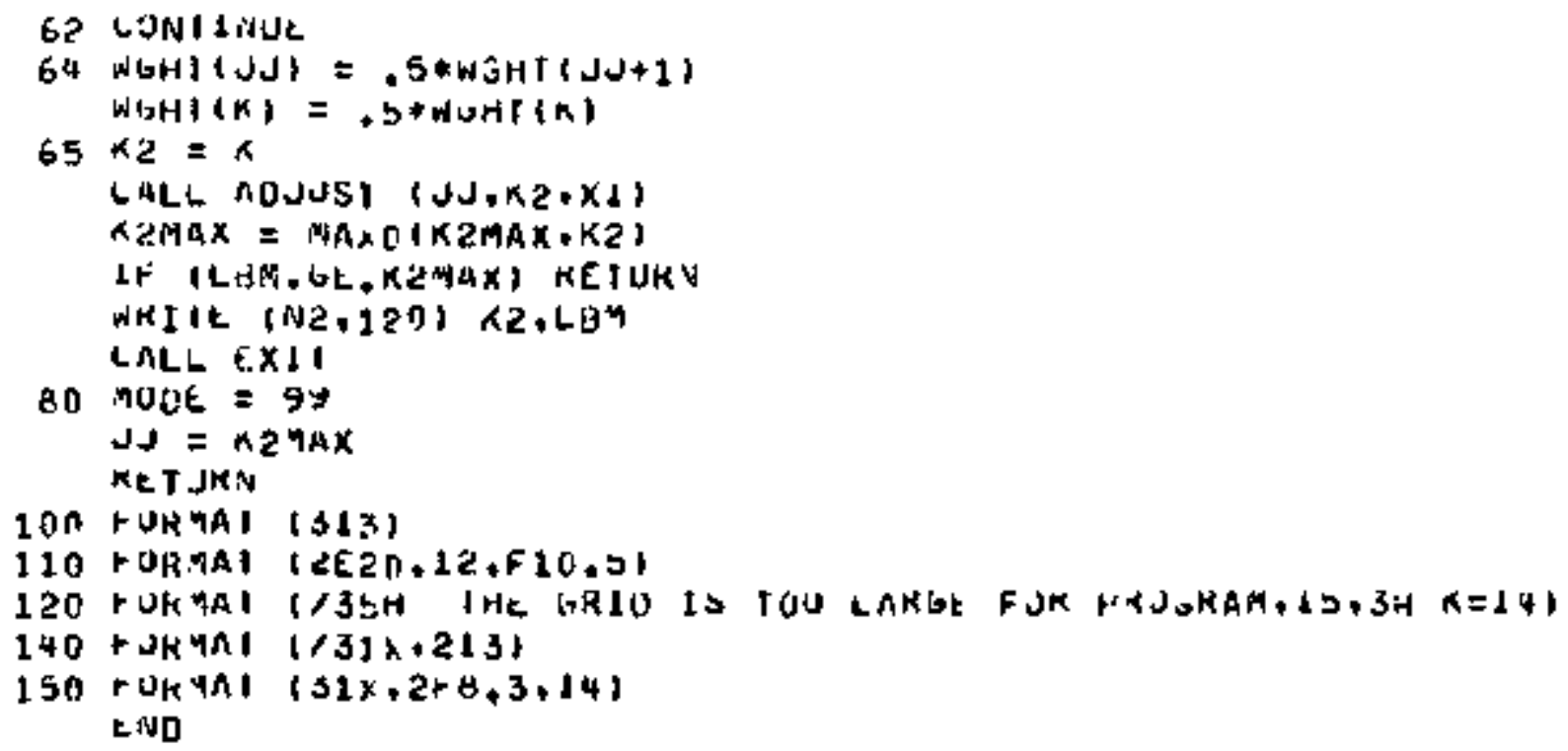




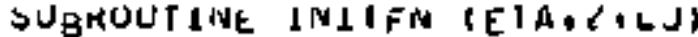

C LUMPUIES I HE IVITIAL CHANACFEHISTIL OAIA JV XI = XIC

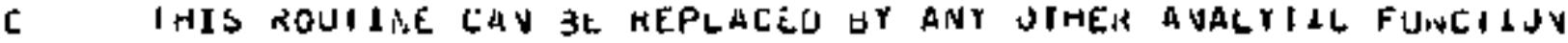

C LIA IS TITE VALUE JF LIA

C \& IS IHE VILUE JF IHE IVIIIAL +JNLIIOV, GIETAJ

LUMPLEX ETA.LIXIP,I,TEMHETJ

KEAL LOGS

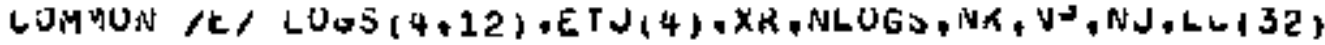

UIMENSION PARAY(b6)

EDUIVALENCE (PARAY(1).LJGOID,1)

JATA $I / 10, \ldots 1,1 /$

$L X=L J+N J$

Af \{Lx,tut\} ud it 5

$K X=(C \mid L X)$

PARAITIKXI $=1$.

$5 \times 1 P=$ CONJGILIA)

c

SUM UP THE PULYWOUIAL TCRHS

$v=4$

$C=(1 \mathrm{~J}(\mathrm{~J})$

$20 J=J-1$

$\left.\angle=\angle A x 1 r^{3}+t\right] J(J)$

If $(J, G) .1\}$ bo to 20

$\angle=\angle * X 1+$

c

LUG TERMS

JU $10 \mathrm{~J}=3$, NLUGS

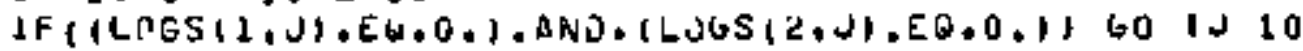

$I L M P=1 .-X I N / C M P L X(L O S S(S+J)+L U G S 14.11)$

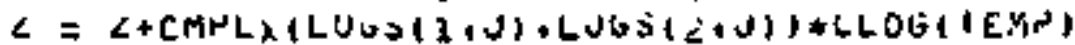

10 GUNT $2 \mathrm{NOU}$

$\left.L=\operatorname{CONJG} 1_{C}\right)$

IF (LX,Ed.I) RETURN

PARAM $(K X)=U$.

HETUK:

ENO

WUHHLEX RUACIISW XIOFS S + XIPASI)

GLMPLEX XLPASI, XI OLO, XIVEW, SUF XI, SUF XIF, S

JATA IOL /1.t-10/

XIOLU $=x I$ HAS

$C$ JU AI MUDI 20 raw TON IIEHAIIONS

Ju $4 \mathrm{~J} k=1.20$

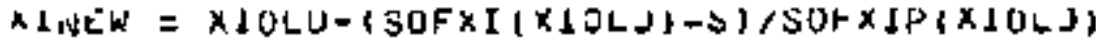

It (LABS $(X 1 \mathrm{VE} W=X I U L D), L E+$ TOL $)$ GU 1050

$X 1 O L U=X I N E W$

40 CUNTINUL

HNIVI 99

90 rURYAI * 4.0 CUNVEKGLNCE*)

50 XIOFS $=$ XIAEW

Ket JKN

EN J 


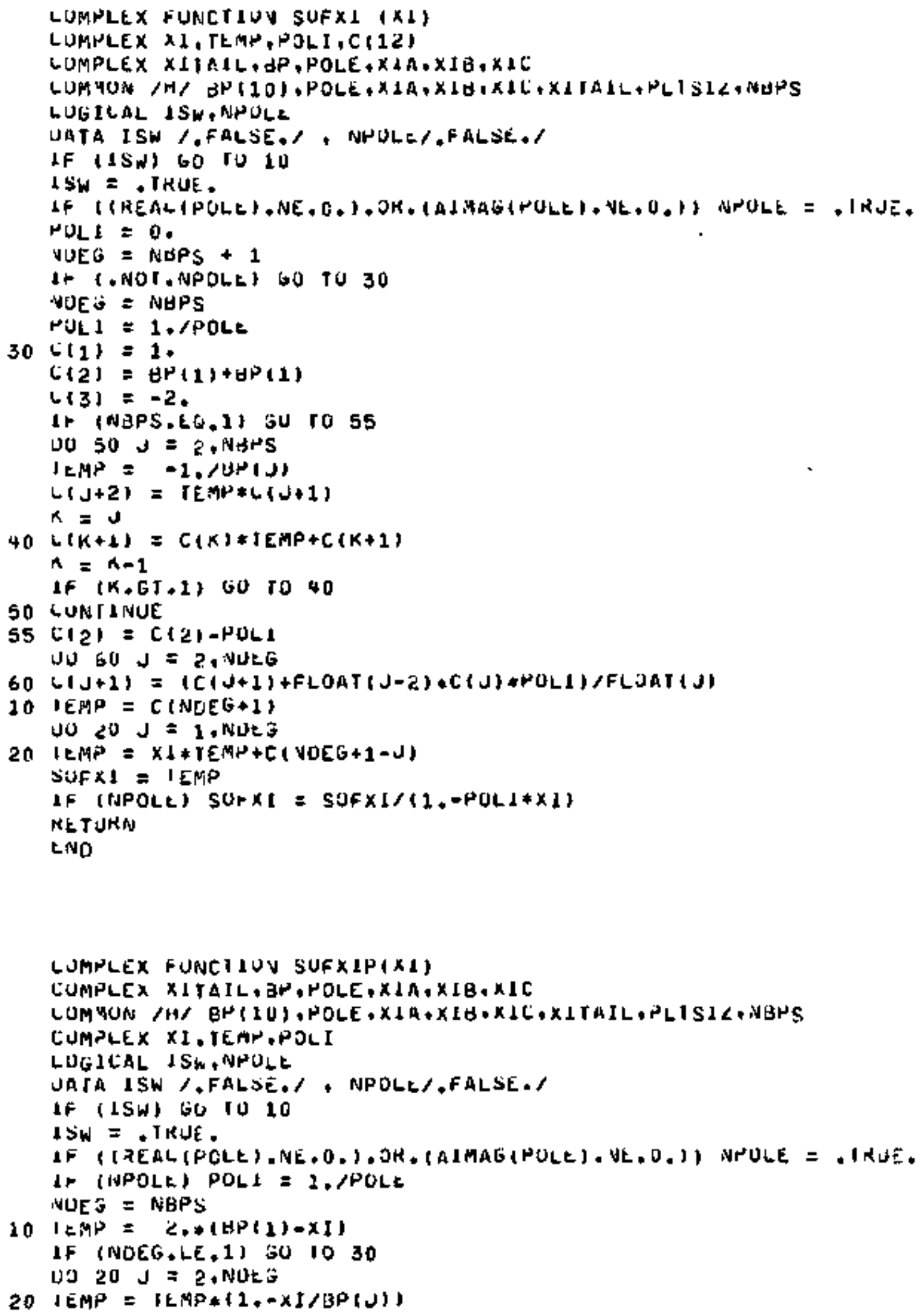


30 SUFXIP $=1 E$ MH

IF NNOLE) SUF XIP= TEMP/ (2, -POLI*XI*(2,-PJLI*XIII

RETUKN

L. No

(UAPLEX FUACILUN XIOFM( T+ HNG XIOLU)

GUMPUIE $\lambda 1$ CLUSEST TU XIULO WHICH HAS HACA WUMBER M hIVU ANOLE AVG WUMUUN / A/ GAMMA, DACH

REAL M, MACH

LUMPLEX HSOU, HSUPR,,$\lambda I O F S+X I O L L$

LUGILAL ISW

JATA DI $/ 3,1410725335097 \Rightarrow /$, ISW/.FALSE,

IF ISWI GO IU 10

iSW $=$. IKUL.

$N A O=P \perp / 1 E C$.

$\checkmark A M=(G A M M A-1,1 / 2$.

LUSW $=1, /$ MACHEMACH) + GAM

$10 \mathrm{LV} \mathrm{YS}=\mathrm{M} * \mathrm{M}$

ANGL = ANGWRAU

$* S=C O S W * E 4 S A /(1,+5 A M * E M S Q)$

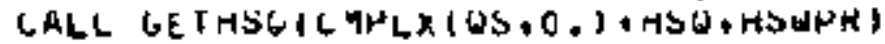

$3=$ SURI (REALIASU) | *LPLX(CUS(ANGL), -SIN(AVGL))

XIOFM $=X I U F S(S, X 1 U L U)$

RE. TUKN

CNO

SUBTUUTINT TIILE

RRIVIS IHE IIILE PAGL OF IHE VUINUI

NLAL MACH,LUGS

LUM MUN $/ A$ GAT TA, YACH

LUMPLE X $U, V, X 1, X 2, X_{3}, Y 1, Y<, Y 3, L A M U A P, L A M U A M, X I, E I A$

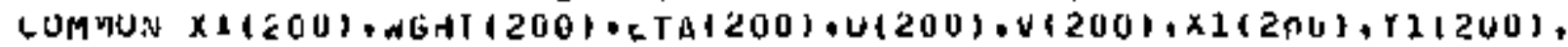

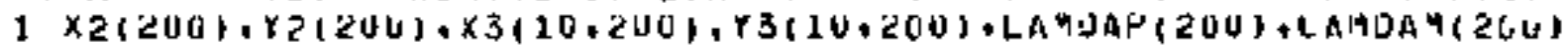

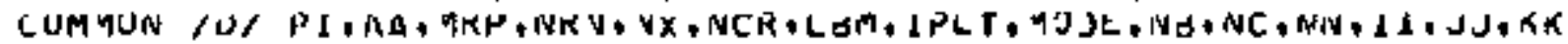

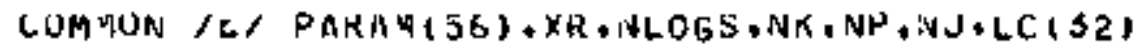

LUM NUN/G，N1,N2,NG, AS T,N3+V4,M1

LUMPLEX XIBAL,BP,POLE, X1A,X1日,XIC

LUM NON $/+1 /$ gPIIO, HOLE, XIA+XIB,XIC,XIIAIL,PLTSIL+NAPS

TEAL MACHA, YACH3, YIOIL

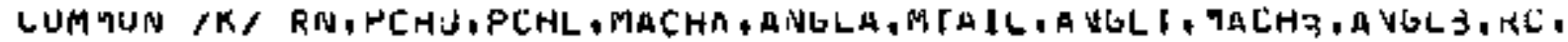

1 A NGLN,IK

UIMENSION $\beta_{1}(56), L \times(56), L O G S(4,12)$

EUUIVALENCE (HARAYT1),LUTSII.11)

NLWLNO N1

Ir $(1 \%$ LT,LT,0) $\mathrm{SO} 107$

HLAO (N1.50) (TARAMGLI, L $=1.56$ )

IF AN1, EOA,M1, GO IO 7

REWLNU MI

KEAO (N 1 , 50) (P1) L), L $=1,56)$ 


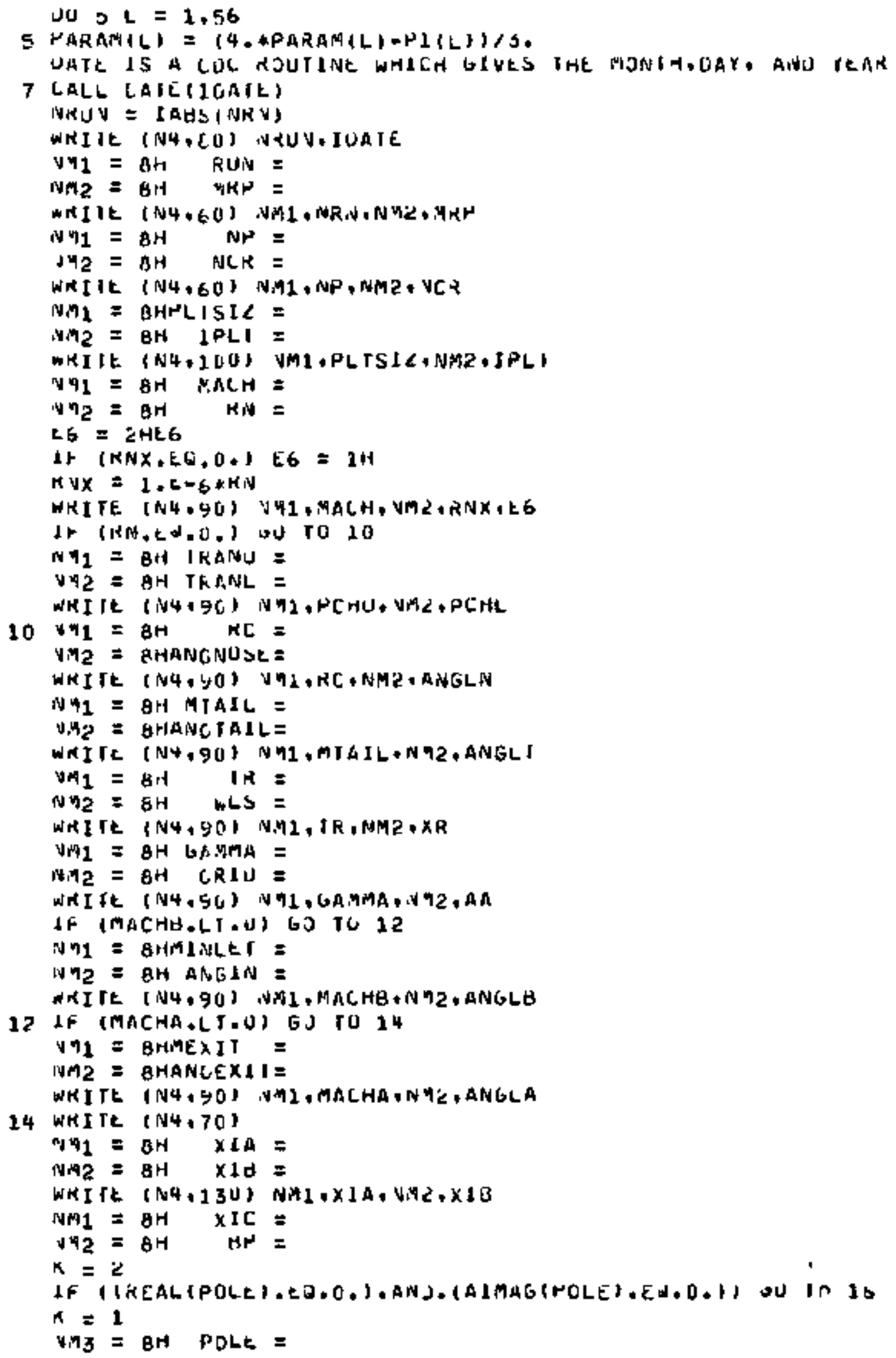


WHIIt $(N 4,130)$ NMI, XIC, VISS,PULE

GO TO 18

16 NKIIE $\left\{N 4,130\right.$ VM1 $X 1 C, V M 2, A^{2}(1)$

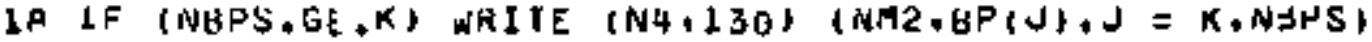

WIITE $1 \mathrm{~N} 4,70\}$

UO $20 \mathrm{~L}=1,56$

$20(X(L)=4 H$,

UU $30 \mathrm{~L}=1, \mathrm{NK}$

$J=L(L+1)$

$30 L x(J)=4 H+1$

NRITt. OUI PULYNJNIAL COEFFICIENIS

$N_{41}=\mathrm{BH} \quad \mathrm{LH}=$

VA? = BII ETSQ

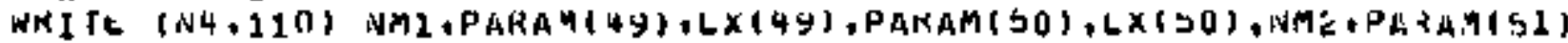

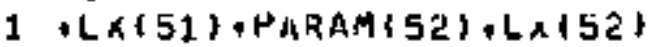

$\mathrm{NA1}=\mathrm{RH} \quad \mathrm{EICU}=$

$N N_{2}=3 H \quad E T F N=$

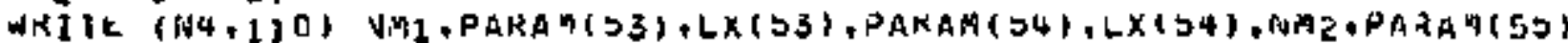

1 . LX(55), PANAM (56), LX 56$)$

C NRIVI OUI LOL LUEFFILIENFS ANU LOCAIIONS

If (NLUGS.EJ.0) GJ TO 45

UU $40 \mathrm{~J}=1+$ NLUGS

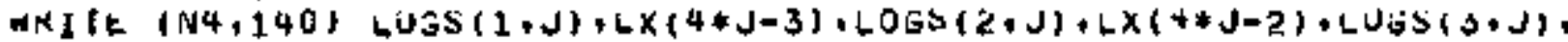

1 LXI4*J-1), LOGS $(4, J)$

40 CUNT \& NUE

45 AKIIE IN4.15U t

LALL HLPAIH(2+,4AXO10, AP ), 2)

IF (IPLT, NL,O) CALL GOPLUITNANI

$K \in T$ UKN

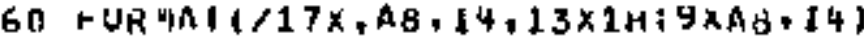

70 PUR TAL (1HC)

BO PUR YAE T1H1/15X+28HIRAVSJNIC CASLAOE UESLSY PUN $15,17 X A 10 / / / 39 X$,

1 GAIAPE 7,1

$90, U R$ YA I $177 x, A B, F 7,3,10 \times 1+\$ 9 x+A B+57,3, A 2$,

100 PR $4 A[\{/ 17 x, A \theta, F 7,3,10 \times 1 H ; 9 \lambda, A B, 14]$

110 ,UR 4AI $(G \times A S, F 7,3, A 4, F 7,3, A 2,6 \times 1 H, 4 \times A B, F 7,3,44, F 7,3, A 2 / 1$

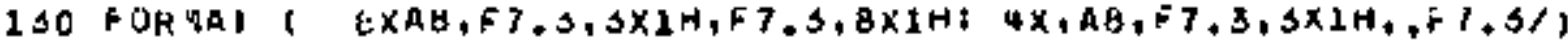

140 PUR UAI $(111 \times 5 H L O G=F 7,3, A+, F 7,3, A 2,6 \times 1 H, 12 \times F 7,3,44, F 7,3)$

$150+$ DRMAT $1 / 130 \times 2 S H$ * AUTOMAIEO PAKAMETEKS ,

50 PUR MAI ( $40 \mathrm{E} O)$

ヒN口

SUBROUTINE AUUTगTIMX!

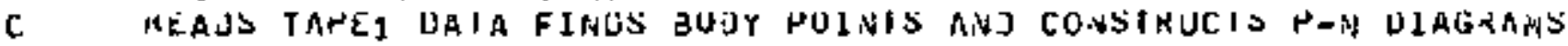

LOMPLEX XI,XIDOUY,CHAR

NEAL MACHN, KAHA

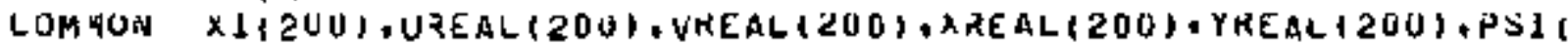

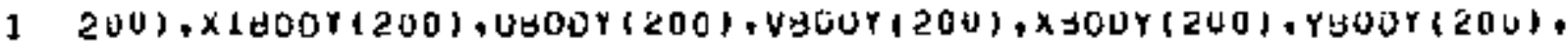

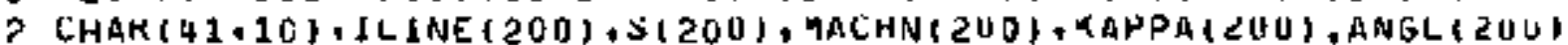

3 ITHLTA200\}, H\{2UO)

COM MON $/$, XARK, AL, XAIMG, YAREAL, YALAG, XEIMG + YBIML, IPTR

LUM NUN IU/ PI, AA, YKP, NKV, VX, NCR,LGH, LPLI, MJJE, NB,NC,NN, II, J J KK 
LUM,YUIG, M1, W2, NG,N7,N3, V4, M1

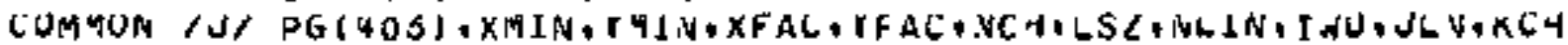
LUMPLEX ROTATE

LNTEGER HP, HN

DATA HP. HN, NKWW/1-1N, IHN+1/

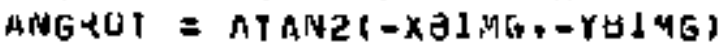

RUTAIE = CNPLXICOS (ANGROI), SIN(ANGROT)

C

SET UP AXES FUR JHE P-N ULAGRAM

LALL PNAXIS( $(0,+0,1)$

$C$ SET UP PLOT MAGE

$I P L=M O U(I P L J / 10,10)$

Ir $(\angle P L, E G, G)$ GO TO

LALL GRIGIA 13.5.1.5)

5 ANIIt $(N 4,200)$

IF (N4,NE, N2) WRITE (N2, 200 )

$x \operatorname{soJY}(1)=1$.

$x B O 0 Y(2)=0$.

I oOJY $(\hat{z})=0$.

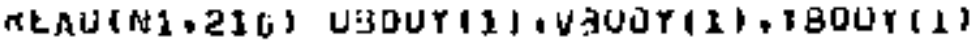

IF (LOF (NH).NE, D) KETURN

तt.AU (N1,210) UOUOY(2), VOUDY(2),X1DOOY(2)

IF INI,NE, NSI 60 TO 7

HEAJ $(M 1,210)$ UKL, VHZ,YN2

Uyourt 1$)=(4 . *$ JBJur 11$)-U k 2) / 3$.

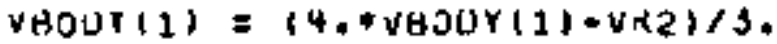

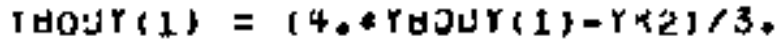

HEAU $\{M 1,210)$ UR2, VK2,XIUJUY 2 )

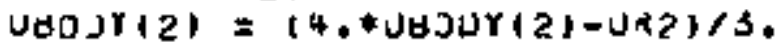

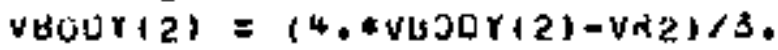

7 MX $=3$

TIL = YBOOY II* ZEAL (KOTAIE) + AIHAG(ROTAIE)

IF (YTL.LI.O.) CALL CPLOI (CMPLA(D.,-YIL).-3)

C

REAJ DATA FOH A PATH OK PWR

10 KEAU (N1.21O) KK, NITS

****CHECK FOR LINU UF FILt****

1F (tUF(NI) * NE + 0 ) 60 TO 160

JO D.J $L=i, N P I S$

KEAU (NI,210) JREALILI,VREALILJ,XKEALILI, YRLALILI,PSITLI, ATILI

15 CONI INUE

IF $(N 1$, NL, $R 3)$ GO TO 20

KEAU $(M 1,210) M A, V P T S$

$v=1$

UO $20 L=1, N D I S$

KEAU 1 H1, 21GI UK2, VK2,XKL+YRL,PSIR2,XILLI

UHEAL IL) $=(4, *$ JREAL $(J)-U H 2\} / 3$.

VKËAL IL) $=(4, * V N Z A L(J) * V N 2) / 3$.

$X K E A L(L)=(4, * X R E A L(J)-X\{2) / 3$.

TREAL 1L) $=(4, *$ * $R E A L(J)-Y \cap 2) / 3$.

rSI(L) $=$ (4.*HSiJ)-PSIN2)/3.

$\checkmark=\checkmark+2$

25 CONI INUE

20 L. I INFS-

WHECK FOK A SUPERSONIC PAIH

IF (KK,GI,O) \$O 1040

C WL ate ON A SUdSONIC PAIH UK FUKR 


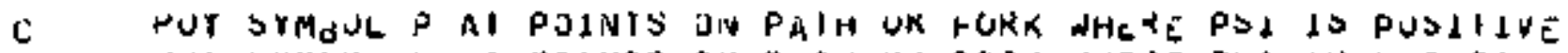

$C$ PJT SYMBUL $V$ AF PJIMIS ON PAIH UR FORK NHERE POL $1 S$ VEGATILE

uU $30 \mathrm{~J}=1, \mathrm{NP}^{\mathrm{O}} \mathrm{S}$

$\mathbf{L}=\mathrm{Hr}$

IF $(H S I(U), L, *) L=,H V$

30 CALL PNI XIJJ,L)

IF $\{K+L T \cdot 0)$ OU TO 10

C Wt AKt ON \& FORK,LOOK + UK BOUY PUINIS

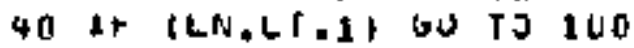

JU $90 \mathrm{~J}=1, \mathrm{LN}$

LALL INTERPIJ, MX, ICHKI

IF ILHK,ES,OI GU 1090

C A BUUY PUINT HAS JEEN FOUNO IN IHE IVTERVAL

LALL GAUHISAMXI

C LHECK FOK ERHONEOJS POINIS

Ir $(K K, 61,0)$ ov 10110

90 CONILNUE

100 IF (KK. LE.OU BOU IO IU

c

SUPEKSONIC PAIT WIIH NO BUOY POINIS

$1301+$ (NROW.NE.1) 601060

$M R Q=N P I S / 6 S+1$

1F (N2, LU.B.th) to to bo

$C$ HRESARE FOR 1 IY PAGE OUIPJT

inT $=N P I S / 36+1$

$\triangle V C=1$

IF( MK(A,NE.S,RT) ING $=2$

60 IF (MOOINHCN-A. MNA).NE, O) 50 TO 150

C

CONSTRUCT P-N IRIANGLE FOR SUPERSONIC MATH

NCOUN $1=0$

U $14 \mathrm{C} J=1, \mathrm{NPIS}, \mathrm{MR}$

NCOJINI = NCOLNI + 1

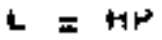

It (HSIJJ)LI, L) L = HN

140 ILINE (NCUUAY) = L

WRITE $(N 4,100)(I L \perp N E\{J\}, J=1$, NCUUNT)

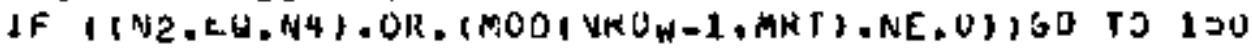

WRITE (N2,1EO) (ILLNE JU) J $=1$, VCOUNT + LNC

150 IF (\$PL.GI.

NKOA $=$ NCOH+1

IF TNPIS.GT,1) GO TO 10

C IKIANGLE IS CUMPLETE

WNI IE (N4, 200$)$

IF (N4, NL.N2) WIITE (N2,200)

NHOW $=1$

GO IO 10

C PLOT LVEKY MKB CHAKACTERLSIIC FRUM THE BOUY TO THE SOHL LIVE

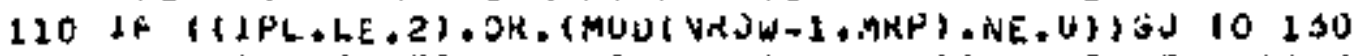

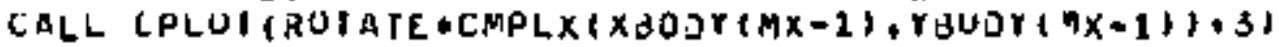

JO $120 L=J, L, W$

120 LALL LPLUI (AOIATE *CMPLX (XNEAL(L+2), YREML $(L+2), 2)$

bo 10130

$1604 x=4 x-1$

WRIIt (N\$4, 290$)$ PG

IF $(1 P L . N E, O)$ CALL OHEGIN $(3.3 .1 .5)$

IF (N2,EQ+N4) KËTJN 
Uo $310 J=2,403+13$

$J P=J+6$

310 WRITt $(N 2,320)$ (PSIL)+L = J,JP\})

320 FORIAT $(1 \times$, BNIO)

KE TUN N

180 PUR.HAT $(65\{1 X+A 1)\}$

c

200 FORMAT (1HI)

****LHANGE (4020) IO (20A4) UN Jo* 360***,"

$210+$ OATAT $(4020)$

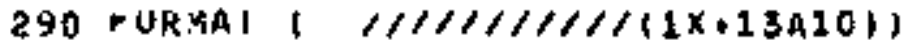

LND

C

SUGRUUTIHE PLIVL $\{<1, K 2\}$

C PLOIS CHARACIENISIICS IN IHE SUPERSONIL REGION

LOMAUN $/ L$ XAKLAL, XAIMG, YAREAL, YAIMG, XGIMO, YBIMG

CUMPLEX XI, XI UUUY, CHAR

KLAL MACHN, KAPPA

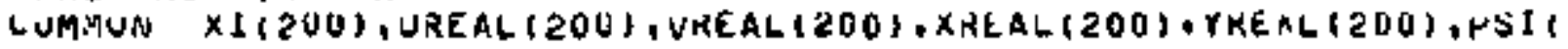

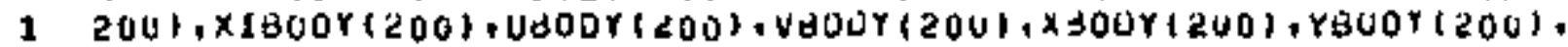

2 СНAR $\{42,10\}+16$ LNE $(200)+S(200)$, MACHN $(200), \angle A P P A(\angle 00), A N G L(200)$

3 . INEIA(200)+ 1200$)$

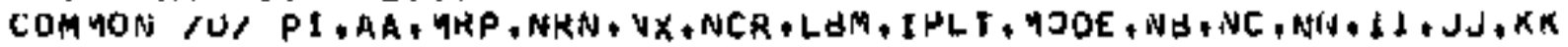

COMMOW/G, N1, N2, N6,N7,N3, V4, M1

CUMPLEX MOIATE

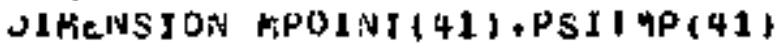

LOGILAL ISW

UATA ISW/.FALSE, , NAR /41/, MAKR/10/

IF ISSH GU TO 5

$\perp S W=$. TKUE.

ANGROT = AIAN2 (-X31AG,-YDIAG)

HUTATE = CHPLXICUS(ANGROI) SINIANGKOT)'

$5 \mathbf{L}=\mathbf{U}$

c

CHECM FUN FIKSH NOW DF TMLANGLE

If $(K 1,61.1)$ bo 1030

$P A C=-P S 1121 / 4 a S(H 51,13)$

$\operatorname{MNO}=M K r$

10 UU $20 \mathrm{~J}=1, \mathrm{K2}, \mathrm{AKJ}$

$L=L+1$

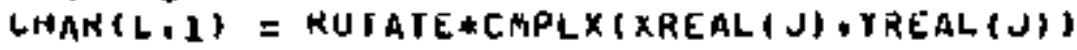

$\operatorname{PSI}(M H(L)=$ HSI (J)

20 MOOINT(L) = 1

LL $=L-1$

C

CHEEK TO SEE IF WE HAVE EXCEEDED JHE JI YEVSION DF CHAK

IF (L, LE, NAR) RETUNN

WRITE (N4,100)

$M K G=M K L+M R$

$\mathbf{L}=\mathrm{U}$

Go 1010

30 JU $70 \mathrm{~J}=1, \mathrm{~K} 2, \mathrm{Mk}$

$\mathbf{L}=\mathbf{L}+\mathbf{2}$

IF (RAC* PSI JU.LE.0.) GU TO 60

RUINI IS UUTSIOE THE BOUY 


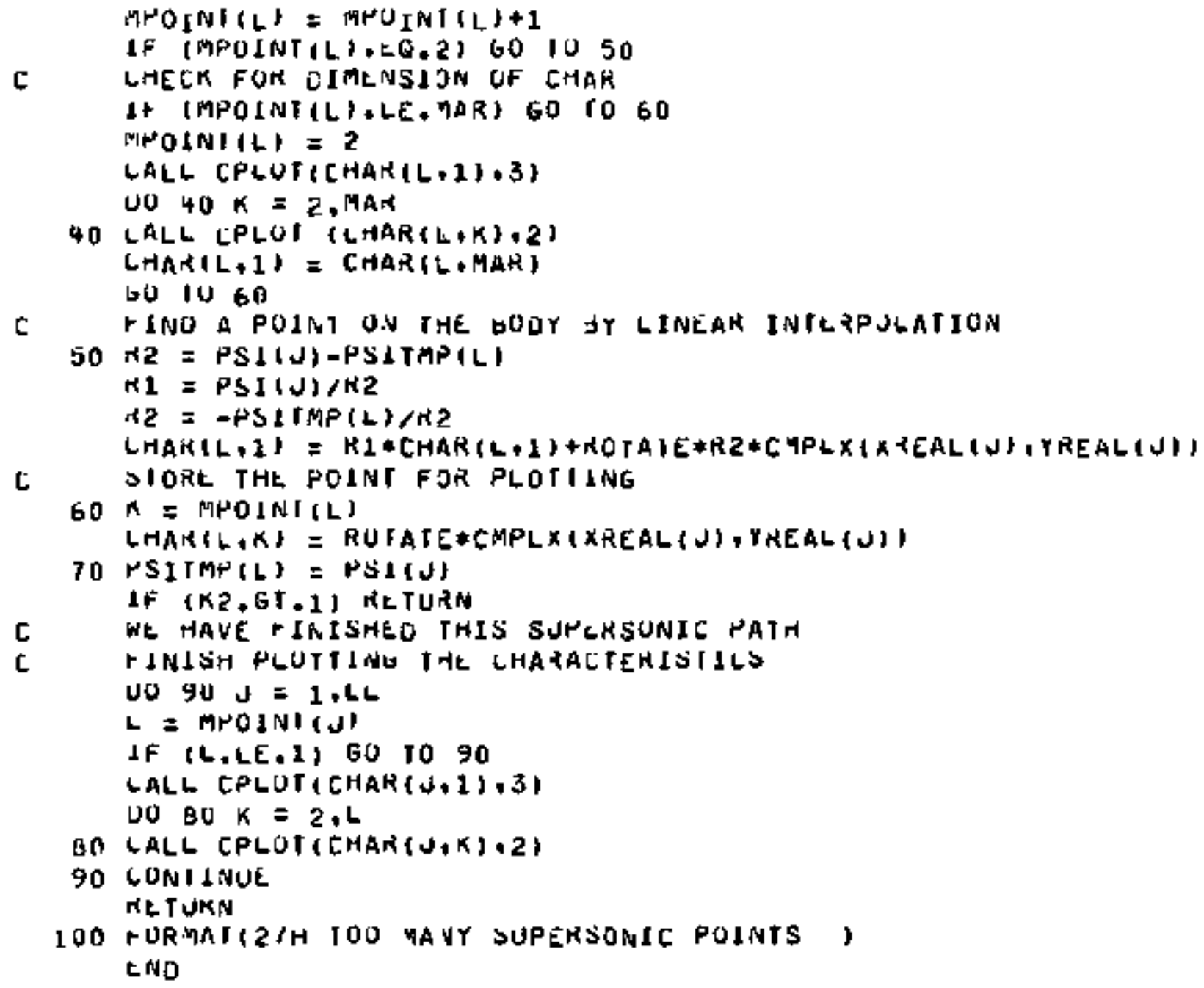

C CAECK FOH A SIGN CHANGE DETHEEN THE SELONJ ANO ITIKU INTESUAL It $(X \& * X C, L \geqslant 0,1,601020$ 
I+ IX X+XL.EL.O.) RETUKN

$20 \quad n 3=1$

$X A=P S 1(\times 1)$

$L A=X C-X B$

$K d=X C=X A$

tt $=\times B-X A$

c

WU LINEAN INTERPOLATION ELTHELN HUINTS 2 AVO 3

$U 23=$ UUEAL $(K 1+1) * X E-U R L A L(K 1+2) * \times B) / K A$

$\checkmark 23=($ VKEAL $(K 1+1) * X L-V R L A L\{K 1+2) * X B) / C A$

$X_{2 B}=(X K L A L(K 1+1) * X C-X K L A L(K 1+Z) * X B) / E A$

T $23=(Y K E A L(K 1+1) * X L-Y K L A L(K)+2) * X B) / C A$

$X 123=(X I(K 1+1) * X[-X I(K 1+2) * X B) / L A$

C

UU LINEAK INTEKPOLATION UETALEN PUINTS 1 AUJ 3

$U_{13}=(U N E A L(K 1) * X[-U R E A L(K 1+2) * X A) / C B$

$V 13=(V K E F L(K)) * X C-V K E A L(K 1+2) * X A) / L S$

$X 13=(X R E A L(K)) * Y C-X R E M L(K 1+2) * X A \mid / L 3$

$r 13=($ YREAL $(K 1) * X[-Y$ ZEAL $(K 1+2) * X A) / L 3$

$X 113=(X 1 \mid K 1) * X C-X I(K 1+2) * X A) / E B$

6. IF PSI IS AOT HUVOIONIC USE LINEAR INILRPJLATIU.Y

If ILA*EC, GT+0.1 SD TO 30

$A S=-1$

ubourtK2) = U2S

vBOUT(K2) $=v 23$

xbour(k2) $=\times 23$

IBOUt (K2) = r2s

$x \perp B$ UUY $(K 2)=x 123$

KETJKN

c

UO WUADRATIC INTERPOLAIIUV

30 WBOor $(K 2)=(U 13 * \times B-U 23 * \times A) / E C$

voour(K2) $=($ V $13 * x \forall-V 23 * x A\} / t C$

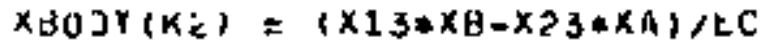

TBOUY\{K2) $=(r 13 * x \in-r 23 * x A) / E C$

$X \perp B J U Y(K<)=\{X\{1\} * X a+X I \leqslant 0 * X A\} / E C$

KET JKN

LWO

SUBKUUTINE BLAUECKI)

C KEORUER IHE KI JOJY MOIVIS,PRINI ANO PLDI IHE KESULIS

NEAL WACN

LOMYUN $/ A /$ GAMMA, MACH

CUM,YUN IL' XAKLAL, XAIMG, YAREAL, YALMG, XBIMG, YBIMG

LUMYUN $/$ I XORLG, YORLG, SLALE

LOMPLEX XI,XI 3 UQY, CHAR

NLAL MACHN,KAPRA

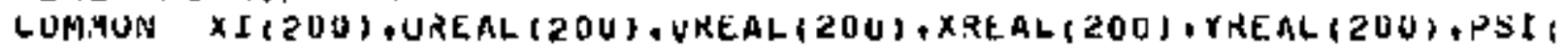

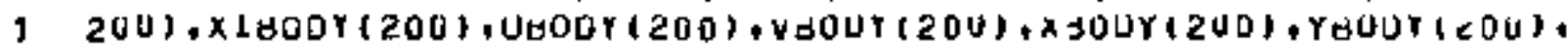

? CHAK $(41,10)+$ ILINE $(200), S(200)$, MACHN $(2 U 0)$, RAPPA ( $20 U)$, ANGL $1 \angle E U)$

3 - THE $(20,2001+4(200)$

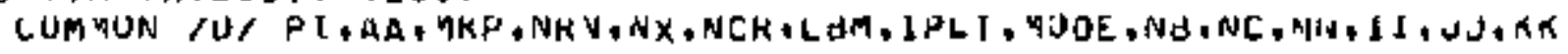

LOMAON/G, $M 1+N 2, N 6, N 7, N 3, V 4, M 1$

LUMPLEX XIIAILIBH,POLE, XIA,XIB,X1C

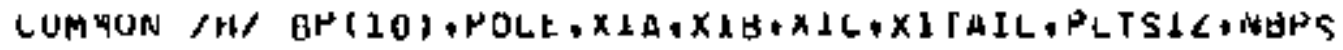


NEAE MACHA, VALHB, YIALL

LUM YUN /K/ RIY,PCHU,PGHL, HACHA, A,

1 ANGLN,IK

CUMYUV /1/ SF, SIZE, ANG, XMAX, YMAX, XUK, YUR, PSS1Z

LOMPLEX TTHT (S), BASE (3)

CUMMUV $/ 1, I I$ ILE $(E)$

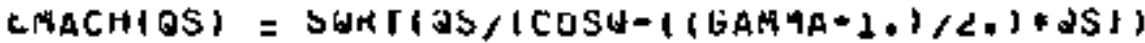

GAM = (GAMHA-1.) $/ 2$.

$\angle U S O=G A M+1 . / 1$ MACH*MACH)

$K A O=180 . / P I$

$1 \mathrm{HL}=$ MOU $12 \mathrm{PL} .1 / 10,10)$

$S \eta=5, / \Delta F$

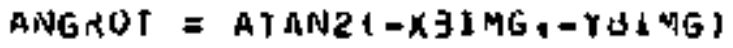

LUSA = COS $(A N G K O 1)$

SINA = SINIANGROT

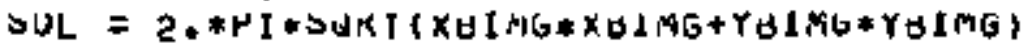

IF (K).LE.1) GU TO 25

C LKEAIE A POINIER LISI

UU $10 \mathrm{~J}=1 . \mathrm{Ml}$

10 I LIYUK $(J)=J$

C

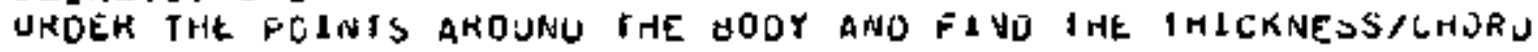

$1 C=0$.

LIAX $=1$

$X I B$ BUY (1) $=X I I A I L$

WU $20 \sqrt{2}=2, K 1$

$K=$ ILINE $\{J-1\}$

LMAXP $=$ LMAX

$\sin x=$ xuUur(K)

$\operatorname{LAAX}=\mathrm{J}-1$

UU SU L $=\$, K 1$

$L L=I L I N L(L)$

It (XBOOY (LL). E. XMX) GO IO $\$ 0$

$x \sqcap x=x B U O Y, L L$ '

LMAX $=4$

30 LONTINUE

IE = AMAXI(TC,AJS(YBUDY (LVAX)-YdUUY(LMAXP) )

IF ILMAX,EQ, (J-1) GO TO 20

ILINL $\{J-I\}=$ LLINE (LMAX)

LLINL ILMAX) $=K$

20 LUNTIIUE

$\triangle I Z E=.07$

$\triangle U L=S O L * S C A L L$

25 WNITE $(N 4,110)$ IC, SOL

IHA $=90 .-A N G L A=$ KAJ*ANG TOT

$1 \mathrm{HB}=90 .-A N G L B-R A U * A N G \times J T$

$I J R V=I H A-I H B$

WKIIC (NH,120) MACHB, IHA, MACHA, IHA, IUR'W

IF $(K 1, L E+1)$ KETURN

LL $\#$ ILIVE $\{\mathrm{KLI}$

BASE(1) $=\times 1 \theta$

EINT\{1\}= CONJG(XIGOOY $\{L L) X \perp \theta\}$

dASE (2) $=X I A$

LINI\{Z\} = CONJUIXIB-XIA\}

HASE (3) $=X I 1 A \perp L=1 . E-6$

CINIC $(3)=\operatorname{CONJO}(x) A-x \perp T A \perp L)$ 


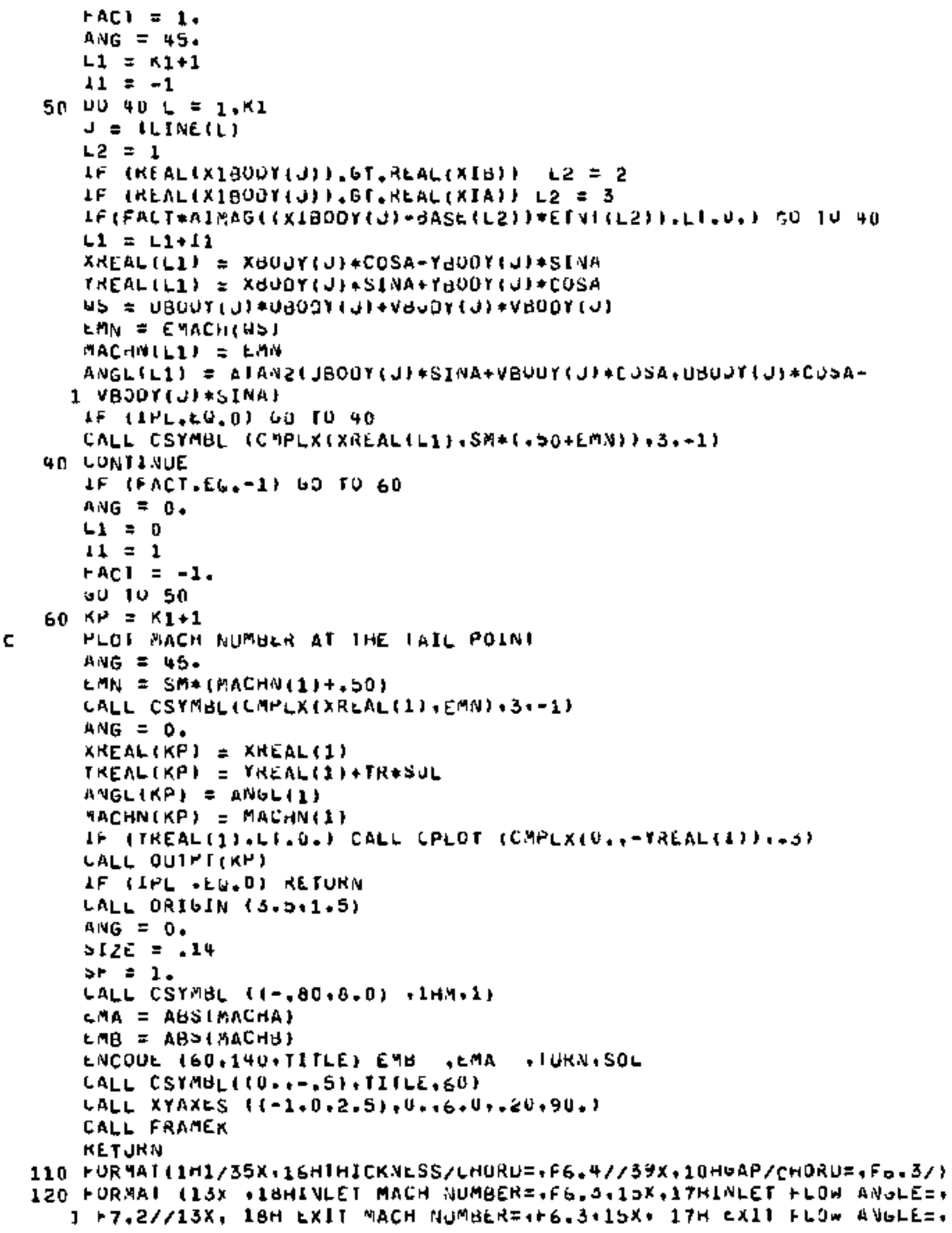




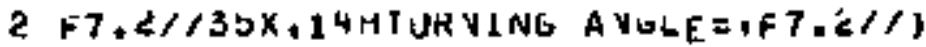

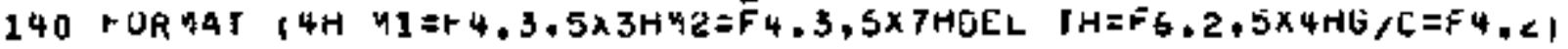

CNO

SUBHUUTIWE BAUNTS(KI)
C ELITINATE MOSI ERONEUUS POINIS

COMPLEX XI,XIUUUY, CHAR

KLAL MACHNOKARMA

LOMMON XI12UU), UREAL (2OU), VHEAL 200$)$, XREAL (200) YREAL 200 , PS1

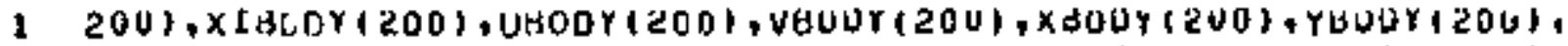

2 CHAK $(41,10), 1 L 1 N E 1200), 3(200)$, MACHN $(200)$, ,APPA $(200), A N G L 1200)$

3 . TH HA (200), HI 200 )

COM

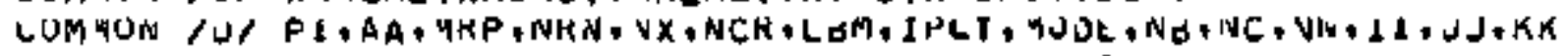

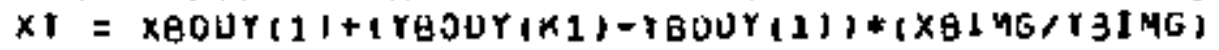

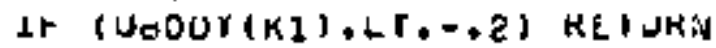

C LUOK FUR POINIS OV THE CLWJRAL SITEAMLIVE:

If (xBOOY(K1).LT.O.) GO FO 10

IF IXHOOTIKI) GT, X1) HETUKN

C SAVE IHIS FOINI

$20 K_{1}=M 1 N U(K 1+1 \cdot L G M)$

NETUR丨

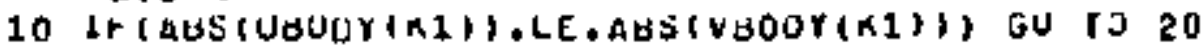

METURN

two

SUBRUUIINE HUGNF(KI)

LOMPLEX ROI

CUAPLEX X1,XIBUUY,CHAR

HEAL MACHN, KAPPA

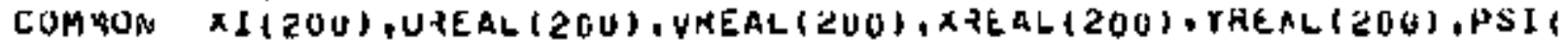

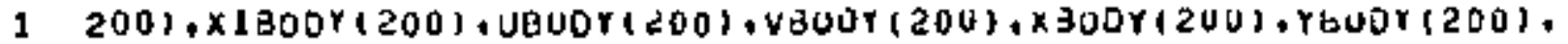

2 CHAK $(41+10,+1 L I N E(200), \$ 120 U), M A C H N(2 \cup 0), 9 A P P A(\angle U O), A N G L(\angle D U)$

3 , T t 1 (A) 206$), H(200)$

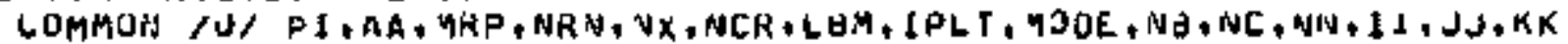

CUMPLEX XITALL, JP, POLE, XIA,XIB,XIC

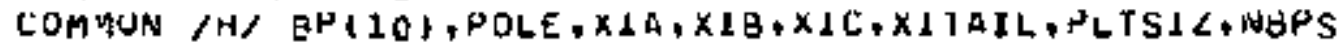

LOMMUN $/ 1 /$ SF,SIZE, ANG, XMAX, TMAX, XUK, YUR,PSSIZ

$1 P^{2} \mathrm{~L}=$ MOU $11 \mathrm{HLT}, 101$

1t (IPL. L G, t) KETJKN

$x(\{)=X I C$

$x[1, V L-1]=x 16$

LALL LOCUS (1HL)

IF (K1.LE.1) HETURN

$n=v$

UU $10 J=1, K 1$

$C$ SHECK FOK SUPLHSOVIC POINIS

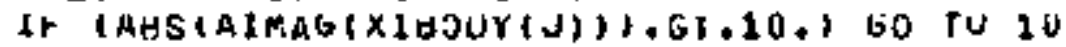

$n=K+1$ 
LALL LSYMBLIX $X$ SOUYTJ),3,-11

10 CUNIINUE

$\triangle P L=I P L T / 100$

25 IF $\left(1+P_{L}, L Q, 0\right)$ MET JKN

If $\{1+L, C O, 2\}$ GO 10 SO

$\perp P L=I P L=1$

It $\{K, G E, K 1) 60$ TO 15

C

PLOI IHE SUPERDOHIC IRIANGLE:

GALL FRA.MLK

LALL URIOIN $(7+3.7 .5)$

$S F=10$.

UU $20 \mathrm{~J}=1, \mathrm{~K} 1$

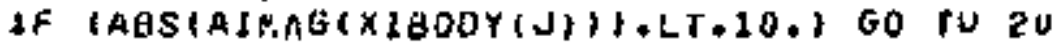

IEMP = AIMAG $(X 1$ DOJY J)

TLMP = IEMP. $\rightarrow 1 G,(100$. TE AP)

$X \perp B U U Y(J)=C M P L X(K E A L(X \perp d O D Y(J)), 1 E M N)$

CALL CSYMBL $(X 1300 Y(J), 3 .-1)$

20 LONTINUE

CALL XYAXES $10,0,1,7,0,+4,0,1$

LALL XYAXES $(10,0,0,7,3, \ldots 1,90$,

(ALL TPLUT $(1-.7,-.7), 3)$

CALL CPLUT $(1,3+, 3), 2)$

IF (LPL,EH, T) RETUKN

30 GALL FRAMEK

CALL ORIGIN $\{2+U .5 .0\}$

$X$ MAX $=6 U$.

st $=50$.

$K N^{2}=K 1+1$

RUT $=C M F L X(X K L A L(K P),-Y K L A L(K P))$

RUT $=R D I / C A O S(R O T)$

$H E V V=3$

UO $40 \mathrm{~L}=1, \mathrm{Kr}$

LALL CPLUT (RUF \#C YPLX(XRLALIL), YREAL (LJ), IPEN)

40 IPEV $=2$

$1 P E N=3$

NO $50 \mathrm{~L}=1 . \mathrm{KH}$

UELS = THETALL JHILI

$X S=X R E A L\{L\}+$ UELS*SIN(ANGL (L))

TS = YREAL $t L)+$ OEL $\$$ *CUS (ANGL $(L)$ )

LALL CPLOT IKOT KCYRLX(XS,YSI,IPEN)

50 IHEN $=2$

METUKN

LND

SUARUUTINE LOCUSIIRL)

CUMPLEX S,XIOFS, XI X X 10, CSORT, XIMINA XIMAX, HSQPR,EIJ

HEAL MACH,LOGS

LUMMUN /A/ GAMYA, MACHI

COMMUN /U/ PI,AA, YRP, NRN, VX,NCK, LBM, IPLI, MOOE, NG, NC, NIV, $11,4 J, K K$

LOM YUN $/ t / L U G S(4,12), t I J(4), X H, N L O G S, N K, N$, NJ.LW(32)

LOMPLEX XITAL, BP,POLE $X \$ A, X I B, X 1 \mathrm{C}$

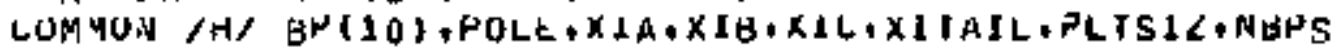


C TINU POINI ON GOUNORY AVU DRAW LINE TO IT

ITENL $=-2$

IF IPEN,LG.SI GO 1020

$X P=X, M A X$

IF $(X X$, LL $0.0, X P=0$,

40

$T P=Y Y+(A Y L-Y T\} /(X L-X X)\} *(X P=X X)$

IF (AUSIYP+YP=Y MAXI, GT, YMAX) GO TO 110

SO CALL PLDI IXP,JP, IABS(IPLVL)

IF (IPENL.E.0.3) GO TO 10

GU 1020

60 LPENL $=1$ ABS ( $1 \mathrm{HENL})$

IF $\{1$ PENL,EQ.2\} GJ TO 20

C

RINU POINT UN DUUVURY AVU JRAL LINE TO II

IPENL $=2$

IF IIPEN.EG.SJ GO TO 20

$Y P=Y M A X$

It $(Y Y, L E \cdot 0, r) Y=0$.

$70 X P=X X+(1 X L-X X) /(Y L-Y Y)) *(Y P=Y Y)$

bu TU 50

BO IF (AABS (IPEN) .EO.3 I GO 1010

LHEVL $=1 P E N L+1$

IF (IPENL+EO.S) GO 1070

LHE VIL $=3$

601040

S0 LALL FRAMEK

$X_{L}=0$.

$I L=0$.

INEVL $=0$

KET JKY

$100 \times$ XR $=X P$

YOR $=Y P$

KET JKN

110 IF (IPENL.EQ.S) GU TO 70

GO 1060

CND

SUBRUUTINE CSYMBL $(X, N+L)$

LUMMUN, I, SH, S1 LE, ANG, XMAX, YAAX, XUK, YUR, PESIZ

UIMENSION $\times(2)$

C

CHAWGE RLLAIIVE NOVEMENTS TO ABSULUTE IVEHES

$X X=X O H+S F+X(1)$

$T Y=Y O K+S F * X(2)$

C LHESK TO SEE IF WE ARE NITHIN THE HAGE

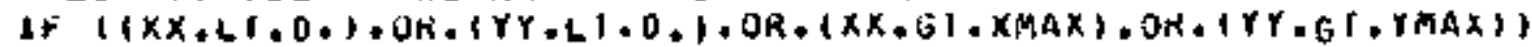

J KETUKN

LALL SYMAUL IXX,YY,SIZE,N,ANG +LI

RETUNA

L. Do 
$M I(2)=Y M I N+R L U A T(N L I N-J) * H^{2}$

CALE PN $(N), H B)$

30 LUNTS NUE

KET UKR

ENO

SUGRUUTINE GUHLOT (NRN)

$\mathrm{C}$
$\mathrm{C}$
$\mathrm{c}$
$\mathrm{C}$

IVITLATE PLOI

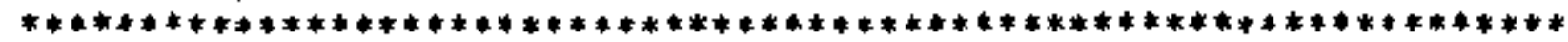

IHIS SUBROUIINE SHUULD ZE REPLACEO BY AVY RJUTINE WHTCH IVIRUCIS

IHE SYSILH IU IVIIIATE A PLOT

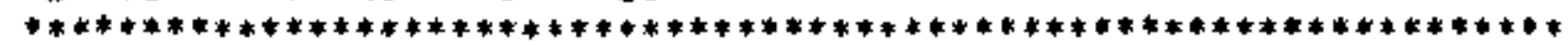

JIMENSIUN 100 S

$1 U(3)=0$

NNU, $=I M E S(N R, Y)$

LNCUUE $120,30,101$ NRUN

IF INIRN,LH,OH GO TO 25

LALL PLU1S $(120,12,11,11$.

NET JKIN

25 LALL PLOTSEL $1120,10+11,11.1$

KET JWM

30 FURMAI (5x,3HKUN, IS)

L VO

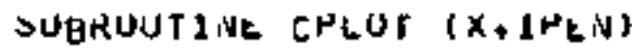

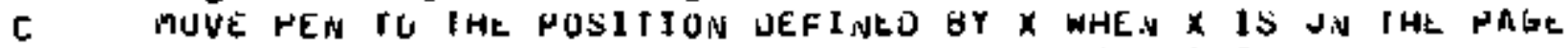
GUMUUN $/ 1$, SH, SELE,ANG, XMMX, YMAX, XUH, YUA, PGSIZ

UIMENSIUN $\times(2)$

UATA XL,YL, IPENL $/ 0 \ldots 0,+U /$

C CHAVEE RELATIVE MOVEMENIS TO ABSULUIE INCHES

$X X=X O R+S F+X(1)$

$Y Y=Y O R+S F+X\{Z\}$

C CHECK TU SEE IF WE AKE WIUHIN THE HAGE

IF (ABS $(X X+X X-X 4 A X), 61, X M A X), 601030$

It IABST TY YY YMAXI, GT, YMAX) GO 1060

IF (IPENL.NE.O) GO TO 80

10 CALL PLOT $(X X, Y Y$ IABSIIPLV\})

IHEIL $=0$

$20 X_{L}=X X$

$Y L=Y Y$

IF (INEN.GI.O) RETUNA

IF IIPENL, $A E, D J$ GO TO 100

$X O K=X X$

$r U R=r Y$

RET UKR'

30 JHEVL $=-1$ ABS $(1 \mathrm{HE}$ HL

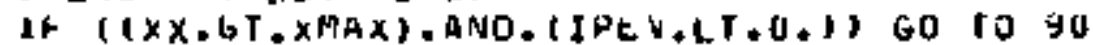

C LAECK TO SEE IF PEN IS ALKEAUY OUT UF BOU IT (IPENL.NE, J) GO TO 20 


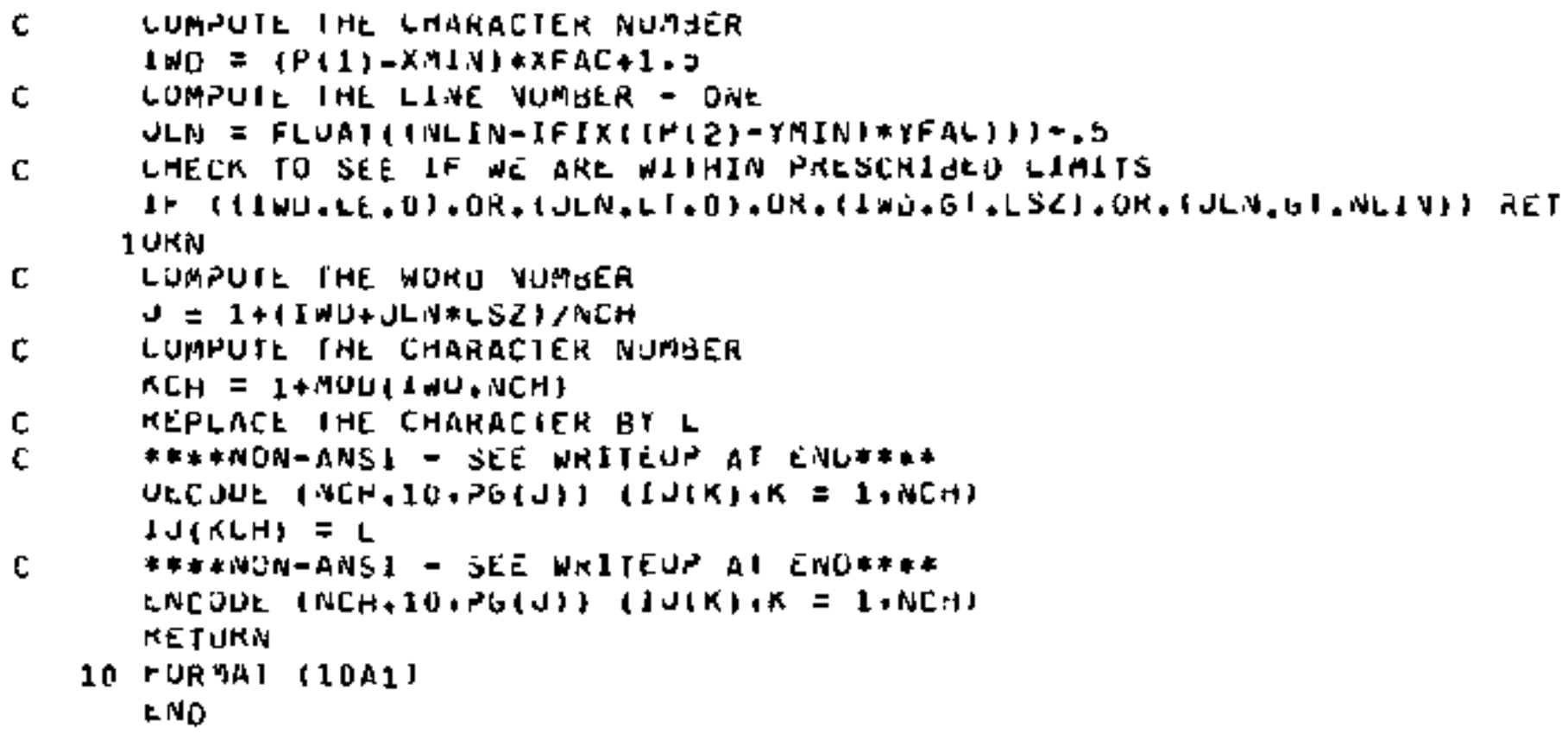


IHETHH= RIHO/KIH

IHT = IHE.TAH

IHE IA $(L)=$ THETAH

$30 R E=1.0+.066 * \eta_{H} \mathrm{HS}=.008 * \mathrm{HH} * \mathrm{MHSO}$

$P K=1 .-.134 * 4 H S W+.027 * 4 H S 0 * M H$

UU AT MOST 200 ITERAILOUS

uU $140 \mathrm{~J}=1,200$

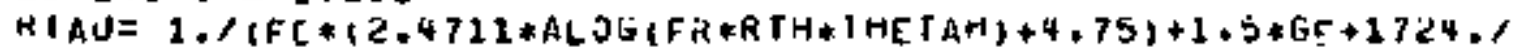

$1 \quad(G L * G E+2(10,1,-16, B 7)$

$A A U=R T H U * R T A U$

HU $=1.1 \mathrm{t} 1 . .6 \mathrm{E} * k \mid \mathrm{AU})$

$H+1=(1+B+1,1 *\{1 .+178 * \operatorname{Mrs} 51-1$.

StP $=-T n \leftarrow I A H * U$ UUS

PIE $=$ HH*SEP/IAJ

HEE AAAXI(PIMIN, AMINI PIVAX,PIE)

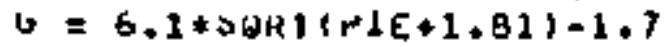

$12=A 8 S(G-G t) / G t$

$\mathrm{GE}=\mathrm{G}$

$U 12=0 I$

$U^{\prime}=(H H+2,-M A S 2) * S E P+1 A U$

IF (J.EG,1) GU TO 110

$11=\operatorname{AdS}((0)-U 12) / 0 T)$

IF (III.LI,TEZ), AVO+\{T2.LI,TEL\}, GO TO 130

110 I HEIAH= IHT +.5*UT*US

140 LUNTINUE

130 IHEIALCP $=U 1 * J S+1 H T$

IHEIAH = THETAILPI

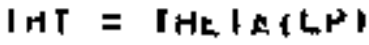

$H(L)=(H(L) * U S+H A *[J S O L U) /(O S+Z S O L U)$

$\mathrm{H}(\mathrm{LP})=\mathrm{HH}$

USOLU $=U S$

$L=L P$

Ir IL.NE,K2) LO IJ 10

$H(K 2)=2 * * H(K 2)-H(K z-I V C)$

H(KL) $=4$.

ReTUKN

Livo

SWEKOUTIME HA (H,L)

r. TUT CHARACTEN L 1 HIO RUN AND COLUMN OEIERMLNED BT NUSIIIUN $P$ JIMELSIOW $P\{2\}, 1 \mathrm{~J} 110\}$

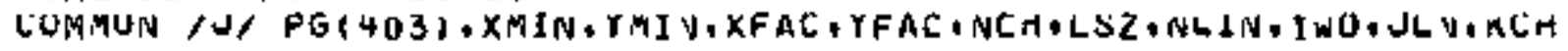
XIIN, YMIN IS THE LUWER LEFT HANU CORNER DF THE GTAPH

XFAC Y YFAC ARE IHE SCALING INCKE,ME IS FUR X ANO $Y$

NEH IS ITE NUMSER OF GHANACELRS INA A MACHINE WORU.1O FOR CJE GSDO LSZ IS IHE NUMBER OF CMANACIEKS WHICH WILL COMHRLSE A PKIVI LLNE IVLI IS IS IHE NUUDER OF LIVES THE OKMPH WILL HAVE

IHE LHARACTEH L WILL APHEAR IN IHE IWU NONU UN LINE JLN ACH IS THE NUMBER OF THE CHAKACILK WLTHIN THE WORU WHICA NILL BE KEPLACES ST IHE I HE CHARACTEN CONIAINLU $1 \mathrm{~V} L$

IHE UIMENSION OF PL MUST $O E$ NLINELSZ/NCH

SEE BLOCK DATA FOA THE ULFINIIJUN UF ELEMEVTS IN IHIS BLOCK 
SLP $=-1 H K I A$ IL K *UaUS

WHI AE (NQ,710) XREALIL), YKEAL(L), ANG,KAPPA(L), MALHN(L)

1 I THE TAPL, SEP + XS, YS

120 LL $=L C+1$

If (LE.LL.55) b0 TO 130

$L C=4$

WIIT (N4,200)

WRIIL (N4,700)

130 LONTINUE

KE JUA

200 HURMAI I IHI//

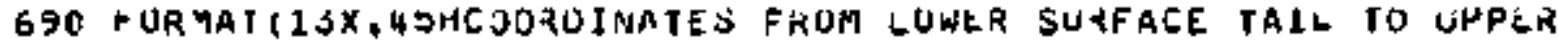

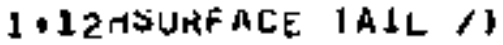

700 FA YAF $19 X, 1 H X, B X, 1 H Y, 6 X, 3 H A N G, 6 X+1 H K+7 X, 1 H M, 5 X, 5 H T H L 1$ H, 5X,

1 3HSEP+7X, ZHXS, 7X, $2 \mathrm{HYS/J}$

710 HR MAI $1+11,5,59,5, F 9,1, F 7,2,58,4,4 F 9.3)$

720 rUKMAI If $11,3, F 9.5, F y, 1, F 7,2, F 8,4,4 x+A 10,4 x, 2 F 9,0\}$

ENO

JUBRUUTIIL NASHYC (K1,K2)

c

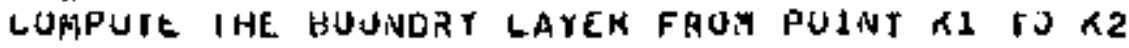

LUMMUN /A/ GAITMA, MACH

LUMPLEX $X \perp, X I G J O Y$, CHAR

ALAL VACHN, KAPHA

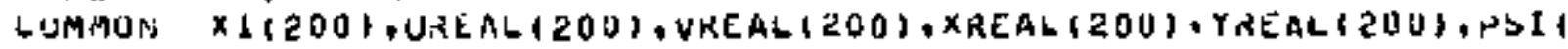

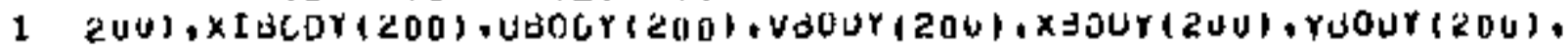

2 CHAK(41,10), LLINE(200), S1200), MACHN(200), KAPPA(LUO), ÀNGL 200$)$

3 . THE IAT20(;) +H1200)

TEAL MACHA, YACHO, MTALL

WUM MUN I A RN, RCHJ,PL HL, WACHA, MNGLA, MTAIL, AVGLT, YALHS, ANGLS, RL,

1 AIVGLN, IN

HEAL MH, WHSG, NU, MACH

UATA IR/.3424,, KTHO/320, , IE1/5,E-3/, IE2/0.E-3/, HIMIN

$1 /=1.5 /, P J M 4 x / 1.64 /$

LAM $=\left(G A M N_{,} A-1 \cdot\right) / 2$.

$\triangle A M L=1 . /(G A M M A-1$,

LSIINF $=1,+G H M * M A C H * M A C H$

INC $=I S I G M\left(1, K_{C}-K_{1}\right)$

$G E=5.5$

$L=\kappa 1$

USOLU = ABS $(S\{L)=S(L-I N C)\}$

$10 L P^{2}=L+I N C$

MH $=.5 *(M A C H N(L)+M A C H N(L H))$

WHSI $=$ MH*NH

$L \$ I H=1++(, A M * \| H S O$

US $=$ ABS $(S(L P)-S I L)$

ULOS = (MACHIV(LP)-MALHN(L))/(US*MH*CSLR)

$J=\operatorname{CSIINF/CSIA~}$

RHOH $=1 *$ GAMI

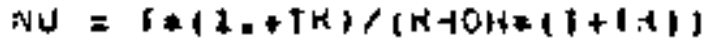

$N I H=R N * M I 1 /(M A C H * M U)$

IF (L.NE.K1) SU TO $3 U$ 


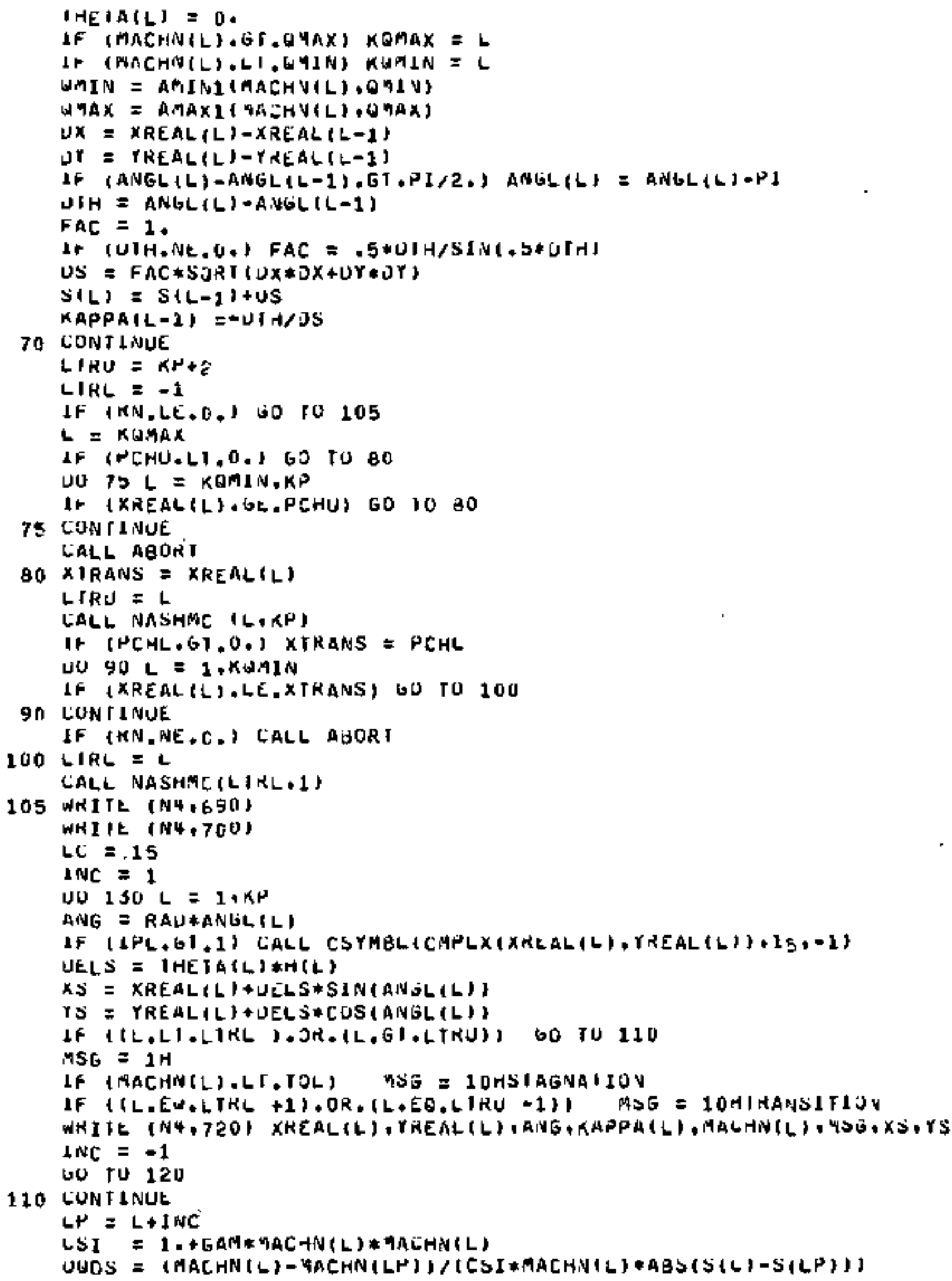


SUBRUUTINE LINES (K1,K2)

LOMYUN ARRAY IIJ

COMPLKX ARKAY

LALL CPLOI (ARKAY $(K 1), 3$ )

$K F^{\prime}=* 1+1$

JU $10 \mathrm{~J}=\mathrm{KP}, \mathrm{K} 2$

10 LALL CPLUT (ARMATIJ).2.)

KETJKN

ENO

SUBRUUTIVE POLNTS (KI.KR)

LUHMON ARRAY (1)

CUMPLEX AKKAT

UU $20 \mathrm{~J}=K 1, K_{2}$

20 LALL CSYAOLt (ANRAYIJ), 26,-1)

KETUTHN

END

SUBRUUTINE OUTHT KKPI

KEAL MACH

LUMYON /A, GAMMA, MACH

LOMPLEX XI, XLUOOY,CHAR

KLAL MACHN, KARRA

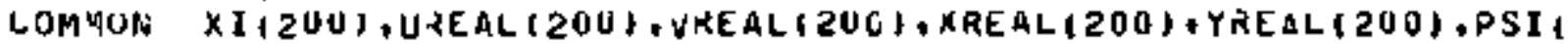

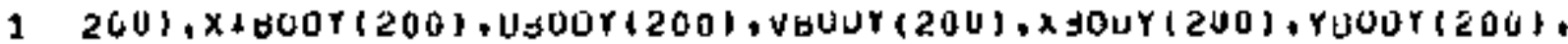

2 CHAK $(41,10), 1 L 1 N E(200)+\$\{200)$, YACHN $(200)+K A P P A(\angle U 0)$, ANGL $(200)$

3 . THETA(200), H(200)

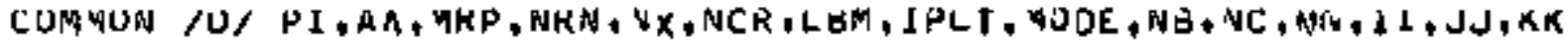

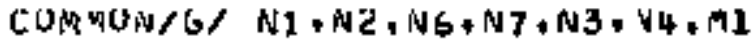

CUMPLEX XIIHIL, AP,POLE, XIA+XIB,XIC

LUMMUN $/ H /$ UP(10),HOLE, X $+A, X \perp B, X I L+X 1 T A I L, P L I S I \angle A N D S$

LOMYUN $/$ II SF, SILE, AIEG, XIAX, YMAX,XUR, YUR,PGSIZ

REAL MACHA, MACHQ⿱ VTAIL

LUMMOA $/ K /$ NN, PCHJ,PCHL , MACHA, ANGLA, MFAIL, AVGL I, YACHA, ANGL J, MC,

1 A.NGLN,IR

$1 \mathrm{PL}=$ MOUIIPLT/10.101

KAD $=180, / P L$

$U L=1, E-5$

GAM $=$, $\$ *$ (GAMMA-1,

NUMIN $=1$

$\operatorname{COMAX}=2$

UMIN = MACHNCI,

WMAX $=$ GMIN

$+(1)=0$.

|HETA|1 $\mid=0$.

$\Delta(1)=0$.

KAPHATKP) $=0$.

Uu $\gamma 0 \mathrm{~L}=\hat{c}, \mathrm{Kr}$

$H(L)=0$. 


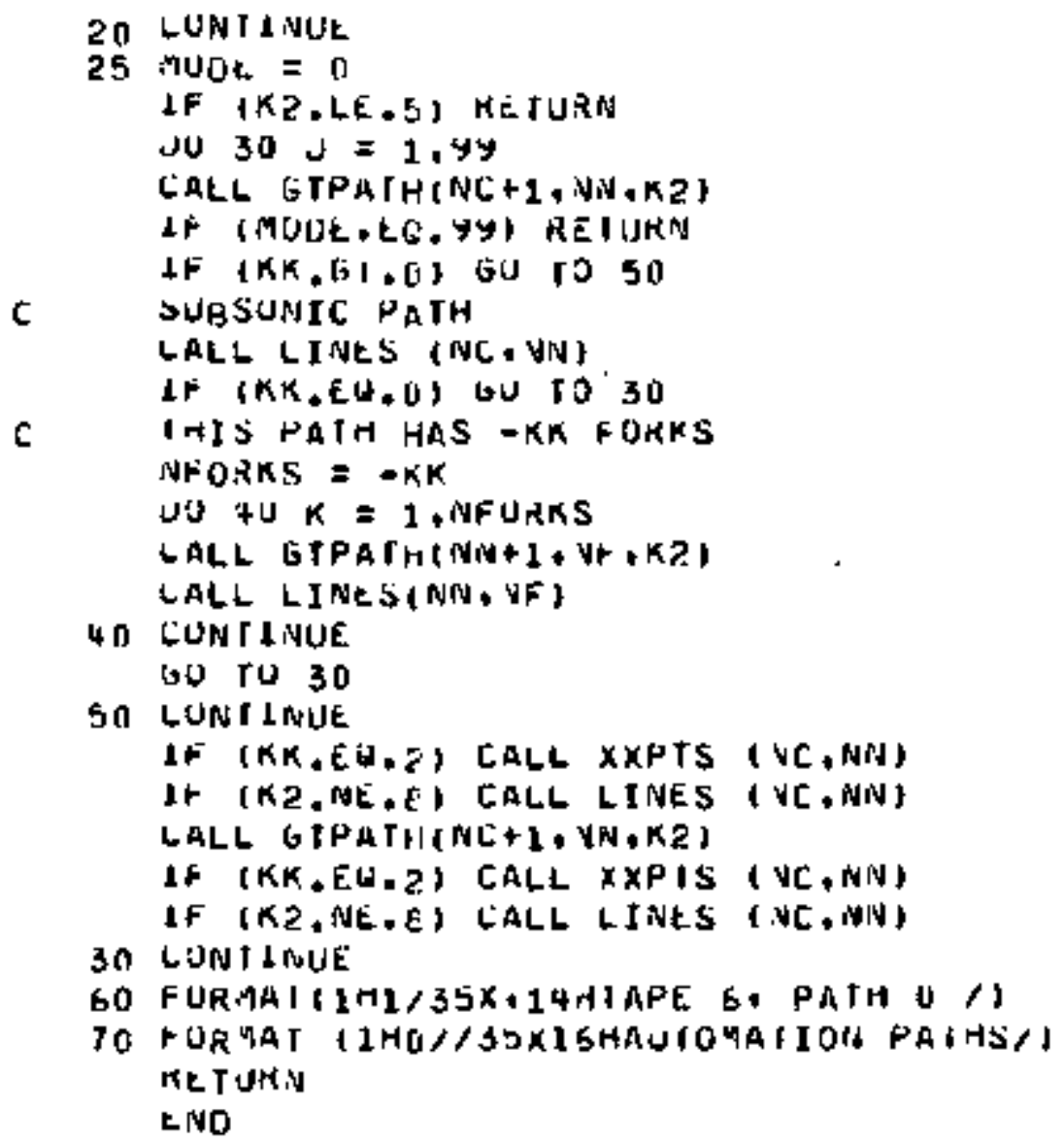


$x \perp=(M P L X(L U G \backslash\{S . J), \operatorname{LOGS}\{4,4)$

ANG $=$ RAU*A1ANLAAIMAL $(X \downarrow)$, REAL $(X)\})$

LALL CSYMLL $(X 1,4,-1)$

$x I=x I *(1 . * 03 / \cos (x I))$

$312 t=.50$

CALL CSYMBL $(X 1,20,-1)$

$S I Z E=.14$

40 LONI INUE

47 ANG $=0$.

$\triangle C F=S F$

$\Delta r=1$.

It INRN, GE.OU SO IO SS

LALL XYAXES $(10,0.1,3.3,3.0, S F 1.0 .1$

LALL XYAXES $1(0,10.1,2,0,3,0,5 F I, 40,1$

LALL CSTMUL $(1-3.0 .-3.5), 1$ IILE, 6U)

UU TU bB

5.5 LALL XYAXES $(10,0 ., 16,3.3 .5 .5 F 1.0 .1$

CALL XYAXLS $(10,0,1,4, \ldots, 4$ SFI,90,)

WALL CSYMEL $(1-4,0,5,5), 11 T L E, 60)$

SP St $=$ SCF

$\triangle I Z E=.07$

Ir (IRL. OE. I) CALL PLPAIHI2+MAX010,NP) IHL+2)

$\$ L^{2} r_{4}=. U 7$

METUKIV

LND

SWGRUUTENE PLPATH(K1,K2)

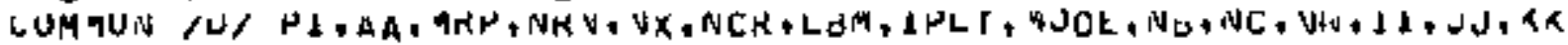

EOMYUN/G/N],N2, NG,N7,N3,V4,M1

NEWINU NG

1+ (K2, LG, W) WRIIE (N4, 60 )

$M D Q E=1$

LALL GTPAIS $(N L+1, N N, K 2)$

If IMODE.LS.9Y) KEIUKIV

IF (KE.Gt, S) CALL LINES (VE,NN)

WUDE $=2$

LALL GTHATH (NC+1,NN,K2)

IF TMUDE,EO,YH) KEIUKN

If (KZ.GL,5) CNLL LIVES (VC,NN)

IF (K2.6I.2) LALL HOLNTS (NNININ)

IF (K2,EW, B) KEIURN

IF (K1.Le.

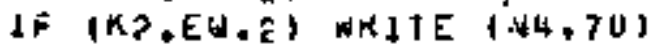

UU ZU MOUE $=3.41$

LALL GTPATH (NC+1,NN, K2)

LF (MOQE, EG, $9 y$ ) KEIUFN

It (1K2,EQ, 4).UR, (K2,EG.7)

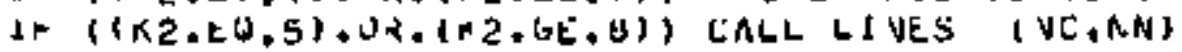

IF (KK.LE. O) GU TO 20

LALL GTPATHI (NL+1, UN, K2)

If (1K2.EQ.4).JR+(K2,EO.7) CALL POINIS (JJ,NN)

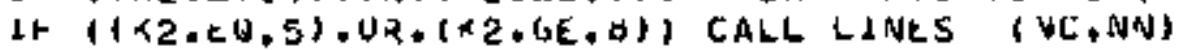


LUMYUN /L/ SF, SIZE, ANG, XAAX, YHAX, XUR, YUR, PGS1Z

LOH YUN $/ 1 \mathrm{~T}$, TI ILE (B)

JIMLNSIUN CONL 20$\}$, IEMP ( 61$)$

EATEKNAL CSOKI SOFXI

SAM $=$ ( $Q A$ WHA-1.) $/ 2$.

COSW $=6 A M+1 . /($ GACH*MACH)

CUMX $=$ AMINJ (CJSW+3.

$R A O=180 . / P I$

AND $=1$

SF $=1$.

SHI $=$ PLISIZ/S.

LALL ORIOLN $(0, \ldots 5)$

XIMIN $=(-7,0,-4,0) *$ SF 1

$X \perp$ MA $=(4,0,5,0) * S F \perp$

$1 X=44$

$J x=36$

$A S Z=11.0$

$1 \mathrm{SZ}=9.0$

If INRN.GE, th LO TO

CALL ORIGIN $12,25,4,01$

$\triangle F I=S F I+S F I$

$X \perp M S N=1-3,70,-2,0) * 5 F I$

$X \perp \operatorname{MAX}=(3,75,3,5) * 5 F 1$

$J x=44$

$1 x=60$

$X \leq Z=7,50$

$r s Z=5.0$

a It $(1+\mathrm{L}, \mathrm{Gt}, 0) 1 \mathrm{NU}=20$

U $10 J=1.5 \mathrm{Nu}$

EMX $=F L U A \mid(1 N U+1-J) / F L D A(I N D)$

$X \perp=\operatorname{con} x * E M X * 4 X / 11,+6 A N * E, H X * E x)$

LALL GETHSE (XI,S YSOPH)

$10 \operatorname{cON}(\{N D+1-J)=\operatorname{KEAL}(S)$

LALL CONIUR (IX,JX,INO,X\$L,Y

SF $=1 . / \mathrm{SF} 1$

LALL OHIGIN $(7.0 .4 .5)$

IF (NRN, $O E, O$ ) 10 IO 5

LALL ORIGIN $(B, 0,6.0)$

5 LALL CSYMBL $(X 1 A, 11,-1\}$

CALL CSYMBL $(x 13,11,-1)$

LALL CSYMBL $X[C, 12,-1\}$

LALL CPLUT(XIL.\$3)

LALL CPLUT(XIB.2)

LALL CPLUI $(X \backslash A, 2)$

$x 10=x \perp 0 F S(0,10),,(-1,+0,1)$

CALL CSYMBL $(X 1), 63,-1)$

NU Sú $J=1$ +NDS

30 LALL CSYMAL $(B+(J), 1,-1)$

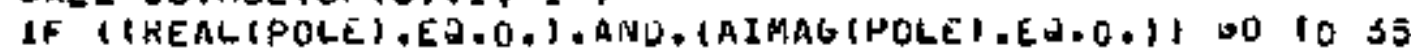
MPOLE = REALIPULE I

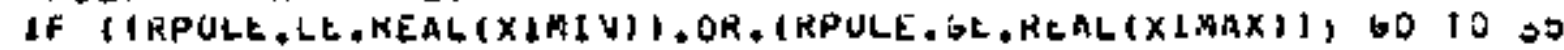

C

MLOI IHE LOCAIION JF THE POLE

GALL SYMUOL $(P U L E+b,-1)$

35 IF INLUGS,EO.OI 60 TO 42

JJ $4 \mathrm{U} J=1, \mathrm{NLOGS}$ 
SUERUTING OKLGIN(X,Y)

CJNMU, /L/ SF, SIZE, APG, XMAX, rMAX, XUH, YUY, RGS1Z

$x \cup R=x$

IUR $=Y$

MET JKN

L. VTRT FKAMEA

$X \cup R=0$.

$T U R=0$.

LALL PLOI (PGSLZ,0, -3)

MET JKK

ENO

SUBRUUTINE XYAKES $T X$ RUT, IOP,SLF, ANGL

C $X$ IS IHE LOEAIIJW OF THE JKIGIN UN ITE AXIS

¿ GUT IS IHE LENGTH UF THE AXIS IO TME LEFT JF THE DKI\$IA

C IUH IS IHE LEIGIH ID THE RIGHT OF IHE JRISDN

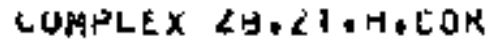

GUAMUN $/$ H SF, SIZE, ANG, XMAX, YMAX, XUR, YUK, HGSIZ

UIMENSION $X 121, Y 421$

ANGO = ANG

$\triangle F O=S F$

$\triangle 1 Z U=\$ \perp Z \mathrm{E}$

$r(1)=x \cup k$

$T(2)=Y J R$

$A N G=0$.

SF $=1$.

$\$ I Z E=.14$

$X U R=X(1)+X 0 K$

TUR $=X(2)+Y U R$

$\angle 3=\operatorname{CMPLX}_{(-B O T, 0 .)}$

$\angle I=C M P L X \mid T U N+0.1$

$\mathrm{Cu}_{\mathrm{R}}=(\cdot .25 .0 .3\}$

$14 C=16$

IF (ABSIANGL), NE, 90, GO 1010

C VERTICAL $Y-A X \perp S$

$\angle B=(0 * 1,1) \angle U$

$\angle T=(0 ., 1,1 * \angle I$

LUR $=(-26,0,1$

NC $=15$

C

UKAN LINE FOK IHE AXIS

10 LALL LPLUI $(21,5)$

LALL CPLUT $(Z B+2)$

$L=I U P$

$\mathrm{n}=\mathrm{HOT}$

IV $=1+K+L$

$S=-F L O A I(K) * D C F$

$H=\angle I / 1 U P$

$\angle B=-F L U A I T K A * H$

$\angle T=\angle B+L D A$

UU $201=1, N$

C

UKAW HATLH MAKK

LALL CSTMUL $(40, N C+=1)$ 
$B=D+F(U A)(1-1) * S C F$

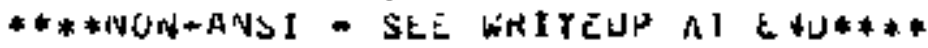

tNCUUR $110,30, A) \neq$

C LABEL $A X d S$

WALL CSYMDL $1 \angle 1+A, 41$

$\angle B=\angle B+1 t$

$\angle P=C \mathrm{I}+\mathrm{r}$

St $=$ SFO

$31 \angle t=3120$

ANG $=$ ANG U

$X J R=r(1)$

$r J R=r(2)$

KE TUKN

30 UK

tND

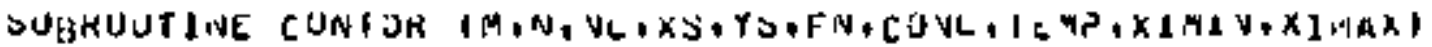

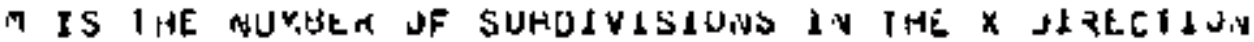

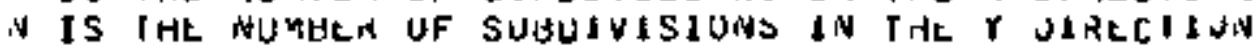

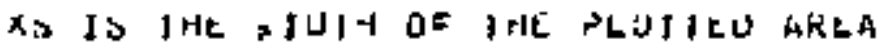

IJ dS THE HISTH OF THE PLUITEU AKEA

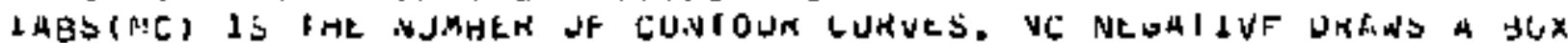
AHOUNU I HE PLOITLU AMEA

I IS IHE COHRLX FUNCHIJV WHOSE ABSOLUIE SUARLU IS TU HE RLUIJEJ

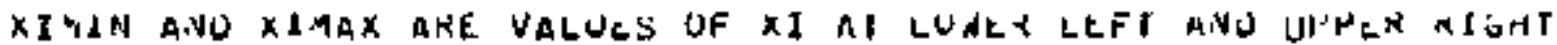
LUNL IS AN ARTAY JF LUUTUJR LEVELS IN IVCRLASIIA URUEF

IEMP IS A TEMHJRAZY AKKY JF LENGIM M

LJPALLX FN, N $X 211 \mathrm{~V}, X \perp$ MAX

UIMENS I UN GUNL $(1), I E$ INP $(1)$

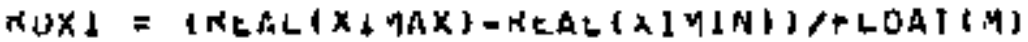

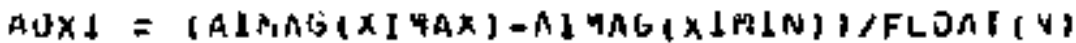

$3 x=x S / r L O A, 1(1,1)$

UT $=$ YS/FLUAII, I

NLL $=$ IANSANL

"I $=r_{1}+1$

Uu $101=1, k$

$w=r N\left(X \backslash M I V+F L W A I(1-1)+H_{W} \times I\right)$

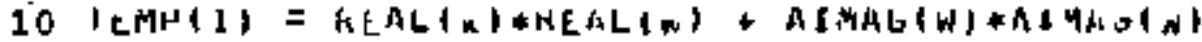

$T+F=C$.

UU $400 J \Rightarrow 1, N$

$x+2=l$.

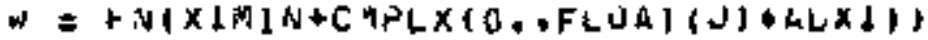

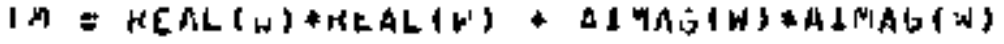

$Y H \beta=Y H^{\prime}+U Y$

wo $3601=1,4$

$X+P=X P^{\prime}+U x$

$N=+N(X \perp M) N+L M P L X(F L O A(\downarrow) * R U X 1, F L O A I(J) * A J X 11)$

$I N=$ REAL $(w) * R E A L(w)+A L$ GG(W)AAIMAG(w)

JUP $=A M A X I T T+T M+I E H P(1), T E M P(i+1)\}$

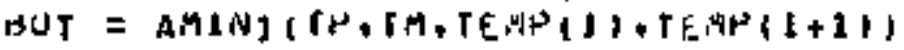

1. (CUNLINCL).LI.JUI) GO IJ 350

uU $40 \mathrm{LJ}=1 \cdot \mathrm{NCL}$ 


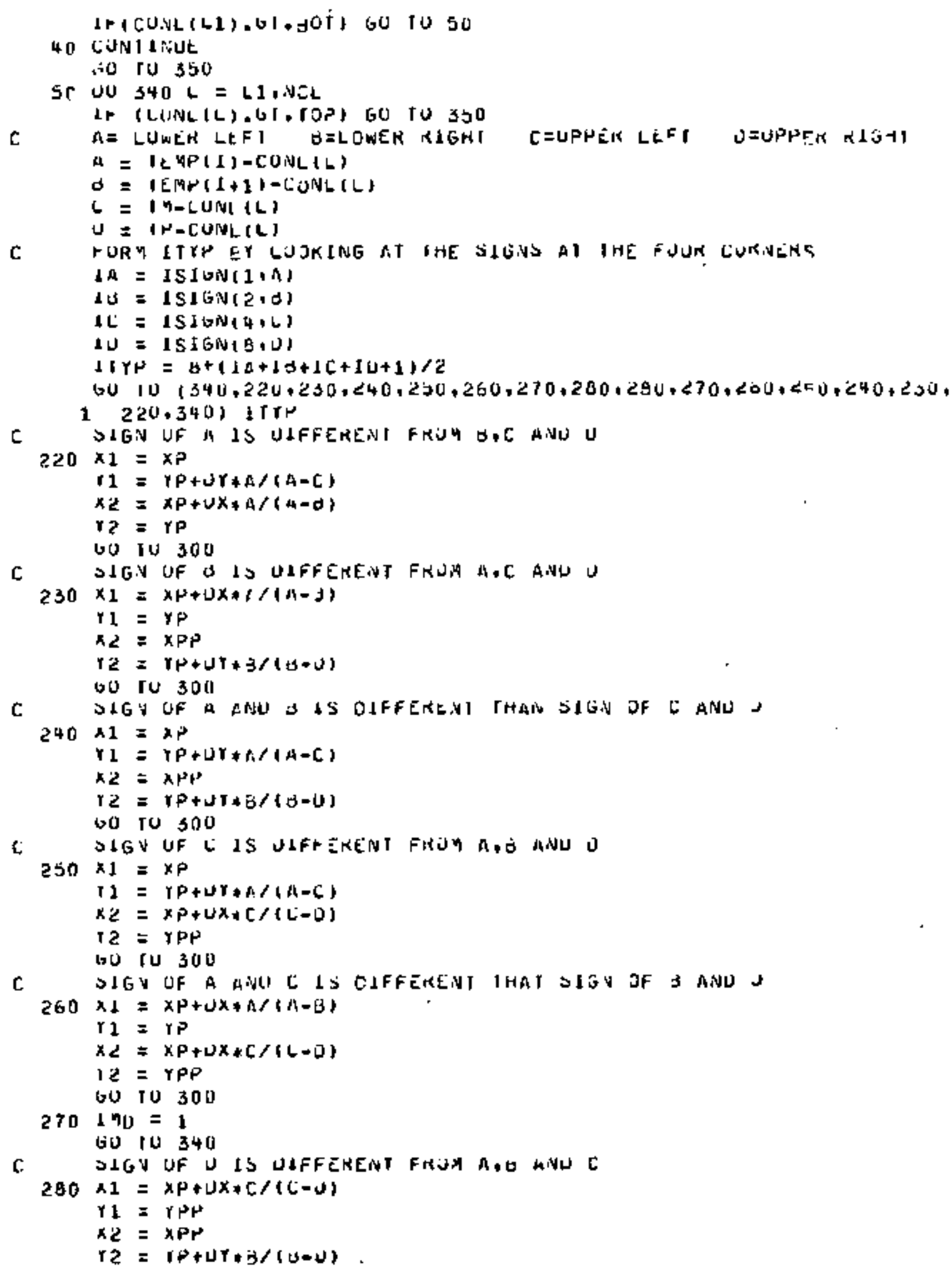


300 LALL CPLOT (CMPLX(X),

CALL CFLOT (CNPLX(X2,Y2), 2 )

340 LUNI INUE

350 IEMP(1) $=7.4$

$X P=X P P$

$I M=I P$

360. CONT1NUE

$\operatorname{lcMP}(M+1)=t h$

$\mathrm{IP}=\mathrm{YPP}$

400. CUNT LNUE

AÉ UUNA

CNO

\section{WUMPLEX FUNCILUN CSOETRZ DRANLHI}

$c$
$C$
$C$

CUMPUIES IHE CUAPLEX SUUARE RUUT UF 2 AND CHUUSES IHE BAANEH

$$
\text { IRE CUI OF THE SGUARE ROUP IS A SIRAIGHT DNE RNJM IHE }
$$

URIGLN RASSINS THROUGH SD DRANCH>

UIMENSION Z(2), ZRANCH(2)

KEAL $1 M A E Z$

NEALL $=211.1$

IMAGK $=\angle\{2\}$

H = REALL*REALZ+I MAGZ*IMAGZ

i] $=0$.

if $T K . E Q=0.1501040$

$\theta=S O R T(, S+\{S Q R I(R)+A B S(R E A L Z \mid\})$

IF (KEALG.GE.0.) GO TO 10

$N=U$

$w=.5 * 1.4452 / \mathrm{H}$

60 TU 20

$10 K=.5 * 1$ MAG $2 / 0$

20 IF (H*ERANCH(t) +R*ERANCH(E), $50,40.40$

30 CSOKI = CMPLXI-I, $-K)$

KETUKN

$40 \operatorname{CSO}(1=\operatorname{CMP}(x)$ ist $+R)$

KETUKN

LND

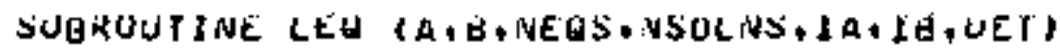

C
C
C
C
C
C
C
C

LINEAK EUUATIUNS SULUTIJIUS WKITIEN AT AEC CDMPUIDNG CENTER (INYU\} SULVE A SYSTEA OF LINEAR EUUATIUUS OF IHE FOKY AXIA AY A MOSIFIEO GAUSS ELIMINATION SCHEAE

NEOS = NUMAER UF EQUATIJNS ANU UNKNOW:YS

WSOLNS = NUMELR OF VECJUA SULUIIONS OCOSREJ

LA = NUMBER OF ROAS OF A. AS UEFINLU BY DIMENSION SIATEMENT ENINY 13 = NUMBER OF RUWS OF a AS DEFINLO BY OIMENSION STATENENG EIVIAY AUEI = UEIERMINANI OF A, HFTER EXII FRUM LED

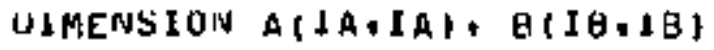

NSIL = NĹ

NASIZ = NSOLNS 
C WOR MALIZL EACH ROW BY IIS LAKGLRI LLEVEVI

C IUR PAKIIAL OETERMIIWANT

UET $=1.0$

UO $401=1 . N S 12$

$H \perp G=A(1+1)$

IF (NSILULE.1) 30 10130

JU $10 J=2, N S 1 Z$

IF (AGSIBIG),GE,ABS(AII,J), GO IO 10

$B 1 G=A(1, U)$

10 LUNI \&NUE

$B G=1.0 / B 2 G$

एO $20 \mathrm{~J}=1, \mathrm{NS12}$

$20 A(I, U)=A(I, J) * B G$

vo $30 \mathrm{O}=1, \mathrm{NB}=1<$

$30 \Delta(I, 7)=3(1, J) \neq B$,

UET $=D E \mid * E I G$

40 CUNTINUE

C

STATR SRSTEM REUUC1IUN

NUASSS $=$ NSILOI

WU $12 U I=1+$ NUMSYS

C SCAY FIRST CULJUN UF CURKLNT STSILM FON LARGEST ELKAENI

C LALL IHE KOW LUATAINING INIS CLEMENT, NOW VBGRW

$N N=I+1$

$\Delta 1 G=A(1, I)$

NUGRW $=1$

UU $50 \mathrm{~J}=\mathrm{MHN}_{\mathrm{N}}+\mathrm{W} \$ \mathrm{I} 2$

If (ABS(dIE), BL, AJS A(J,1)), 60 J0 5U

$\triangle 1 G=A(0,1)$

NGGKW = J

50 LONTINUt

DG $=1.0 / \Delta I E$

$c$

SWAP NOW I WIIH HJW NBGRW JNLESS $I=N B G K A$

IF (NBGRW,LQ+1) GJ TO 80

C

SWAP A-MATRIX KOWS

JU $60 \mathrm{~J}=1, N S \perp Z$

IEMP = AINGGKW:J)

AINSORW,U) = A(I, J)

60 AII J) = PEMF

UET $=-U E T$

$c$

SAAP B-MAIKIX KOWS

DO $70 \mathrm{~J}=1, \mathrm{NOSIL}$

ItMP $=$ Q

U $(N d G R, W\}=B(\downarrow, J)$

70 O $(I+\mathrm{I})=[E$ IT

ᄃ

LLIMLAATE UNKNJWNS FROM IIRST LOLUMN OF CJRREN SYSTEM

C

Bo UJ $110^{\circ} K=$ Ant NSIZ

COMPUTE PIVOTAL MJLTIPLILA

HMULi $=-A(K, I) * B G$

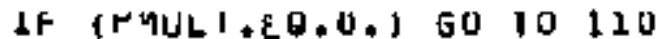

C APPEY PMULI TO ALL COLUMAS OF THE CUAREVT A-MATHIX NOW UU $94 J=$ NN,NSLZ

90 $A(K, U)=$ PMULI*A(I,J)+A(K,J)

c

APPLY PAULT TU ALL CULUMNS OF MATHIX a

HO $100 \mathrm{~L}=1,40 \$ 12$

100 B(K,L) $=$ PHUL I*d(I,L)+U(K,L) 
110 LONTINUE

120 CONAINUE

UU 3ACK SUESILIJIUN WIIA d-MATHIX COLUMA = NCOLS

c

130 LU 170 NLOLS $=1$, YBS12

C UU FUH RUN = WKOW

UU $1601=1, V>1 Z$

NROW $=N S I Z+1-1$

$1 \succeq M R=0.0$

C NUMBER OF FREVIOUSLY COMFJTEU JNKNUNNS = VXS

NXS = NSIZ-VROA

C ANE WE OUIAS IAE BUTTOM KUW

1) (NXS, L Q . O to to 150

JU $140 \mathrm{~K}=1$, $\mathrm{N} \times \mathrm{S}$

$n K=N S I Z+1-K$

140 IEHP = TEMP+H(KK, YCULB) *A(NRUW,KK)

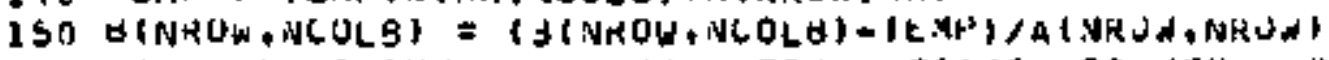

c

HAVE WE FIAISHEO ALL KOWS FON d-MAIRIX COLJUN = ULOLS

160 CONFINUE

C

HAVE WE JUST FIVISHEU WIIA GOMAIMLX COLUMV NCOLBENSIZ

170 LUNIDNUE

C NOW FINISH CUMRUIING THE JETERMINANT

UU $180 I=1+N \$ I 2$

180 Ut $=$ DEI+R $1,+1)$

KETUNAN

C Vu

DLOLK DATA

LUMUN/G/ N1, HE, N5,N7,N3, $44, M 1$

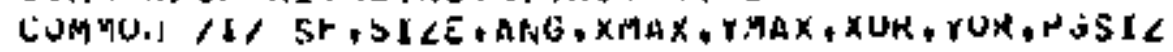

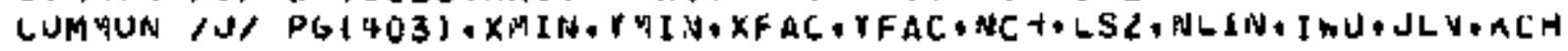

UתTA N1, N2, VS, VH, VIG, $1,7 / 1,2+3,4,6,7 /$

C ***CHAMGE NCH TO 4 rOR $104360 * * * *$

C. ****CHANGE LSL TO 12U OV 1 B $360 * * * *$

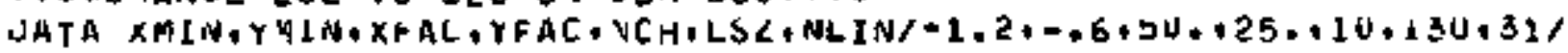

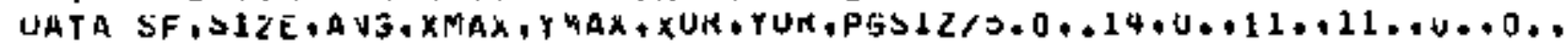

$1 \quad 12.00 \%$

5NO

$c$
$c$
$c$
$c$
$c$
$c$
$c$

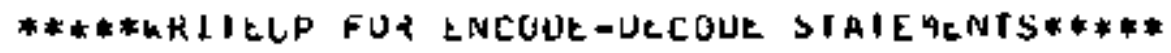

ENCUUE/JECCDE STATEMENTS

ENCUUE IS SIMLLAR ID A FURMATTEO WKITE STAIEMIENT

UtCJUE IS SIMILAR IO A FUHMAIILO KLAU STAIEVLNI

VO TAPES ARE ALTUALLY 1 VVULVLO SINEE THE IRANSFERS TARE HLAEL WITHIN COKE

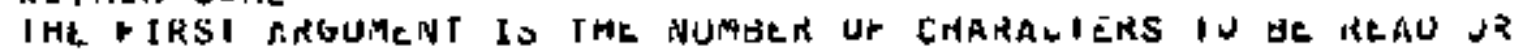




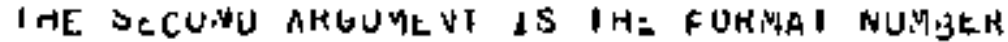

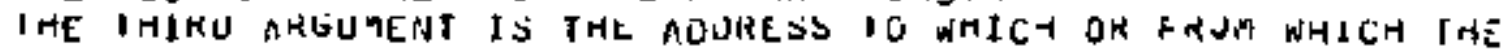
$1 / 0$ LISI WJLL WE WRITIEV JR KEAU

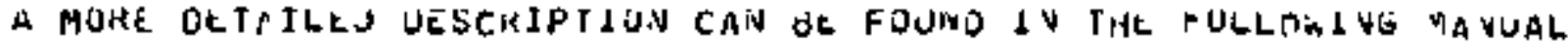

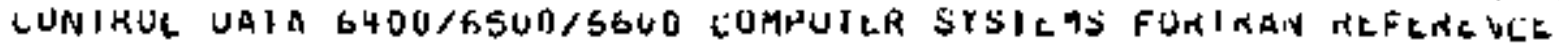

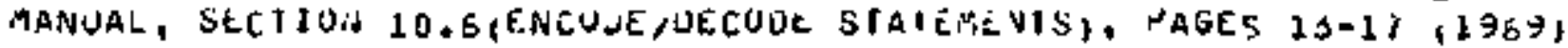

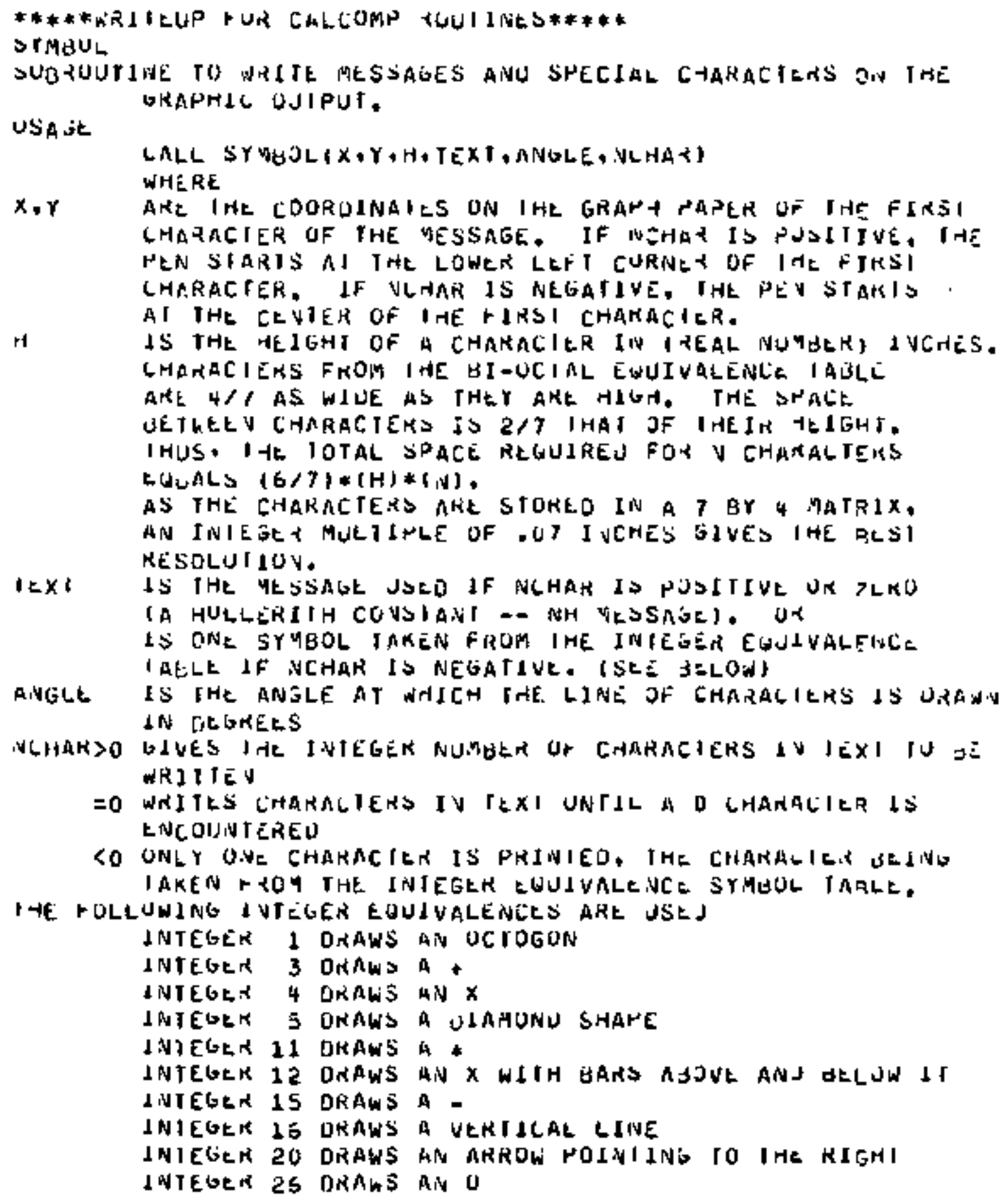




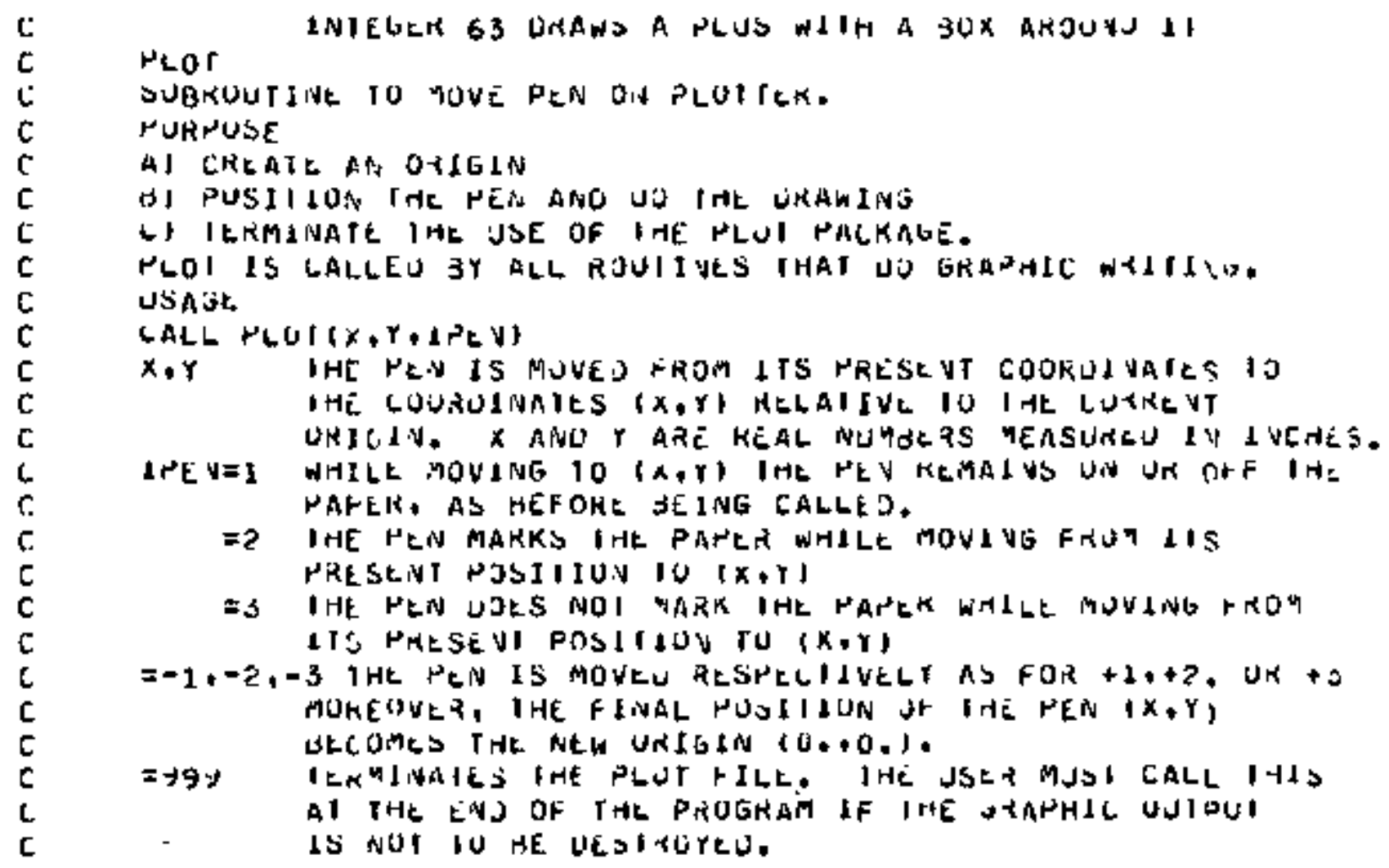

99 
This report was prepared as an account of Government sponsored work. Neither the United States, nor the Administration, nor any person acting on behalf of the Administration:

A. Makes any warranty or representatjon, express or implied, with respect to the accuracy, completeness, or usefulness of the information contained in this report, or that the use of any information, apparatus, method, or process disclosed in this report may not infringe privately owned rights; or

B. Assunes any liabilities with respect to the use of, or for damages resulting from the use of any information, apparatus, method, or process disclosed in this report.

As used in the above, "person acting on behalf of the Administration" includes any employee or contractor of the Administration, or employee of such contractor, to the extent that such employee or contractor of the Administration, or employee of such contractor prepares, disseminates, or provides access to, any information pursuant to his employment or contract with the Administration, or his employment with such contractor. 